Portland State University

PDXScholar

\title{
The Role of Parent Coaching by Pediatric Physical Therapists: An Exploration of Current Practice
}

Nancy Ann Cicirello

Portland State University

Follow this and additional works at: https://pdxscholar.library.pdx.edu/open_access_etds

Part of the Disability and Equity in Education Commons, Educational Leadership Commons, Educational Methods Commons, and the Educational Psychology Commons Let us know how access to this document benefits you.

\section{Recommended Citation}

Cicirello, Nancy Ann, "The Role of Parent Coaching by Pediatric Physical Therapists: An Exploration of Current Practice" (2005). Dissertations and Theses. Paper 5184.

https://doi.org/10.15760/etd.7060

This Dissertation is brought to you for free and open access. It has been accepted for inclusion in Dissertations and Theses by an authorized administrator of PDXScholar. Please contact us if we can make this document more accessible: pdxscholar@pdx.edu. 
THE ROLE OF PARENT COACHING

BY PEDIATRIC PHYSICAL THERAPISTS:

AN EXPLORATION OF CURRENT PRACTICE

\author{
by \\ NANCY ANN CICIRELLO
}

A dissertation submitted in partial fulfillment of the requirements for the degree of

DOCTOR OF EDUCATION

in

EDUCATIONAL LEADERSHIP:

POSTSECONDARY EDUCATION

Portland State University

2005 


\section{DISSERTATION APPROVAL}

The abstract and dissertation of Nancy Ann Cicirello for the Doctor of Education in

Educational Leadership: Postsecondary Education were presented April 28, 2005 and accepted by the dissertation committee and the doctoral program.

COMMITTEE APPROVALS:

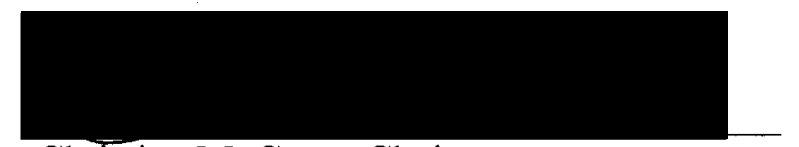

Christine M. Cress, Chair

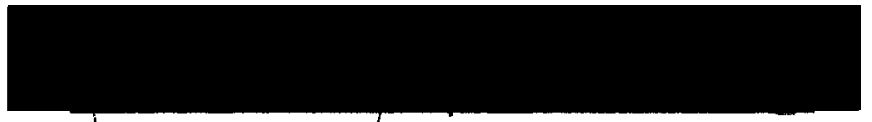

L'eslie J. Munson (

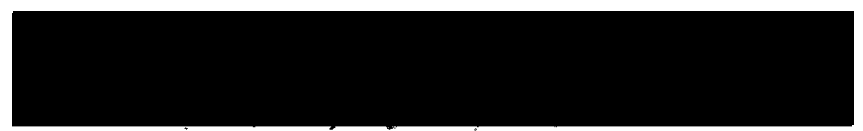

Janine M. Allen

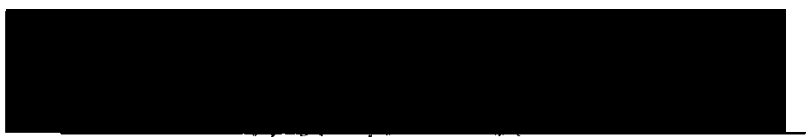

Christine Chaille

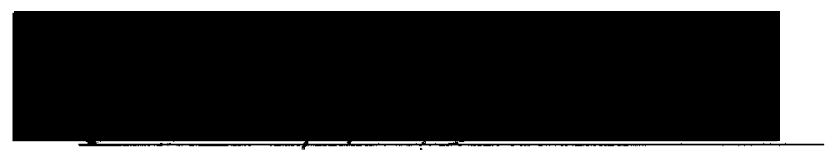

Leslie McBride

Representative of the Office of Graduate Studies

DOCTORAL PROGRAM APPROVAL:

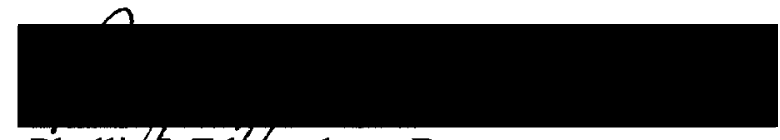

Phyllis/J. Edhhundson, Dean

Graduate School of Education 


\begin{abstract}
An abstract of the dissertation of Nancy Ann Cicirello for the Doctor of Education in Educational Leadership: Postsecondary Education presented April 28, 2005.
\end{abstract}

Title: The Role of Parent Coaching by Pediatric Physical Therapists: An Exploration of Current Practice

Children with disabilities are not the sole clients of the pediatric physical therapy practitioner. However, research, best practice, and federal mandated legislation oblige therapists to transition from a traditional medical child-centered model of intervention to a family-centered model. This model places an emphasis on instructing parents, guiding their development as the dominant change agent for their children. Viewing parents as the predominant learner during intervention sessions is hampered by the paucity of family-related and adult-learning content in the professional preparation programs in higher education. It is further inhibited by professional attitudinal beliefs that continue to place a higher value on child characteristics for clinical decision making.

This qualitatative study explored the scope of four private practice pediatric physical therapists' role as a parent coach. Each therapist was videotaped with two young children diagnosed with movement dysfunction and their mothers. Using a 
coaching framework presented by Hanft, Rush, and Shelden (2004), therapist/parent interactions were analyzed within the phases of initiation, observation/action, reflection, and evaluation. In addition, interpretation of these observations was also viewed through the theoretical lenses of adult learning and motor learning.

The findings indicated that parent coaching was minimally employed by these four therapists. The lack of family-centered focus, minimal adult learning theory knowledge/application and nominal motor learning application to parental handling skill development further establishes a diminished attention to the potential for building parent competence. The research-to-practice gap confirmed a need in professional preparation and continuing education. Recommendations are made for a holistic model that includes application of both adult and motor learning in conjunction with a coaching model. 


\section{ACKNOWLEDGMENTS}

To my first teachers, Mom and Dad (Helen and Salvatore Cicirello), who have supported and loved me, "sink or swim," thank you for your ever-present yet unstated expectation that I would swim my life's journey. To friends Christine Macfarlane, $\mathrm{PhD}$ and Steve Haley, $\mathrm{PhD}, \mathrm{PT}$, who consistently nudged during the low times to "just get the damn thing done," I thank you for keeping the reality of it all in perspective. To Jennifer Peterson, whose son I treated, thank you for asking the question how as it was the impetus to commence this doctoral journey. Additionally, I am grateful to the many parents with whom I have worked during my career as they have been instrumental in my learning about families other than my own, especially Debbie and Mike Golder, Julie Fleisch, and Adelina Martinez. To Uncle Charles, Tecla Thiman, Aunt Mary, David Golder, and Jim Dawson, though you passed away during my graduate studies, I value the richness you each brought to my life. Thank you to Sue Woods for her early editing assistance in the beginning years of this journey.

I extend appreciative thanks to the therapists, mothers, and children who were participants in my study. Thank you to Darcy Umphred, PhD, PT, for her collegial review. Finally, ardent thanks to my dissertation committee for direction and advice, and special thanks to my committee chair and advisor Christine Cress, $\mathrm{PhD}$, for her mentorship, counsel, and enthusiastic support with each step and draft. 
TABLE OF CONTENTS

PAGE

ACKNOWLEDGMENTS i

LIST OF TABLES iv

LIST OF FIGURES v v

CHAPTER I INTRODUCTION

CHAPTER II LITERATURE REVIEW 11

Early Intervention Federal Legislation $\quad 11$

Professional Attitudes Toward Family-Centered Care $\quad 11$

Family-Centered Intervention Practices 15

Parenting and Parent Education $\quad 19$

Parent-Professional Reciprocity $\quad 25$

Summary of Family and Parenting Literature 33

Adult Learning Theory $\quad 36$

Teacher-Learner Relationships $\quad 41$

Gender and Culturally Responsive Learning $\quad 47$

Motor Learning $\quad 54$

Summary of Adult and Motor Learning Theories $\quad 59$

CHAPTER III METHODOLOGY

Location and Physical Therapy Sessions $\quad 63$

Theoretical Contexts and Framework $\quad 65$

Study Sample $\quad 68$

Observational Data $\quad 71$

$\begin{array}{ll}\text { Quantitative Data } & 72\end{array}$

Data Analysis $\quad 73$

Researcher Observation Items $\quad 76$

Interview Questions for Pediatric Physical Therapists $\quad 78$

Interview Questions for Mothers $\quad 80$

Position of Investigator $\quad 82$

Summary $\quad 84$ 
$\begin{array}{ll}\text { Demographic Data } & 87\end{array}$

Results and Analysis $\quad 95$

Identified Benefits and Barriers to Coaching $\quad 142$

Gender, Ethnicity, and Age 145

CHAPTER V DISCUSSION AND CONCLUSION 154

Summary 155

Model Adaptation and Implementation 158

$\begin{array}{ll}\text { Potential Barriers } & 161\end{array}$

Additional External Corroboration $\quad 166$

A Holistic Model 169

$\begin{array}{ll}\text { Limitations } & 170\end{array}$

$\begin{array}{ll}\text { Future Studies } & 172\end{array}$

$\begin{array}{ll}\text { Recommendations } & 173\end{array}$

$\begin{array}{ll}\text { Conclusion } & 176\end{array}$

$\begin{array}{ll}\text { REFERENCES } & 182\end{array}$

$\begin{array}{ll}\text { APPENDICES } & 189\end{array}$

$\begin{array}{lll}\text { A } & \text { Physical Therapist Invitation Letter } & 190 \\ \text { B } & \text { Parent Invitation Letter } & 192 \\ \text { C } & \text { Physical Therapist Informed Consent Form } & 194 \\ \text { D } & \text { Parent Informed Consent Form } & 196 \\ \text { E } & \text { Video/Audio/Photo Release Form } & 198 \\ \text { F } & \text { Observation Notation Form } & 200\end{array}$




\section{LISTS OF TABLES}

TABLE

PAGE

$1 \quad$ Gender Learning and Voice Considerations $\quad 50$

2 Physical Therapist Participant Demographics 89

3 Parent Participant Demographics 92

4 Child Participant Demographics 94

5 Therapy and Parent Directed Time 125

6 Therapist Reported/Calculated Average
Directed Parent Education

$7 \quad$ Learning Style of Learners 132 


\section{LIST OF FIGURES}

FIGURE

PAGE

1 Therapeutic Reciprocal Interplay of Therapist, Parent, and Child 


\section{CHAPTER I}

\section{INTRODUCTION}

Pediatric physical therapists have a very unique role in their provision of rehabilitation and habilitation services to children with disabilities. The child with a disability is not the only client of the pediatric physical therapist (PT). Each child's caregiver, parent(s), extended family member(s) and/or educator(s) are also recipients of service. Such service ascribes the role of educator to the physical therapist. Typically, an individual entering a higher education program of physical therapy with the intent of working in a pediatric environment does so with the aim of working directly with children with disabilities. Post graduation employment introduces the entry-level practitioner to the realization that there are numerous non-child clients for whom they have responsibilities.

Higher education physical therapy curricula are already teeming with competence-based requirements specific to this field of study (Brown, Humphry, \& Taylor, 1997; Effgen \& Chiarello, 2000). However, physical therapy curriculum does not typically include family-related or adult-learning content to any significant extent (Cochran, Farley, \& Wilhelm, 1990; Effgen \& Chiarello, 2000). Mahoney et al. (1999) commented that higher education curricula for therapists and educators of young children has an emphasis on working with the child and not with adults. McBride and Peterson (1997) and Mahoney and Wheeden (1997) shared a 
reluctance by early intervention professionals to incorporate relationship-focused procedures due to limited training. Hanft and Pilkington (2000) identified the emphasis in professional preparation on atypical development of children and an under-emphasis of typical development, natural environments, and family/sibling/peer involvement as a challenge to providing appropriate therapy. Kelly and Barnard (1999) indicated that the lack of preservice training in theories of adult learning has been and is a deterrent for a professional transition from child focus interventions to acknowledging and supporting the respective adults associated with each child of concern. Iversen, Shimmel, Ciacera, and Prabhakar (2003) concluded that some early intervention providers attributed their lack of comfort in working with families to absence of formal training in family assessment and communication skills. A major impetus for bringing attention to the educator role of professionals serving children with disabilities has been legislation directed toward the public school system of this country.

Children with disabilities have received services from a varied group of professionals in school settings as mandated by the Education of All Handicapped Children Act (1975) for over a quarter of a century. Subsequent legislation amended the original 1975 legislation to extend services to children age $0-5$, referred to as Early Intervention (EI). In the 1997 reauthorization, recognition of parent relationships (parent-child and parent-professional) became a focal point of service delivery. Professionals are now required to view the needs of a child within the context of the family, including more directly serving parents. 
Though initial and subsequent federal legislation for mandated early intervention services has its origins in public school systems, state departments of education do not universally hold the contracts to administer these programs. Regardless of the funding and administrative source for EI provision, all contract providers (public or private) are required to comply with the same regulations and requirements, recognizing the importance and value of parental involvement. Family-centered service delivery includes instructing parents and/or guardians in performing home programs focused on goals they have for their child. This service delivery model recognizes parents as the initial and often primary facilitator of their child's development. Thus, much of the service provided to families with young infants and children enrolled in early intervention programs or outpatient therapy clinics should be directed toward instructing parents in ways to facilitate their child's development. Instruction would be inclusive of gross and fine motor skills, speech and language development, and cognitive and adaptive behavior skills. It should also incorporate educating parents on topics such as typical child development, specific diagnostic pathology information, and directing families to various support agencies. Regardless of service environment and payer, interventions need to be responsive to the needs of the consumer recipients (Palisano, 1994). A family-centered service should ultimately negate any medical versus educational debate, especially in light of contemporary models of motor learning, control, and development (McEwen \& Shelden, 1995). 
In a truly family-centered service model, parents of children with disabilities in EI programs are the primary learners of the various professionals who are members of the child's service team. To date, much of the outcome research in EI special education has examined child specific developmental gains as the dependent variable with parental involvement as the independent variable in measuring the success of interventions. This research has been predominantly in developmental areas of speech and language, cognition, and adaptive behavior skills. Research, especially in physical therapy interventions for children with motor dysfunction, has not addressed the education of parents of identified children. Absence of specific parental learning outcomes warrants attention on numerous fronts. Leonard (1996), in generically discussing parenting sans having a child with a disability, cautions his readers to consider the parental learning void created when professional caregivers, vis-a-vis therapists, dominate the intervention handling. Receptivity towards honoring multiple elements of diversity that individual families bring when seeking and acquiring services must be part of an inclusive service delivery model. Children and adults with disabilities served by physical therapists and/or other professionals are an expansive heterogeneous population. The pathological diagnoses are varied and span a wide severity continuum. The individual's age, cognitive ability, family configuration, cultural and ethnic heritage, and social capital increase the complex nature of service, which is further multiplied by the same layers of variation among the parents or caregivers. Disability, recognizing no boundaries of diversity, necessitates 
pediatric physical therapists' attention to cultural responsiveness to the everchanging demographics of their service recipients as part of a comprehensive family-centered approach.

Issues critical to the value of teaching parents as a part of pediatric service delivery stem from indications presented by Effgen and Chiarello (2000) and Cochran et al. (1990) state that family-centered models are not a consistent content priority in higher education professional preparation programs. O'Neil and Palisano (2000), in measuring attitudes of 25 pediatric physical therapists practicing in early intervention, reported identification of child characteristics as the most important factor (76\%) in clinical decision making. Family-centered service models urge therapists to transition from isolated impairment focus of service to a comprehension of disability within a social model of service in the contextual framework of family and social community. Appreciation of the multiplicity of working with family units is crucial to understanding, appropriate, and effective early intervention service. Numerous authors underscored the consequence of natural environment contextual value (Bronfenbrenner, 1995; Hanft \& Pilkington, 2000; Mahoney et al., 1999).

A paucity of research is also evident in measuring pediatric physical therapists' effectiveness as educators of parents of children with disabilities. Precursory to effectiveness is whether pediatric physical therapists (a) recognize their parental educator role and (b) identify what are educational/teaching opportunities. This begs the questions of whether therapists teach parents and, if 
so, how do therapists teach parents of children with disabilities? Furthermore, are the elements of recognizing teaching opportunities, practice, and skill taught in the professional education programs, or is teaching a "learned on the job" skill? In the specific professional education program, it is unclear whether the expectation of this recognition occurs in the formal classroom or within the context of the clinical internship. The extent to which clinical internship instructors make skills of parent education a priority for physical therapy students is unknown. Additionally, as mentioned earlier, therapists may or may not have an adequate familiarity with adult development and learning theories, thereby impacting their ability to be effective parent educators.

A major challenge for pediatric therapists is balancing the focus between child-centered interventions and family-centered interventions. This may include numerous overlapping intervention opportunities where child and parent learning are occurring simultaneously. McCollum, Gooler, Appl, and Yates (2001) highlighted supporting parent-child relationships amidst professional-parent and professional-professional relationships that sustain an ebb and flow overlap in early intervention provision. This support reinforces parent competence.

Physical therapy curriculum has, in recent years, increased attention to theories of motor learning with concomitant rehabilitation and habilitation application. In habilitation efforts, motor learning theory application is readily observable with therapists' promotion of individual children's sensorimotor function (learning gross and fine motor skills in context). The extent therapists 
apply this same knowledge when instructing parents how to facilitate their child's motor development, in concert with adult learning theories, is presently unknown. The dual educator role, simultaneous instruction to parent and child, makes the physical therapist's educator role that much more challenging and thus of interest to examine in greater depth. Identification of both adult learning and motor learning strategies employed by practitioners providing physical therapy to infants and young children with disabilities and their families is needed before the educational effectiveness of such strategies can be measured.

The purpose of this study was to initiate a better understanding of pediatric physical therapists' educational role with parents of young children with physical disabilities. At issue is the importance of placing increasing attention on the parental learner that will ultimately impact motor development of a child diagnosed with motor dysfunction. Attending to the family unit provides contextual and environmental pivots for therapists to base their service delivery that may be more responsive to family needs. If not addressed in these larger contexts that reflect a more social model of disability, intervention is more likely to take on a therapist dependent nature. Pediatric physical therapists are remiss if they do not address issues beyond the impairment level of child-specific disability that include developing strategies that would guide parental learning towards that end. Understanding and appreciating the nuances of adults as learners is judicious for the development of a competent practitioner. Not being adequately prepared for the practice environment competency of instructing parents, be it in the didactic or 
internship portion of formal higher education professional preparation programs or post-entry level continuing education opportunities could well be viewed as negligent. Families with young children diagnosed with motor dysfunction and/or multiple handicapping conditions have never been a homogenous group in any element of diversity, be it social, ethnic, racial, economic, or the child's diagnosis. Infants, young children, and youth with motor dysfunction have long been the primary recipients of pediatric physical therapy. Consequently, physical therapy educational preparation has been focused on child-specific content. Until fairly recently, little consideration has been given to the parents of these children as learners. Similarly, though not the focus of this study, teachers and educational assistants can be considered adult learners in relation to these same children in a similar vein. Young children with movement dysfunction are served by pediatric physical therapists in a variety of settings; however, the importance of working with parents remains constant. Knowing whether pediatric physical therapists are functioning as what Hanft, Rush, and Shelden (2004) referred to as coaches and if so, how, was the focus of this research inquiry. These authors have embraced the term coaching rather than teaching. This term more accurately defines the desired cultivation of a collaborative partnership between parent and professional where each partner learns from the other. Utilizing strategies that guide and encourage parents' competence can ultimately lead to increased parental selection and implementation of cogent strategies that will enhance their children's participation and development. Thinking about the transfer of knowledge and constructing 
capacity in terms of coaching rather than parental education challenges practitioners to expand their repertoire of professional/parent interactions. The art of coaching will take time for individuals to master; however, it should not be ignored as it can bridge the current gap of transitioning from child-centered to family-centered interventions.

The comprehensive research question was: if and how are pediatric physical therapists educating mothers of young children with physical disabilities to enhance and guide their children's gross motor skill development in the context of providing early intervention physical therapy services? Identifying the parental teaching/coaching skills of pediatric physical therapists may suggest success or inadequacies of professional school preparation for this specific aspect of the provision of family-centered physical therapy interventions. The review of literature will first summarize federal legislation for early intervention services to gain a perspective on the specific requirements and responsibilities of practitioners. Though much of this literature is delineated in the context of an educational model, the requirements and responsibilities are germane to all practice settings. Second, characteristics of family-centered service are described to better understand the "non-child" recipient of pediatric physical therapy service in early intervention provision. This facet is examined to gain a differential perspective between childcentered and family-centered and thus why a transition from the former to the later has been slow. Parenting, parent education, and parent-professional reciprocity are presented in subsequent sections to further elaborate on the parent learner in EI. 
These sections address the unique situation and position that parents hold in the context of early intervention. Adult learning and development theories followed by discussion of gender, and cultural considerations continue the literature review to address the broad heterogeneity of parents as potential learners. Motor learning theory completes the literature review as a critical element in teaching (coaching) parents handling skills that could facilitate child motor development as well as daily physical management that is safe and sensitive to natural contexts of family activity and participation. All these elements are critical for coaching to be responsive, inclusive and, effective. Individual learner characteristics and styles cannot be ignored and thus addressed in the following literature review. In order to address these issues, as they specifically pertain to pediatric physical therapy, the research design and methodology used are presented in chapter 3. 


\section{CHAPTER II}

\section{LITERATURE REVIEW}

Early Intervention Federal Legislation

Physical therapists and other professionals serving infants and young children with disabilities may often provide services under the auspices of state educational systems. Consequently, as a group, they are required to adhere to legal policy and procedures. Federal legislation, the Education of All Handicapped Children Act of 1975 required that children with disabilities receive services such as physical therapy to allow them to benefit from their education. Reauthorization of the Education of the Handicapped Act amendments (1986) amended the original 1975 legislation to include serving children age $0-5$ through special education (1986). Renaming the original act to Individuals with Disabilities Education Act (IDEA, 1997) reflected a philosophical transition towards recognition and appreciation for family-centered and community-based programming value. In addition, the 1997 reauthorization recognized the importance in serving not only the child, but also the child's parents. Thus, the child is not the only client of the various professionals involved in EI services.

\section{Professional Attitudes Toward Family-Centered Care}

Professionals are required to view the needs of the child within the family context as EI services for infants and young children with disabilities have emphasized a family-centered approach. Dunst, Johanson, Trivette and Hamby 
(1991) described family-centered care as "a combination of beliefs and practices that define particular ways of working with families that are consumer driven and competency enhancing" (p. 115). This approach recognizes the importance and value of parental involvement in the development of their children. Professionals must, therefore, strive to recognize supporting parental learning as another integral part of their work role. Reflective of its support toward family-centered care, the pediatric section of the American Physical Therapy Association (APTA) included similar language in its published competencies for physical therapists in early intervention (Effgen, Bjornson, \& Chiarello, 1991). Effgen and Chiarello (2000) itemized not only competencies in the myriad of intervention strategies related to body systems (neurologic, musculoskeletal, cardiopulmonary, and integumentary) but also environmental adaptations and family-centered care. Family-centered care includes attention to supporting the family unit, enhancing family competence, partnering with the family to encourage child development and functional independence, and promoting child and family community inclusion.

O'Neil and Palisano (2000) described attitudes of 25 pediatric physical therapists towards family-centered care in EI programs. Therapists (100\% female) were all practicing in EI with at least three children less than 3 years of age, to whom they had been providing therapy for three or more months. Subject respondents were from a convenience sample in southeastern Pennsylvania averaging more than 10 years of pediatric work experience. Eighty percent of the respondents were White with a mean age of 38.9 years. Attitudes were measured 
using a modified version of the Measures of Processes of Care-Service

Providers. Findings suggested that some specific child-focused direct interventions were significantly associated with the family-centered service model. These included: (a) emphasis on functional activities, (b) incorporation of feedback, and (c) emphasis on generalization during intervention. Additionally, the majority of PTs $(76 \%)$ identified child characteristics as the most important in clinical intervention decision making, whereas only $20 \%$ indicated family considerations as the most important. The authors suggested that this may reflect the nature of the physical therapist's role as a knowledgeable resource in child motor development. Furthermore, the authors hypothesized that if pediatric physical therapists had positive attitudes towards a family-centered service model, they would have made their intervention frequency and duration decisions based on family rather than child considerations.

Formal documentation for accountability of this new requirement is made through the Individualized Family Service Plan (IFSP). Elements of an IFSP, such as a family goal page, should demonstrate that $\mathrm{EI}$ is attending to and responsive to the entire family, not just the child. McWilliam et al. (1998) reviewed 100 IFSPs from four agencies. The agencies used primarily home-based EI services, homebased service coordination, center-based segregated services, and center-based inclusive services. In examining the family-centeredness of these IFSPs, the authors worked on four basic assumptions. First, the document should be for the entire family as well as the professional. Second, the IFSP should indicate what the 
family wants. Third, it should reflect recommended practices. Fourth, the IFSP should be functional and useful to those who will be working from it. These authors further stated that an IFSP should be procedurally sound so that:

“a) families have documentation about what is happening; b) all service providers involved know what is happening; and c) intervention is systematic - not erratic, arbitrary, and haphazard" (McWilliam et al., p. 70). Attending to such factors can only reinforce exemplary coaching. McWilliam et al. used an IFSP FamilyCentered Rating Scale to assess measurement validity among the four agency types. Twenty-one items were grouped in the categories of cohesion, functionality, and clarity factors. The authors reported high ratings in identifying the family's role and writing in the active voice. Lowest ratings were displayed in the areas of integration across disciplines/professionals, specificity, and positiveness. Of special note was that the majority of goals written were child related, not family related.

McWilliam et al. (1998), using data collected in 1993, stated that the specific family-centered goals collected for this study had changed very little since 1986 when IFSPs were first mandated. They suggested that either such goal writing has been well established or that the professionals who are writing the goals are not likely to change their goal writing tactics. Further explanation of this phenomenon included references to additional studies by the lead author and other researchers demonstrating that families appreciated a child-focused intervention and saw this as a priority. Transition towards a more family-centered service in EI 
has been and continues to be slow. The authors suggested that family-centered models might not yet be clearly understood by the professionals. Nor are these models a content priority in higher education professional preparation programs (Cochran et al., 1990; Effgen \& Chiarello, 2000).

Iverson et al. (2003) compared the attitudes of parents and early intervention providers relevant to family-centered services. Seven of 11 service providers of varied disciplines completed an open-ended questionnaire regarding barriers to developing collaborative family-professional relationships. Four of the seven $(59 \%)$ respondents expressed having confidence in building such relationships. Those not expressing confidence, reported lack of formal training in family communications and assessment for their lack of confidence. Though suggested, causation must be gingerly considered due to the very small respondent pool, a discussion of whether family-centered intervention should be addressed as part of professional preparation could allay what seems to be a chasm between families and professionals.

\section{Family-Centered Intervention Practices}

Dunst et al. (1991) defined family-centered care as "a combination of beliefs and practices that define particular ways of working with families that are consumer driven and competency enhancing" (p. 115). Filer and Mahoney (1996) identified three salient processes for providing positive family-centered care. Service providers should: (a) give parents an opportunity to identify their concerns, needs, and goals for their child; (b) listen to and respond to parental requests; and 
(c) communicate effectively with parents regarding types of services available and how they will meet the parental needs.

McWilliam et al. (1998) summarized previous literature and stated that family-centered services include "viewing the child in the context of the family, responding to family concerns and priorities, working in partnership with families, and enabling families to use resources to meet their needs" (p. 69). Indeed, professionals working with a young child with a disability must acknowledge that the child is but one component of a family unit. Though their educational backgrounds may have focused on functional limitations (inability to walk or complete activities of daily living) and/or impairments (physical deficits) of children, physical therapists must comprehend the multiplicity of factors involved in the functioning of families. This multiplicity of factors may include entities such as social capital, economic status, educational levels, ethnic and cultural practices, and health and wellness values. Attending to the child's role in the context of her or his family and community at large signifies a therapist's comprehension of disability within a social model of service. Isolated impairment (lack of strength or range of motion) and functional limitation (inability to sit or walk independently) attention is much more characteristic of a solely medical model of viewing the child and her/his family.

Kolobe, Sparling, and Daniels (2000) summarized the key elements of family-centered care proposed by the National Center for Family-Centered Care. Recognition that the family is the singular constant in a child's life topped the list. 
Other proposed elements included facilitating networking between families with similar issues, promotion of parent and professional collaboration, and incorporating the developmental needs of children into the health care systems. Also included in the proposal was the suggestion for programs to guide policies that would provide emotional and financial support to meet family needs. Honoring diversity of all kinds and designing health care services that would be flexible, accessible, and responsive to families' needs completed the proposed listing of key elements.

Even though a child with special needs may be the primary focus of the professional's expertise, the intervention efforts must be delivered in tandem with the health, educational, and informational needs of the family unit. The Section on Pediatrics of the American Physical Therapy Association adopted a policy statement in January 1990 and Early Intervention Competencies for physical therapists in February 1991 that included specific language directed towards family-focused services (Effgen et al., 1991).

Thirty years ago parents were not often considered a critical component of successful interventions. However, with increasing emphasis and movement towards family-centered service models in EI, parent education and its delivery mode have become a more prominent focus. Mahoney et al., (1999) referred to principles of interventions cited twenty years earlier that continue to have current application. Predominant in these principles was the emphasis on learning in the child's natural environment, the home, which would allow greater opportunity for 
full family participation in the teaching process and maximized consistency over time (Bronfenbrenner, 1995). Hanft and Pilkington (2000) articulated that working in natural environments such as the home enables therapists to position themselves adjacent to the parent as coaches rather than as lead players. Hanft and Pilkington continued by presenting valuation for coaching caregivers during typical routines such as meal time, negotiation of home environment, and/or play, which will enhance the prospect of compliance rather than adding what is often perceived as additional parental delivered "therapy treatment" onto already full schedules. Thus the likelihood for the child's learning to be generalized to other environments is enhanced because the child's natural reinforcing agent, his/her parent, is the one who is teaching the child. Teaching parents directly builds upon their natural reinforcing role and thus provides them with additional skills for dealing with new and emerging child behaviors when they occur. The professional, who is engaged in home visits, is able to work one-to-one with an entire family unit.

Individualization of instructional goals for both the child and parent is a service provision reality and requirement. Higher education preparation for pediatric physical therapy practice provides appropriate information regarding the child member of the family unit (Effgen \& Chiarello, 2000). However, as stated above, parent member curricular content is often absent or minimal at best. Bodies of literature, such as special education, early childhood education, adult education, and/or sociology, typically untapped by physical therapists, may provide insight to the breadth of parenting import germane to best practice in an early intervention 
environment. Gaining these added dimensions would be informative in developing needed competence towards provision of best practice. The struggle lies in whether such content should be part of entry level preparation or packaged in advanced studies or continued education, given that PT programs essentially must prepare graduates for working across a "womb to tomb" life-span. Given that the majority of PT practice is not directed to long-term chronic disability or the pediatric realm, the challenge to include such content is fraught with numerous barriers. Entry level programs have evolved to granting clinical doctorate degrees and graduates seeking to enter pediatric practice find themselves only meagerly prepared to work with children with disabilities and their families due to the complex nature of this particular practice arena. Regardless, parent education must at least be mentioned in entry level preparation.

\section{Parenting and Parent Education}

Parenting is the quintessential example of care as it is the human species' initial introduction of a unique relationship across varied contexts and environments. Parenting serves an important and unique role in child development. Within families, caring stands in sharp contrast to the more public, professional caregiving that has grown in the United States today. Gordon, Benner, and Noddings (1996) defined caring "not as a psychological state or innate attribute but as a set of relational practices that foster mutual recognition and realization, growth, development, protection, empowerment, and human community, culture, and possibility" (p. xiii). They continued, stating that practices of caring are 
"required in relationships that are devoted-for however short or long a period of time-to helping educate, nurture, develop, and empower, assisting others to cope with their weaknesses while affirming their strengths" (p. xiii). These relationships must encourage comfort and advantage despite elements of change, crisis, vulnerability, or suffering.

As stated in the introduction, early intervention services for infants and young children with disabilities have increased emphasis towards a family-centered approach. Family-centered service delivery includes teaching/instructing parents and/or guardians in performing home programs focused on specific goals that parents have for their child. This service delivery model recognizes parents as the initial and often primary facilitator of their child's development. Thus, much of the service provided to families with young infants and children enrolled in EI services should be directed towards instructing parents in how to facilitate their child's development.

Parents of children with disabilities in EI programs, in fact, become the primary learners of the various professionals who are members of the child's service team. A number of years ago, "The Family Circus" cartoonist Bill Keene's (1990) daily submission showed a mother holding a newborn with an older brother asking a question of his mother. The accompanying text read, "If babies don't come with directions, how do mommies know how to work 'em?" Keene's humor pinpoints the question of how do individuals, on becoming parents, know, understand, and perform the parenting roles of caregiver and facilitator of 
development? More specifically, how are parents supported in this critical caring responsibility?

How parents learn to care for an infant, when indeed no instructions are included upon arrival, is the impetus for discussing teaching and learning implications for developing parental support by all professionals when providing early intervention services. Early intervention programs specifically designed for children with disabilities and their families place significant focus on practices of childhood education and care. Much of EI research, with parents as the independent variable, has thus far centered on examination of specific child developmental gains as outcome measures. The paucity of specific parental learning outcomes, in particular for parents of a child with a physical disability within the context of physical therapy EI services, begs attention.

Mothers are the predominant parental participant in EI programming and consequently have been the primary adult subject in research findings. Therefore, it is important to include some exploration into the specific practice of mothering and the aspect of caring. Leonard (1996) presented an interesting insight into mothering as practice versus child-rearing techniques. She suggested that generic rearing techniques (e.g., toilet training, self-feeding) that supposedly can be learned as technical skills may conflict with the practice of mothering. She defined mothering as a practice that provides an opportunity to develop caring and nurturing of an infant and/or child. Child-rearing techniques can insure that a child will meet developmental milestones and requisite skills for school acceptance. In 
contrast, mothering as a practice can "give content and meaning and a notion of the good to women's lives, and serves, through an ethic of care, to nurture and preserve both individual children and important meanings and traditions within families and in the culture" (p. 124). The practice of mothering is particular to each individual mother-child dyad. This particularity of individual dyad pairing necessitates the attention pediatric physical therapists must manifest when working with children with disabilities and their mothers. Therapists coaching a mother in facilitating her child's development must do so with observances that are culturally, socially, and intellectually sensitive.

Learning to mother can be based on the individual mother's intuitive understanding of her own child, much more so than written texts providing prescriptive child development information (Leonard, 1996). Phillips and Soltis (1998) explained Dewey's belief that "intelligence is creative and flexible - we learn from engaging ourselves in a variety of experiences in the world" (p. 39). Upon becoming a mother, a woman's focus is the child to whom she has a commitment. The challenge she assumes over the ensuing years is to raise her child to become a contributing member of society. This challenge can be equated to the initial step of problem discovery that Dewey constructed to indicate that learning had taken place. Subsequent steps include searching for possible solutions, utilizing previously learned information, and then forming a plan of action to test the solution possibilities. 
Phillips and Soltis (1998) also discussed the value of social context of learning in a description of the theoretical work of Vygotsky. Vygotsky placed a high value on learning from others. He emphasized that much of what one learns from others is reflected through imitation of social experiential learning. "Interacting with adults and peers in cooperative social settings gave the young learner ample opportunity to observe, imitate, and subsequently develop higher mental functions" (p. 59). If all learning only occurred on the basis of individual actions, it would be quite tedious and not advance very far. Informal coaching given to a new mother, either by her own parents or others, immediately following the arrival of an infant allows for this very social experiential learning. Though not always feasible or realistic, many new mothers can gain valuable confidence in their child-rearing capabilities with this support. Both Dewey and Vygotsky would likely have found value in the premise that mothering is more than technical skills.

In contrast, the broader concept of parenting as a technical skill can be identified with learning in terms of cause and effect/stimulus and response. This learning falls under the description of operant conditioning contributed by Skinner (Merriam \& Caffarella, 1999). Consequently, the task of parenting can more readily be delegated to substitute caregivers who may in fact be more skilled in the "right techniques" to facilitate or promote the assumed external outcome of mothering, achieving developmental milestones such as toilet training or spoon feeding. Though, in certain instances, substitute professional caregivers may alter the effects of abusive or devastating parenting, such delegation does undermine 
family traditions that would enhance maternal practice of facilitating children's familial cultural and social development. Leonard (1996) further stated that delegated parenting via professional caregivers "also ignores the gap between acquisition of formal guidelines for parenting and the experiential learning that is required in order to know how and know when to apply the techniques" (p. 135). This statement behooves the physical therapist, as well as other professionals, to work in a supportive manner with mothers rather than becoming the "surrogate" caregiver for the child during the very limited therapy intervention session. What seems to have been lost in the striving for more independence and individual liberty is the "everyday familial and social practices as resources for learning how to mother a child" (p. 136). Mothering as a practice is problematic, because it is inconsistent with seeking autonomy within our liberal individualistic philosophy. It is further problematic in that the system of available out of home childcare is often disorganized, inaccessible, expensive and inequitable. Professionals serving parents of children with disabilities are part of this system. Rather than viewing their parental interventions as a means to change or alter the practice of mothering, professionals need to develop reciprocal relationships with mothers. Reciprocal relationships reinforce good coaching. Research specific to professionals' and specifically physical therapists' interactions with parents via the parental educational component of EI though lacking, is critical. Understanding the reciprocal nature of this educational component is imperative. 
Parent-Professional Reciprocity

It is important for EI professionals to develop a plan with the parents of a child with disabilities regarding the desired outcome(s) as required by the federally funded law. Outcomes will range from family-centered outcome goals to specific child-centered outcome goals or may even reflect a combination of parent- and child-focused intent. Some outcomes may be specific to parent and professional. Any and all of these outcomes may present individually or concurrently. The more highly skilled a practitioner is, the more success a particular intervention is likely to achieve. The interplay between these potential outcomes may wax and wane between and within physical therapy sessions. The extent of overlap needs to be viewed on a continuum that can expand and contract dependent upon the specific need per given session. Figure 1 illustrates this perspective with dashed lines circling each pairing to suggest non-rigid boundaries. The bidirectional arrows suggest the continuous nature of reciprocity that can occur.

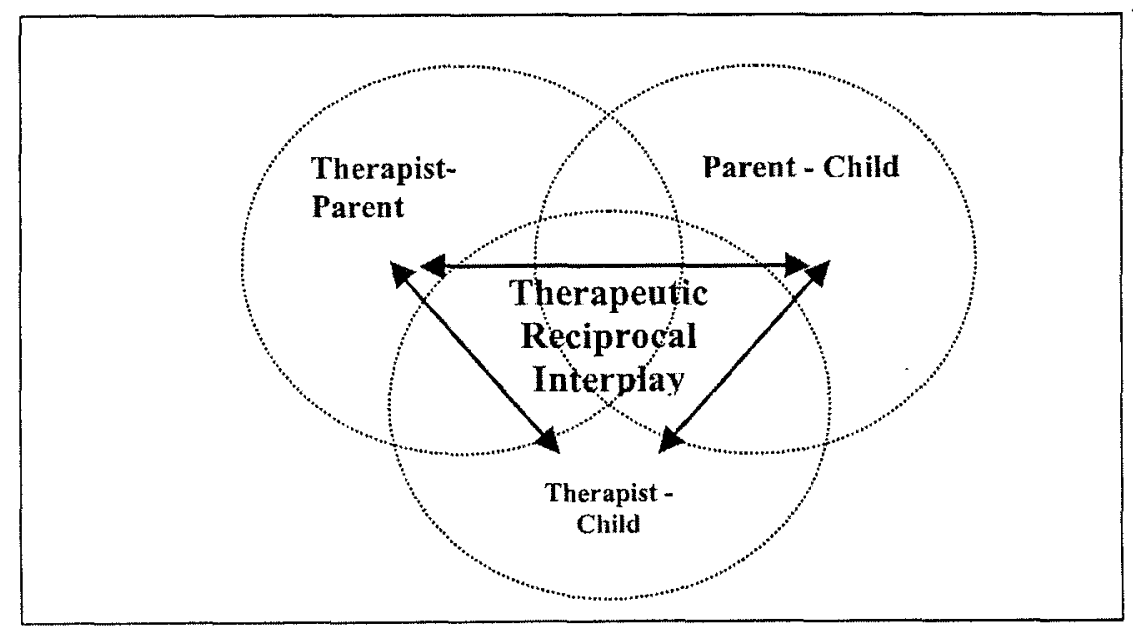

Figure 1. Therapeutic reciprocal interplay of therapist, parent, and child. 
The fall 1999 Topics in Early Childhood Special Education journal was devoted to parent education in early intervention. Mahoney et al. (1999) introduced the topic by making a call for a renewed focus on this seemingly key component of providing EI services. Mahoney et al. defined parent education as "systematic activities implemented by professionals to assist parents in accomplishing specific goals or outcomes with their children" (p. 131). Dinnebeil (1999) reinforced this definition by stating that enhancement of developmental outcomes for infants and young children is dependent upon the family context for each child. She added to the suggested definition that families should be given the opportunity to identify their own learning needs. Dinnebeil stated that matching appropriate learning strategies to specific outcomes of activities is essential for providing quality parent education. Articles in this journal indicated that professionals lack agreement regarding the goals and relevance of parent education.

Winton, Sloop, and Rodriguez (1999), in response to Mahoney et al. (1999), countered that perhaps the term parent education is no longer appropriate. They believe it implies, in the minds of parents and professionals, a more formal instructional encounter where parents are the recipients (i.e., unknowing learners) of the providers' teaching (i.e., knowing professional experts). The strongly seated connotations associated with "parent education" do not necessarily express the transition that has occurred in the field. Descriptive labels must also change to reflect that practice and implementation strategies have changed. Winton et al. suggested that the term parent education needs significant "rehabilitation" before it 
could be successfully resurrected in EI. These authors urged consideration of the more encompassing label "parent-professional collaboration." Indeed special education team models, including services in EI, are being described as collaborative to indicate a transitional shift from former model descriptors of multidisciplinary, interdisciplinary, and transdisciplinary teams. This new terminology is being used concurrently in the field and in professional higher education programs. Furthermore it is much more compatible with the concept of parent-professional reciprocity and a coaching approach to build parent competence.

Helping parents become aware of a new skill for their child, praising the parent for their parent-child interactions, praising the parent for recognizing skill emergence, and assisting a parent in the application of specific techniques are examples of how professionals can intervene in a family-centered model of service delivery. McCollum et al. (2001) reported on an EI model program that focused on enhancing parent-child interaction. This program, Parents Interacting with Infants (PIWI), has been based on the numerous interactions that occur in EI programs. These include the relationship between parent and child, between professional and parent, and among the professionals themselves. The main focus of the program is supporting and building the parent-child relationship. In addition, the program emphasizes parental understanding of their child as compared to more general child development. The authors stated that the parent-child interaction is one of the most important contexts for early learning. Furthermore, the program highlighted 
“family orientation, positiveness, sensitivity, responsiveness, friendliness, and child/community skills" (p. 38). The program gave importance to feelings of parental competence being in concert with positive parent-child interactions.

Marcus, Swanson, and Vollmer (2001) reported the effects of parent training on parent and child behaviors. The authors utilized procedures based on functional analysis. The subject pool was comprised of four children diagnosed with developmental delays and aberrant behaviors, and their parents who were the training recipients. The training model included the following steps: (a) baseline data collection, (b) intervention overview, (c) role-play, (d) model, (e) immediate feedback, ( $f$ ) delayed feedback, (g) observation, and (h) follow-up. The role-play portion of the training model consisted of the therapist role-playing the child with the parent practicing the specific skill in the assumed parental role. The therapist modeled working with the child, which was followed by the parent working with the child when comfortable. At the point of time when the parent began working with the child, immediate and delayed feedback was given to the parent by the interventionist. In all four mother-child dyads, improved child behaviors corresponded to improvements in parents' performances. Feedback is a strategy utilized by athletic coaches for some time and generalizing it to professional/parent collaborative efforts is a critical part of the overall coaching model proposed by Hanft, et al. (2004).

Ketelaar, Vermeer, Helders, and Hart (1998) reviewed specific research that examined parental involvement in intervention programs for children diagnosed 
with cerebral palsy. The authors' review yielded 16 studies that met their inclusion criteria of parental participation of any kind and children with specific diagnosis of cerebral palsy. Of these, only 7 had the parent involvement as an independent variable. Finding consistency between more studies was challenging, making it quite difficult to generalize; and, therefore, the authors clearly stated that it was difficult to truly conclude that parental involvement was supported by the findings. Though the authors were only able to review a very small number of studies, they did make practice recommendations. What surfaced was that parents need to be actively engaged in all aspects of the intervention, and that parental problem-solving skills and independence need to be supported. Their review indicated that the family's concerns and priorities in tandem with those of the child must be a priority. Additionally, it is most important that physical therapists encourage parents' participation in setting goals that reflect the priority concerns for themselves and their children, and programming is more successful when it adapts to the family's capabilities, situations, and daily routines. Encouragement of parents setting goals is yet another example of coaching strategy applicability. The authors concluded that parents must be given scheduled opportunities to assess and change previously set goals. To achieve the suggested steps, collaboration between parent and professional is necessary.

Schreiber, Effgen, and Palisano (1995) measured the effectiveness of parental collaboration on home program compliance. The experimental group collaborated with the therapist/investigator to develop a home program while in the 
home setting. The control/comparison group received a "therapist-prescribed" program taught to the parent at the child's school. Though not statistically significant, the experimental group showed a mean compliance of $80.3 \%$ as compared to $77.5 \%$ compliance in the control group. The authors concluded that home programs might be more likely to be carried out if they are reflective of what actually occurs routinely in the family's home. Attending to the parental cues when developing home programs will often inform therapists as to the appropriateness of the choices and potential parental compliance. As Dinnebeil (1999) summarized, "Parent education activities address the specific learning outcomes of parents, with consideration of the parents' learning characteristics and the sociocultural systems within which their families exist" (p. 164). Therefore, alertness to family diversity is an important consideration in successful PT intervention.

Kelly and Barnard (1999) presented a relationship-focused model for parental education. This model, defined by the authors, has as its priority "fostering growth-producing parent-professional and parent-child relationships" (p. 151). The emphasis of this proposed model was that the reciprocity between parent and child should evolve and be mutually rewarding.

The physical therapist, like all the EI professionals, must attend to the development, not only of the child, but also of the parent who is learning an entirely new vocabulary, way of coping, interacting, and quality of life. Therefore, physical therapists need to be aware of adult learning differences to adjust their 
teaching strategies. Supplementing coaching with this awareness can strengthen a physical therapist's efforts toward building parental competence. These attributes are no different than if the child did not have a disability and may preclude parents who may or may not have expertise in the disability and early intervention.

Turnbull, Blue-Banning, Turbiville, and Park (1999) proposed a parental partnership rather than a parental education model because there exists a need to support families in areas more global than child development. Bailey et al. (1998) included: (a) enhancing the ability of the family to work with professionals, (b) developing an effective support system for the family, (c) creating a positive vision of the future, and (d) improving familial quality of life as additional focal points of family-centered service models. Turnbull et al. encouraged professionals to consider intervention from the child's perspective and also in a more socioecological frame of reference. Rather than the child with a disability and his/her family being "fixed" to fit the existing environments, adaptations of the environments that the diversity of families live in should be the origin of the accommodations and supports.

Alluded to earlier, Rush, Shelden, and Hanft (2003) and Hanft et al. (2004) described a set of skills, reflective of evidence-based practices that link research to practice, for an adult learning strategy they label "coaching." Building on the parent/family strengths (i.e., capacities), these authors have sought to focus on the value of professional preparation in the realm of adult learning. The structured process for development of parent-professional partnerships, having a focus on 
shared skills, knowledge, and experiences, allows for competency development of adult care providers. These authors emphasized three facets as key to successful coaching: (a) personal discovery, (b) focus on meaningful performance, (c) and a process orientation. Personal discovery refers to what is determined as known by the learner and what new learning is sought. Meaningful performance is achieved when attention is given to tasks within specific contexts. The orientation of process affords a mechanism to improve instruction, experiment with new methods, solve problems, and build partner relationships.

The coaching process framed by these authors is divided into five phases: (a) initiation, (b) observation or action, (c) reflection, (d) evaluation, and (e) continuation or resolution. Rush et al. (2003) have clearly stated that this is not a linear process. Personal development of the adult learner is strongly linked to the observation or action and reflection as coached by the professional service provider. Initiation allows for a coaching relationship invitation. Observation and action encompass all the opportunities for the learner to be instructed, supported and guided in her/his learning. Reflection places a much greater emphasis on instructing the learner to analyze her/his behavior. Partners in such a coaching dyad may traverse between the phases of observation/action and reflection numerous times during one intervention session. Evaluation of the process may not necessarily occur with every coaching session. It can occur following the session as the provider self-assesses service effectiveness. The continuation phase is 
determined following evaluation of outcome achievements and thus allows for plan development for future sessions.

Summary of Family and Parenting Literature Review

The literature reviewed thus far and the intent of family-centered service mandates indicate the importance of physical therapists educating parents of children with disabilities whom they serve. However, as McWilliam et al. (1998) reported, efforts in accomplishing parental education are not all that evident in the written individual family service plan (IFSP) documentation. Measurements of success have been primarily child-centered. There is a paucity of research addressing specific parental outcomes and it seems that studies that do exist lack attention to adult learning issues. No studies were identified that examined specific outcome measures of successful teaching/instruction to parents as documented on IFSPs. No studies identified what constitutes examples of parental teaching taking place in specific physical therapy intervention sessions. Dinnebeil (1999) made several suggestions of how this could be accomplished. Identifying elements of successful professional-to-parent teaching moments linked to IFSPs could provide valuable information to professional higher education programs such as physical therapy. Identifying categories of teaching encounters could provide solid examples for what Mahoney et al. (1999) suggested as a necessary transition in higher education curricula to include a focus on working with adults as well as with children enrolled in EI programs. 
Winton et al. (1999) suggested "collaborative consultation" and "activitybased intervention" as labels that could more accurately describe how families are or should be served in family-centered service models. These descriptive labels currently enjoy a positive connotation with current "best practice" when viewed in concert with principles associated with utilizing natural environments. This was exemplified via the embedding of teaching moments into everyday child and family routines in the home. Compliance is much more feasible and has greater generalizability than in a self-contained classroom environment. Parentprofessional collaboration also can imply and should lead to shared decisionmaking when the relationship is responsive in either direction. Families need to be considered the primary members of the team with the PT professional being one of many supporting cast members. Parents are typically the children's most consistent historians, fervent advocates and ongoing teachers who need to be heard and heeded. Their opinions are critical to any successful outcome.

McCollum (1999) articulated the importance of recognizing parents as highly valued and knowledgeable providers of information. She acknowledged the disfavor that the term "parent education" has incurred; however she does not think the concept it was meant to convey has had a similar disapproval. Despite the fact that there is reportedly less emphasis on parent education in research and teaching of professionals, other aspects of intervening with families are emphasized. There are increasing efforts to better understand family systems and to recognize families as users of service systems in the practice arena. Establishing collaborative roles 
with families is becoming more apparent to practitioners and program administrators.

According to McCollum (1999), EI professionals have skills and information to give parents. She further stated that parents want to know that professionals have this expertise and that they want to learn from the professionals. However, she warned against jumping on the proverbial bandwagon by returning to the old parent education paradigm. Recognizing and developing a new paradigm of a collaborative and reciprocal education between parent and professional for the best interest of the child is what she believed should be sought. Perhaps initial interpretation of family-centered models has been too rigid. Parents have the choice to be involved or not, but regardless of their decisions, parents still need to be given appropriate information in order to make this and subsequent decisions (McCollum, 1999). Considering the pediatric P'T as a coach rather than an educator may bridge the necessary paradigm shift. To be a skillful coach, pediatric physical therapists need a practical understanding of teaching and learning theories, gender and culture influences, and motor learning theories.

Early intervention pediatric physical therapists need to practice the principles of a collaborative and family-centered model that includes children and their parents. Parent learners, specifically mothers, who have infants and toddlers enrolled in EI programs, may be as young as 13-14 years and as old as mid to late 40 s and will come from all walks of life. Awareness of and sensitivity to adult learning theory, adult development, gender, and cultural responsiveness are 
imperative for quality interventions with parents and families. Thus, as noted in the introduction, Kelly and Barnard (1999) identified the lack of preservice education in theories of adult learning as a deterrent for transitioning practices such as physical therapy to a family-centered model. Examining key elements of adult learning theory may allow researchers to identify specific family intervention strategies that can be incorporated into models for responsive professional education programs.

\section{Adult Learning Theory}

An adult teacher-learner relationship, between a physical therapist and parent, is established at the moment a child and his/her parents initiate pediatric physical therapy services following a medical or self-referral. What families have in common is a major life event, the commencement of a parent-child relationship, coined by Levinson (1980) as a "marker event." Giving birth or adopting a child with a disability often adds to the adaptations necessary for family functioning in current and future environments. The chronological and cognitive age of individuals becoming parents may span several decades. As might be expected with this wide age range, there is vast diversity in terms of socioeconomic factors, cultural background, formal educational levels, and support systems.

Consequently, a physical therapist's approach to a learning event must be socially and culturally responsive to each individual family.

The classroom of this learning relationship is unique in that it may be the family home or it may be an outpatient clinic. The subject matter is the child 
and/or the family's ability to meet the child's needs. The partnership of the PT and parent is the teacher-learner relationship, and the documented family service plan equates to a lesson plan or learning contract with specific learning objectives.

If pediatric physical therapists identify families, particularly mothers, as the originators of the learning objectives for individual sessions as well as long term, it is imperative for physical therapists to understand theories of learning. As noted earlier, minimal attention is currently given to adult learning theories in PT curriculum despite the recognition that EI physical therapy is federally mandated to have an increased parent focus. Other PT practice environments (hospitals, outpatient clinics, assisted living centers, and home health) are increasingly moving towards increasing the patient education component of PT service. Such a shift provides more cost-effective interventions in response to third party, insurance, payer limits in a costly health care atmosphere. The continuum of learners a physical therapist will work with and coach extends across the life span as well as social, cultural, and economic strata. Thus, it is both logical and imperative that all physical therapists and physical therapy students gain an understanding of learning theories to better address their varied audience of learners.

Merriam and Caffarella (1999), in their work titled Learning in Adulthood, reviewed five major theories of learning that include behaviorist, cognitivist, humanist, social learning, and constructivist. The complexity and challenge of teaching parents of infants and children with physical and multiple disabilities suggests that service providers recognize the intersection of all these theories at any 
given time of an intervention. Each of these teaching/learning paradigms will be described briefly as examples for how they can act as heuristic devices to inform PT practice.

From the first major theory of learning, the behaviorist stance, Merriam and Caffarella (1999) summarized three underlying assumptions. First, observable behavior is the core of study rather than an internal thought process. Some form of learning occurs with a change in behavior. Second, behavior is shaped by the environment rather than by an internally driven source. Third, the probability of repeatable response is dependent upon how close in time two events occur and the reinforcement value. Welcoming an infant into a family configuration often changes the previously established dynamics. Behavior will and does change. A physical therapist must be able to anticipate and respond to these behavioral changes.

The second major learning theory, cognitive orientation or cognitivism gives value to the interpretation of sensations and gives meaning to events of learning as compared to a passive cause and effect concept of learning. The socalled "locus of control" for learning is much more internal in this theory of learning. Merriam and Caffarella (1999) described the works of Ausubel and Bruner as examples of a cognitive learning orientation. They reported that Ausubel stated that learning is only meaningful when an individual can relate it to some already previously learned element and that Bruner highlighted learning via discovery. Three almost concurrent steps in this process are: (a) the acquisition of 
new information, (b) massaging new information to fit new

circumstances/situations, and finally (c) assessing the fit to the need. A parent of a newly identified infant with a disability will most assuredly be discovering a new world of learning. This can be either in terms of becoming a first-time parent compared to never having been a parent, or the different parenting challenges involved when the child is disabled. Physical therapists who recognize and value cognitive changes parents are experiencing are more likely to create environments conducive to parent-PT reciprocity and educational coaching.

Merriam and Caffarella (1999) identified Maslow and Rogers as strong examples of a third learning theory, humanist orientation toward appreciating yet another learning paradigm. These authors listed the prominent components of Maslow's theory as physiological needs (security and protection), belonging and love, self-esteem, and lastly, need for self-actualization. They go on to list the characteristics of Rogers' learning principles as (a) personal involvement, (b) selfinitiation, (c) pervasive, (d) evaluated by the learner, and (e) essence is meaning. Learning focused on the needs of the learner is more valued than the actual content. This reinforces the family/parent goal section of the Individual Family Service Plan (IFSP) for EI documentation which should identify the needs of the parent. Such goals could include wanting information regarding specific diagnosis support groups, how to complete simple wheelchair maintenance, or how to safely move a child in and out of a bathtub. 
The fourth learning theory summarized by Merriam and Caffarella (1999) was that of social learning orientation, which proposes that people learn through observing others. As discussed earlier, children learn within a social setting. The same is true for adult learning. These authors identified Bandura as a primary influence in advancing this theory. The major emphasis was that there is no need to imitate what can readily be observed. The importance of environmental context and the learners' interactions with the environment are crucial. Attention, retention, behavioral rehearsal, and motivation are key components of observational learning. The emphasis of the concept of "natural environments" for providing EI services in the child's home would certainly reinforce this theory as compared to non-home environments where services may also be provided. Though, by contrast, other non-home environments where families can observe and connect reciprocally with other families going through similar experiences may have just as much value for some families.

In some respects, this latter environment can be representative of the social contructivist view of learning, the final theory discussed by Merriam and Caffarella (1999). Constructivism paradigm suggests a construction of meaning, making sense of numerous experiences. By means of a dialogue type process, learning occurs through the building of relationships between learner and more skilled members, such as a PT, in the learning process. This relationship reciprocity is important in the negotiations critical to parent-professional exchanges so that learning is relevant and meaningful. As each family is a unique unit unto itself, a 
social constructivist view of learning may be the most responsive to the focus on the intent of family-centered intervention. Each individual family member will experience exchanges with the professional regarding their interactions and goals for the child who is disabled. Thus, the professional may be constructing meaning from numerous interactions from multiple persons, including siblings, grandparents, other extended family members, as well as friends, neighbors and peers of child and the parents. While a constructivist approach is probably most applicable, other theories must not be negated. Learning is a multifaceted and layered entity that is not neatly compartmentalized. Thus, at times, a PT may apply a behaviorist or humanistic strategy as the most appropriate intervention and concomitant coaching strategy. To be skilled in selecting what is best for the child and parent at any given learning opportunity, a physical therapist must establish a responsive teacher-learner relationship.

\section{Teacher-Learner Relationships}

Establishing a teacher-learner relationship includes addressing the distribution of power between the learner and the teacher. Decisions are needed for what, how, when, and where learning will take place. This will vary in accordance with a constructivist observation of individual family dynamics. In early intervention programs relationship establishment begins during the initial meeting. Chiarello, Effgen, and Levinson (1992) provided an outline of the team process typically used to arrive at service decisions for the child and family. This can translate into learning strategies, learning outcomes, and criteria for measurement. 
Freire's work, as summarized in Tennant and Pogson (1995), compared a problem-posing approach to a banking approach for teacher-learner relationships. In the problem-posing approach, the learners are given the opportunity to determine their own goals. This can be accomplished by physical therapists through the process of mutually generating goals and objectives with families, often through documenting an Individual Family Service Plan (IFSP). Parental learners who are valued will apply knowledge and skill as they pursue their goals. In parent/therapist dialogues during this process, therapists learn significant information and lessons from parents. The learner's identification and perceptions of problems rather than the physical therapist's reinforces constructivist teaching and learning. Therefore, recognition that learning objectives in an early intervention environment are owned by the families is critical to achieving successful outcomes for both parent and child.

Understanding theories of learning and being cognizant of the learnerteacher relationship subtleties alone does not complete the complexity of educational preparation for therapists to provide best practice early intervention. An additional entity is a comprehension of adult development. As alluded to earlier, parents, and in particular, mothers, of children with disabilities have a multi-decade age span. Though one does not typically consider a teenager an adult, motherhood often positions the adolescent female parent into adult categorization. Comprehending phases of adult development may enhance a pediatric physical 
therapist's approach to parents when providing intervention that is responsive to both child and parent.

Robertson (1998) introduced three themes of transformation in his theoretical presentation of phases in adult development. These included resistance, grief, and courage. Families proceed through stages of denial, guilt, grief, and acceptance as they strive to comprehend the figurative death of the dreams and aspirations for their child. These stages parallel Robertson's categories and are reminiscent of the stages of death and dying articulated by Kubler-Ross (1969). Robertson elaborated on the work of van Gennep as he identified surges of growth transition to plateaus of stability in adult learning as the "between transformation" phases. The first between transformation phase is separation, or letting go of former reference frames. A family coming to grips with the knowledge that the child they have is not the child they had hoped for is an example of this separation. Having a child with a disability is most often an unanticipated change of expectations and is initially viewed as quite traumatic.

Transition is the second "within transformation" phase. Robertson (1998) referred to this as a neutral zone period where one must deal with ambiguity, not knowing or lacking order. As parents enroll in programs such as EI, they begin to gain insight, gather information, and integrate this new knowledge. The final phase is "new beginnings" or incorporation of ones' growth. Families build on their previous experiences and as they acquire knowledge, they evolve as a whole family (not a family and a disabled child). These learning changes are representative of 
the cognitive developmental growth that parents will make. Perhaps an awareness of these phases would cue a physical therapist to structure the initial interviews and subsequent periodic coaching initiations to more appropriately address family concerns and generated goals. This would be especially important because parental grieving is never completed because with each developmental milestone not achieved, grief is revisited.

Cognitive development, within the parameters of rearing a child with a disability, is not context-free. The indicator of cognitive development is the successful application of learning on a daily basis in dealing with real-life issues. There is often no one right answer or solution to the challenges arising for a family with a child who is disabled. Information at any given moment is incomplete and families learn to live with numerous ambiguities. Perry (1981) offered a scheme of cognitive development that, like Robertson, emphasizes the value of transitions between more static positions.

Dualism, Perry's (1981) first position, defines a period of absoluteness where an authority is the keeper of all knowledge. Parents often view therapists in this light, as the "experts" who will fix the problem or dispense pertinent information. Viewing therapists as experts diminishes the possibility of recognizing the therapist as a coach who will learn with them. The majority of parents of newly diagnosed children lack the knowledge base to gauge a professional's competence and recommendations, rather the parent wants to be propped by the professional at this very emotional time (Piggot, Hocking, \& 
Paterson, 2003). Transitioning to Perry's second position of multiplicity is characterized by challenges to authority where the PT may not be the "all knowing expert." Frequently, parents will meet other parents and begin to establish a peer group that has the commonality of having a child with a developmental disability. By sharing information and treatment options, parents come to realize that knowledge is uncertain and complex. Parents are introduced to a greater variety of possibilities and must begin to decipher and discriminate to make their own choices. This transition can be interpreted as laying a foundation for PT/parent reciprocity that can enhance parental learning.

The next shift leads to relativism. This transition is exemplified by the change from "what" to think towards a "manner" of thinking. There is recognition that problem solving depends upon a variety of situations. In other words, answers and approaches are context dependent. As Perry (1981) stated, "the person, previously a holder of meaning, has become a maker of meaning" (p. 87). This transitional shift appears to be a supporting example of constructivism theory. As such, this transition can be regarded as allowing for the reflective component of a coaching relationship. Adult cognitive development in the position of relativism is demonstrated by behaviors of thinking independently, exploring different perspectives, and accepting more responsibility. Thus, parents gain confidence as they accommodate and adapt to their individual situations. Perry's later stages are labeled commitment within relativism. Making sense of what has been learned, 
followed by making choices and decisions of how to proceed with "the cards one has been dealt" are representative of these later stages and thus a true reciprocity.

It is important to recognize that there is no set time frame for this development, and this gives support to the observation that though the presence of change is consistent in all families, it is unpredictable. Perry (1981) chose a helix model to describe the pattern of his theory of adult cognitive development. This creates an environment of learning that is able to expand, contract, and recycle. The value of a flexible model such as this facilitates appreciation of what all learners, including parents of children with disabilities, go through as they mature. It also lends to the appreciation that parents of children with disabilities are all across the spectrum in their individual adult development. Consequently, there will be significant recycling to previous stages or positions of development as each parent strives to gain a point of stability from which to move forth. Pediatric physical therapists must therefore recognize the varying stages of their numerous clients and respond accordingly. For example, a therapist might have to support a parent with each non-achieved motor milestone of one premature twin. While some parents are accepting of the initial mention of augmentative mobility, others will be taken aback.

Perry (1981) concluded his presentation of cognitive development by questioning the sacrifice of hope as new cognitive growth threatens the balance of stability. A concrete example of this questioning exists in the ultimate parental realization that their child will never walk independently, after holding out hope for 
this accomplishment. The challenge for therapists is to learn the art of teaching/coaching parents and fostering their respective cognitive development. Therapists, in acknowledging their roles as educators, are behooved to understand learning theories, adult learning and adult development.

Finally, the majority of parents participating in weekly sessions of early intervention programs are the mothers. The majority of pediatric physical therapists are also female. Therefore, considering the element of women as learners in the reciprocally responsive parent-professional relationship must also be addressed along with the element of diverse cultural backgrounds.

Gender and Culturally Responsive Learning

Parents' feelings of caregiving competence may positively influence their actual caregiving skills. The parent-professional relationship can support such perceptions of competence. Case-Smith and Nastro (1993), two occupational therapists, interviewed five mothers of children with disabilities. The mothers appreciated the hands-on instruction, pictures, written instruction sheets, and opportunities to observe the therapist working with their child. The participant mothers recounted the importance of a social reciprocity with the therapist. This work supported an earlier study by Hinojosa (1990), in which eight mothers of young children with a diagnosis of cerebral palsy were surveyed regarding the influence of therapy services on family life. The mothers reported the information provision and parental support through the social relationship that developed as very positive. Each physical therapist will develop a myriad of parental- 
professional relationships. Each dyad, unique in terms of age differential, ethnic heritage, social, economic, and educational histories, will challenge the therapist to constantly construct meaning to individual parent learning. These studies and the following corroborated the work of McCollum et al. (2001) that reported positive parent-child interactions resulting from valuation of parental competence.

Washington and Schwartz (1996), using qualitative methodology, interviewed two adoptive parents of children with disabilities. The researchers specifically sought to explore the mothers' perceptions of therapy services on their caregiving competence. Three major themes emerged from their study and were coded as: (a) knowledge is power: a family-centered outcome; (b) mother-therapist relationship: building a team to support a child; and (c) communication skills: an essential attribute. The subject mothers described their respective therapist as "a friend," "an advocate," "a mentor," and a "primary source of support." This provides additional support to the importance of reciprocity in a parent-professional relationship. Mothers in the study "indicated that a sense of being valued for their knowledge, respected, and 'heard' were essential components of an effective working relationship with their therapists" (p. 49). One of the therapists interviewed as a part of this study referred to the "therapist acting as a guide" to parents as the parent "drives the agenda" (p. 50).

The specific subjects of the last three studies cited were women. The reported maternal comments are examples of "voice," as has been described in the body of women's learning literature. In both Women's Ways of Knowing (Belenky, 
Clinchy, Goldberger, \& Tarule, 1986) and Knowledge, Difference, and Power (Goldberger, Tarule, Clinchy, \& Belenky, 1996) five perspectives of women's position of knowing were described. The perspectives were labeled as silence, received knowledge, subjective knowledge, procedural knowledge, and constructed knowledge. Silence is described as the position in which women experience no voice and are subject to the opinions and demands of some external authority. Received knowledge is indicative of women receiving and reproducing knowledge but not creating their own knowledge. Subjective knowledge refers to the perspective of women conceiving knowledge as personal, private, and intuitive. Procedural knowledge implies that women are devoted to learning and its application to acquire and inform new knowledge. Finally, constructed knowledge defines a position in which women regard knowledge as contextual, see themselves as knowledge creators and value subjective and objective strategies for knowing. This position is similar to Perry's (1981) notion of being able to commit to engagement within various relative contexts. This supports a constructivism view where physical therapists with parents co-create knowledge.

The therapist descriptors reported by mothers in the study by Washington and Schwartz (1996) can be informally aligned to women's positions of knowing (Belenky et al., 1986) as seen in Table 1. Though what the study participants of Washington and Schwartz truly meant in their descriptor of "friend," it could potentially be an example of received knowledge more from the standpoint of an advisor or instructor. In the early stage of establishing a relationship with a 
therapist, the mother may be experiencing a more symbiotic friendship rather than a more developed friendship of reciprocity. "Primary source of support" could potentially be a descriptor of received knowledge, transitioning to subjective knowledge where the mother may begin to be a support to others mothers. Procedural knowledge may be interpolated via the description of a therapist being a "mentor." In the role of mentor, therapists would be encouraging mothers to set their own agendas and direction of learning. This is a strong example of the initiation phase of coaching from which a therapist can build on the parental lead. As per the physical therapist's comment, parents "drive the agenda" of the intervention. Finally, mothers describing a therapist as an "advocate," may be an example of supporting mothers in creating knowledge, constructed knowledge. Table 1

Gender Learning and Voice Considerations

\begin{tabular}{|ll|}
\hline Silence & (none provided) \\
Received Knowledge & "Friend" \\
Subjective Knowledge & "Source of Support" \\
Procedural Knowledge & "Mentor" \\
Constructed Knowledge & "Advocate" \\
\hline
\end{tabular}

Adapted from Belenky et al., 1986; Goldberger et al., 1996; and Washington and Schwartz, 1996.

Therapists, as referred to above, will be in any or all of these positions as well. For some, it will be directly related to their years of clinical experience and acquisition of competencies for quality intervention skills. For others, the shared experience of being a parent may be reinforcing or supportive. Specifically 
focusing on procedural knowledge, the therapist may be simultaneously applying "separate knowing" and "connected knowing." Therapists' separate knowing could be exemplified through the lens of the discipline specific observations, validating findings in examination of the motor dysfunction and what they may specifically instruct the parent to do. Therapists' connected knowing could be exemplified by consideration of the lens of another person, empathizing with stated parent needs. The metaphorical dance between mother and professional must be carefully choreographed given that these shared perspectives may not always be synchronous. When therapist and parent perspectives are asynchronous, clear, positive communication will be challenged. Another issue that demands attention in this dance of parent-professional relationships is cross-cultural competence.

Learning events that are crafted from the parent-professional dialogue must be culturally responsive. A good PT coach must have an informed understanding of the family that is also informed by cultural contexts. Masin (1995) surveyed the attitudes toward physical therapy received in early intervention programs of CubanAmerican and African-American mothers who had children with disabilities. The results of her study supported the need for physical therapists to understand and appreciate cultural aspects of child and family care. Cuban-American mothers displayed the concept of personalismo, relating to professionals in a personal way and often indicating that the professional as "all knowing." The African-American mothers were found to be much more satisfied with PT when maternal suggestions were respected and acknowledged. There was also a greater interest in therapy 
with the African-American mothers when efforts were specifically directed toward motor development improvement. Masin concluded that an awareness of cultural influences is tantamount for therapists to provide culturally relevant services in a family-centered service model of EI.

Providing culturally responsive interventions elicits minimal debate by professionals and families alike. Hanson and Lynch (1990) stated that early interventionists must engage in four tasks to become ethnically competent. These professionals must first give credence to their own values and assumptions. Second, they must gather and analyze appropriate information regarding the family's cultural community. Third, to what extent individual families function transculturally must be determined, and lastly, professionals must review each family's orientation to issues of child-rearing. Professionals are continually challenged by the cultural assumptions they bring to the parent-professional communication needed to establish appropriate child and family goals (Harry \& Kalyanpur, 1994), as well as how they interpret parent-infant interactions (McCollum, Ree, and Chen, 2000) and parental beliefs regarding disabilities (Danseco, 1997). These communications and interpretations have increasing intricacies attached when the disability impairments of the child are more extensive. The core cultural configuration of the dominant (or so-called established) mainstream is typically that of a European Protestant segment whose values are often measured by success, achievement, and independence (Harry \& Kalyanpur, 1994). As the majority of pediatric physical therapists are part of this 
European Protestant segment, attention to cultural responsiveness in the changing demographics of the U.S. is tantamount in order to utilize appropriate coaching strategies in parental education.

Given the preceding review of pertinent teaching and learning literature, it is apparent that the educator role of a pediatric physical therapist is strikingly complex. There are many intersecting and overlapping influences and no easily obtainable absolute solution to the myriad of issues facing each individual family with a child who has a disability. As physical therapists and other related professionals continue to provide early intervention services to infants and young children with disabilities and their families, it is crucial to have pertinent and applicable research in the realm of teaching and learning as it applies to the parents of children with disabilities. The need for this knowledge is valuable at entry level preparation and continuing education venues.

Effective coaches in the world of early intervention must also possess solid content knowledge and skill regarding motor learning theory. Pediatric physical therapists, as habilitation specialists, must also attend to the promotion of individual children's sensorimotor function (learning gross and fine motor skills). Understanding and applying theories of motor learning from a context of habilitation, in conjunction with educational theories of teaching and learning, are critical in this effort. Infants and young children with physical disabilities often require physical assistance to acquire motor skills. The 1-2 hours per week therapists are able to spend with a child pale in comparison to the potential parental 
interactive time. Instructing parents how to physically encourage their child's motor development requires that they learn new motor skills. Therefore, it is logical that therapists apply motor learning theories while instructing parents, the recipient adult learners. A discussion of applicability of motor learning in this context follows to complete a full understanding of the complexity of pediatric physical therapist practice in EI provision.

\section{Motor Learning}

Motor learning is a critical element in the physical therapist's educator role while working with parents of infants and young children with disabilities. Improving motor skills or motor performance are at the heart of neurological rehabilitation and habilitation in physical therapy practice across the age span and pathologies. An infant born with a developmental disability or anyone acquiring a disability may present with delayed or impaired motor function. The extent of motor dysfunction may range from lateness in walking, inefficient or ineffective ambulation, clumsiness, or incoordination, to the opposite continuum of never being able to walk, sit independently, or hold one's head up, requiring total assistance for all aspects of activities of daily living. Physical therapists are challenged to utilize effective treatment approaches in rehabilitation/habilitation. Critical components of any successful motor learning program include the abilities of the learner, the desired task or goal to be accomplished, and the context in which activity will take place. Feedback is a final component in providing an informative motor learning program, be it to the child with the disability through a responsive 
body system or a parent who will be providing the daily practice opportunities for her/his child.

The facilitation models of intervention that gained prominence in the mid 70s shifted emphasis from individual, isolated muscle contractions to total patterns of movement (Gordon, 2000). However, long-term learning has been relatively unsuccessful with these older models of "sterile" clinical "hands on" facilitation. More recent advances in understanding the learning and relearning of movement have recognized the importance of attending to the intersection of the movement task and the environment in which the task is accomplished. Advancement in rehabilitation/ habilitation approaches has transitioned to more "real-world" completion of motor tasks in context and is referred to as a "task-oriented" approach (Horak, 1991). A task-oriented approach recognizes that motor behaviors are goal directed and guided by the feedback information that indicates the extent/depth of performance accomplishment (Gentile, 2000). Environments can be physical or social with the respective interaction behaviors being labeled by Gentile as functional or communicative. Performing tasks in meaningful environments with the ability to generalize to other and novel environments is becoming a major criteria in measuring rehabilitation/habilitation success. Increased attention to physical environments in pediatric physical therapy practice is seen in guidelines emphasizing the importance of natural environments.

Bronfenbrenner (1995) stated that the interactive style of caregivers, social environment, is a strong influence on children's development and learning. Dunst 
et al. (1991) found, in a study of 63 parents/caregivers and their children, that natural environments that included everyday activities were important settings for supporting and strengthening the competence of children. Examples of natural environment practice application are the increased number of in-home therapy sessions, full inclusion preschool and education placements rather than selfcontained special education classrooms and a myriad of other community settings for intervention. Such setting variations are indicative of pediatric physical therapists responding to the valuation of context for motor learning.

Dunn, Brown, and McGuin (1994) presented a framework for the ecology of human performance that specifically addresses how practitioners could contemplate the intricacies of context that could include issues of teaching and learning while providing therapy interventions. This framework emphasized the relationship between person and physical environment, expanding beyond a limited, singular interpretation of the physical element of environment to also include temporal, social, and cultural elements. These authors suggested that by attending to these various elements, therapeutic interventions might reflect acceptance of alternative paths. These included: (a) establishing or restoring the person's skills and abilities, (b) altering the actual context in which the person will perform, (c) adapting the contextual features and task demands to support performance in context, (d) preventing the occurrence of maladaptive performances in context, and (e) creating circumstances that promote more adaptable or complex performance in context. Providing early intervention for a child with a disability 
and simultaneously attending to the diverse components of parent-professional reciprocity demands attention to all the elements of context. These elements should reinforce good coaching techniques as well.

Another very important component of motor learning is feedback. Feedback is critical information that occurs during and after a specific performance of motor behavior. Intrinsic feedback occurs as a natural consequence of behavior and can be informative as to the outcome of movement or about the movement itself (Gentile, 2000). Movement outcome feedback is often referred to as knowledge of results. Movement performance feedback is referred to as knowledge of performance. Extrinsic feedback, that which supplements the intrinsic information, is referred to as augmented feedback. Whereas intrinsic feedback is inherent in that it is generated by the individual's performance sensory awareness, a coach or teacher typically provides extrinsic/augmented feedback. When the performer is receiving rehabilitation/habilitation interventions towards an end of improving a movement dysfunction, a physical therapist is the provider of augmented feedback. Similar to intrinsic, augmented feedback can be categorized as either knowledge of results or knowledge of performance. As the purpose of this study was to understand the extent to which pediatric physical therapists teach parents through the various lenses of teaching and learning, gender, culture, and motor learning, a more in depth explanation of augmented feedback is necessary. Schmidt and Lee (1999) devoted an entire book chapter to augmented feedback in their text Motor Control and Learning. These authors summarized 
numerous dimensions of augmented feedback. As above, knowledge of results $(\mathrm{KR})$ and knowledge of performance $(\mathrm{KP})$ refer to post movement information about the outcome of the movement in a specific environment and post movement information about the nature of the movement performance. These authors included the dimensions of feedback being concurrent, presented during the movement, or terminal, presented post movement. Feedback can be presented immediately after the action (immediate) or delayed in time (delayed), and in either a verbal or nonverbal form. The final dimension these authors presented was that feedback is either accumulated or distinct. By this they were referring to feedback that represents a compilation of past performances as compared to feedback that is specific to each individual performance.

A pediatric physical therapist can be readily observed to apply augmented feedback to the young child as she/he smiles wide-eyed with exclamation with an accompanying handclap following the child's completion of a motor task. Often the child will respond with repetition of the apparently praiseworthy accomplishment. As mentioned earlier, the pediatric physical therapist has the concurrent challenge of providing feedback to a parent learning how to encourage his/her child in motor development. To do so requires the therapist to recognize the learning opportunities of the parent.

Dinnebeil (1999) suggested that the learning opportunity may consist of the professional assisting parents in gaining awareness of their child's new or emerging skills. Acknowledging a parent's excitement and recognition of skill achievement 
by their child can also be considered an opportunity for learning. Demonstrating or modeling a handling technique is yet another opportunity that would support family-centered intervention. By having the parent perform the skill/technique with accompanying feedback before ending the intervention session, therapists may enhance the likelihood of parental compliance and generalization. The parent would then apply the techniques on a daily basis within the home environment during a naturally occurring caregiving task or social engagement. To experience successful learning, the parent must feel competent with the newly learned skills.

\section{Summary of Adult and Motor Learning Theories}

Prospective students to physical therapy higher education programs, as well as many current physical therapists, desiring to or practicing in pediatric environments have as their primary incentive, working directly with children with disabilities. The practice environment, federal legislation, monetary reimbursement and value of parent compliance with home programs demands that pediatric physical therapists be responsive to parents in the delivery of appropriate and effective early intervention service. Stated in the introduction, physical therapy curriculum does not routinely include family-related or adult-learning content as this material is typically in competition with the extensive competence-based requirements (i.e., basic sciences of anatomy, physiology, neuroanatomy and pathological conditions of all body systems) of the field. The purpose of this study was to gain insight and understanding of the applied educational role pediatric physical therapists have with parents, particularly mothers, of young children with 
physical disabilities. If we can better understand the teaching and learning dynamics of teaching parents the motoric skills needed to guide their respective children's gross motor development, we have the potential of more effectively serving children with disabilities and their families alike. To do so, an examination of strategies and techniques currently being utilized by practitioners may offer tangible recommendations for professional curricula (didactic or clinical internships) development opportunities. 


\section{CHAPTER III}

\section{METHODOLOGY}

Cresswell (1998) asserted that an initial reason to undertake a qualitative approach to research was the very nature of the research question and to study individuals in natural contexts. These included the items of the nature of the research question, the topic to be explored, and a need to present a detailed view of the topic. Mellion and Tovin (2002) explained that qualitative research takes "an integrative, naturalistic approach to the world, and is thought to better inform researcher about the complexity of human behavior and social interaction" (p. 110). A qualitative study is an example of an inquiry process that may directly lead to understanding a social or human problem. In Berg's (2001) introduction of Qualitative Research Methods for the Social Sciences, he stated "quality refers to the what, how, when, and where of a thing-its essence and ambience" (p. 3). In this light, this study utilized a qualitative methodology to descriptively identify teaching and learning strategies pediatric physical therapy practitioners used with parents as part of providing intervention. This was accomplished by direct observations of therapy sessions and interviews with parents and therapists. The descriptive nature of this initial examination of current practice could establish a basis for improving the parental educational role of pediatric physical therapists. 
Pediatric physical therapists are responsible to children with disabilities and their families. Often, their role with an infant or very young child is predominantly related to the child's dysfunction in terms of functional limitations and physical impairments. Thus, a major emphasis of the physical therapy intervention has been enhancing a child's motor development. To do so often requires an adult care provider to physically assist, which entails learning a motor skill set of physical guidance that is effective and timed appropriately in a context of functional significance for child and family member(s). Formal PT education, especially in a medical model approach, includes basic sciences of anatomy, physiology, neuroanatomy, clinical biomechanics, and pathological conditions across the life span. Unfortunately, because it makes up only a small percentage of physical therapy practice, entry-level pediatric specific content is often limited to introductory typical child motor development and overviews of the complexities of developmental disability pathologies. Moreover, while the content introduces students to early intervention, as defined by federal legislation and practice competencies, developing parent educator skill competency if at all is often minimal. Students, new graduates, and even seasoned therapists are challenged in an educator role capacity that is complex and multidimensional. How best to provide parents with information on typical development and pathological conditions, techniques to enhance a child's development, appropriate resources for support, and advocacy as a part of family-centered intervention are but a few examples of the complex nature of pediatric physical therapy. 
Best practice dictates that pediatric physical therapists, in concert with all early intervention professionals, are prepared for the multiplicity of roles (direct service provider, educator, consultant, collaborator, advocate) in providing physical therapy to infants and young children with disabilities. Currently, entry-level preparation for family-centered practice that recognizes the therapist-educator role for parent learners is not adequately occurring in PT curriculum content (Cochran et al., 1990; Effgen \& Chiarello, 2000; Iversen et al., 2003; Kelly \& Barnard, 1999; Mahoney et al., 1999).

\section{Location and Physical Therapy Sessions}

Early intervention physical therapy services are delivered in a variety of locations dependent upon what agencies have the EI contract and where parents choose to seek services. Data collection for this study occurred at the site where therapy was provided. It is recognized that sites (i.e., family home, outpatient clinics, or school) may vary dependent upon where the therapists provide physical therapy for their self-selected family units. Given that models of natural environment for service delivery are inconsistent due to public school funding challenges and anticipated summer data collection, therapists in outpatient clinic sites were recruited. Observations in the respective therapy settings provided familiarity of location for the child and parent and thus were expected to decrease potential novel environmental influences of an unfamiliar setting that could otherwise change the established session dynamics. 
Pediatric physical therapy sessions are typically $45-60$ minutes in duration where the PT works with an infant or child who presents with a motor dysfunction and the parent(s). Parental education and support, if implemented, is often accomplished in tandem with child-centered therapy. For example, the physical therapist may directly intervene with a child, assess the child's response as a model for the parent, instruct the parent in the skill, followed by having the parent demonstrate the newly learned skill with appropriate feedback.

Conducting this research at the initial therapy encounter would have been preferred for analysis from the lens of establishing parent-therapist reciprocity and rapport. However, this investigator respects the "emotional trauma" some parents may experience upon learning of their child's diagnoses and therefore consciously chose not to intrude at this time. The potential of emotional trauma is an illustration of Robertson's (1998) resistance and grief transformation themes of adult development. In other words, parents first need time to emotionally process the situation before being able to fully engage in therapeutic management. Seideman and Kleine (1995) described two explicit phases of participation capacity for parents of children with disabilities. The first phase is characterized by an inability to skillfully comply with expectations of home activities due to their initial preoccupation with grief. The second phase is exemplified by parents' ability to partner with therapists as they recognize the importance of their input. Piggot et al. (2003) suggested that therapists listen for markers such as a mother's mention of personally identifying her role in the therapy plan or recognition of her child's 
progress. A 4-6 month window should have allowed for PT-child familiarity to be established which often puts parents at ease and thus opens the door for intervention(s) that can be more directed to parental instruction. In addition, all intake documentation required for either federal legislation and/or third party payers will have been completed and therefore therapy frequency securely established.

\section{Theoretical Contexts and Framework}

Though the focus of this study was directed to the specific teaching and learning of the parent-PT interaction, the respective child of concern is participatory as the impetus of these interactions. The fact that infants and young children with physical disabilities referred to physical therapists are not a homogeneous group exacerbates the complexity of inquiry. At PT service initiation, these children will present with a variety of known pathologic conditions (e.g., cerebral palsy, myelomeningocele, muscle atrophies and dystrophies) or any number of unknown etiologies with resultant motor delays with or without accompanying mental retardation. Infants and young children specifically diagnosed with motor dysfunction of cerebral palsy exhibit a variety of physical impairments that create significant challenges in physically caring for the child (Olney \& Wright, 2001). The heterogeneity of cerebral palsy makes for difficult prediction of child outcomes, not to say family outcomes (Eicher \& Batshaw, 1993). Variances in ages, cognitive abilities, family configurations (e.g., natural or 
adoptive parents, single or coupled parents), cultural and ethnic heritages, and all socioeconomic status levels add to the multiplicity.

The observational framework used for this study was a coaching model from Hanft et al. (2004). Rush et al. (2003) and Hanft et al. suggested a collaborative process of coaching families and professional colleagues that includes observation and reflection that would promote a care provider's ability to support a child's development. As described by these authors, coaching contributes a structured process for attaining parent/therapist reciprocity in such areas as knowledge, skills, development of competence, and confidence. The five phases of coaching outlined by the above authors include (a) initiation, (b) observation and action, (c) reflection, (d) evaluation, and (e) continuation or resolution.

The nature of coaching requires responsiveness to development and learning styles of parents as well as therapists. This reinforces the nature of parenttherapist reciprocity. Consequently, utilizing the coaching framework for the research investigation, the theoretical concepts of adult learning and development, gender, and cultural diversity must be considered in tandem with theories of motor learning (physical guidance motor skill set).

Identifying a parent's learning and interactive styles and how these will impact the child's development allows a therapist to be inclusively supportive to all parents under the auspices of providing family-centered interventions. Hanft and Pilkington (2000) suggested a number of means by which a therapist may support parents' learning styles. These include: (a) matching parent training and support 
strategies with parent learning styles; (b) grading complexity of new information with current child care knowledge; (c) integrating new knowledge with past learning and experience; (d) providing opportunities to practice, modify, and repeat new skills in appropriate contexts; and (e) encouraging reflection on parent, child, and therapist performance, and self-monitoring of performance (pp. 5-6). Communication with parents was identified by numerous authors (Dunst et al., 1991; Filer \& Mahoney, 1996; McWilliam et al., 1998) as a distinctive element of family-centered best practice. Processes specifically identified by Filer and Mahoney included: (a) parents given an opportunity to identify their concerns, (b) PT listens to and responds to parental requests, and (c) PT effectively communicates in terms of how parental needs would be met. Examination of these processes succinctly meld with the coaching phases established by Hanft et al. (2004).

It was anticipated that the type and extent of therapist and mother communication observed would lend itself to categorization within the context of women's voice (Belenky et al., 1986; Goldberger et al., 1996; Washington \& Schwartz, 1996). The investigator asked mothers to describe the therapist/parent relationship and determining best fit with the relationship being one of a friend, a source of support, a mentor, or an advocate could establish possible identification of how subjects position themselves in knowing within the context of gender. In turn, therapist responses to questions regarding diversity were analyzed with respect to what they knew about the family's cultural community, how the family 
functions in the greater community, and the family's orientation to child-rearing issues (Hanson \& Lynch, 1990).

How individual therapists formulate their coaching approach and implement their interventions should be indicative of the extent to which they incorporate adult teaching and learning theories and sensitivity to diversity with interventions that apply theories of motor learning for child and parent. In particular, a constructivist theory of teaching and learning would be especially evident in a coaching model as proposed by Hanft et al. (2004) because it promotes an active process that includes learner initiated impetus (initiation), cooperative problem solving (observation/action), and constructing one's own meaning (reflection) (Phillips \& Soltis, 1998). A detailed description of the research design follows.

\section{Study Sample}

In June and July 2004, four private practicing pediatric physical therapists in the Pacific Northwest were recruited to participate in the study. The investigator knew and previously worked on a limited basis with three of the therapists prior to their entry into private practice as well as attending numerous professional continuing education courses together. The investigator knew of the fourth practitioner and initiated the invitation contact as the number of clinicians in private practice is quite limited. Private practitioners were recruited rather than school district PTs due to potential scheduling limitations of school summer vacations. In turn, they were asked to invite parents of children in their respective 
practices to participate. The therapists were asked to extend invitations to those parents whose child had a diagnosis or suspected diagnosis of cerebral palsy (CP) between the ages of $0-5$ years when it is more likely that parental involvement in therapy would be evident. The $\mathrm{CP}$ diagnosis was chosen as it manifests as movement disorder that typically requires the adult to physically participate in guiding and promoting motor development. Movement disorders are also the main focus of a pediatric physical therapist's involvement.

Therapists were invited and asked to choose individual families who met the child criteria and would agree to being videotaped and interviewed (Appendix A \& B). Prior to study initiation, approval from Portland State University's Human Subjects Research Review committee (HSRRC) was obtained. Therapists and parents signed an informed consent form prior to participation (Appendix C \& D). All participants also signed a photo release form to allow for videotaping (Appendix E). Parents were requested to sign a photo release on behalf of their respective children who were filmed during the intervention sessions. The researcher recognized this manner of access as a potential bias for limiting possible participation; however, it did allow for recognition of parental comfort level by the respective therapists. One therapist indicated that she only had two children on her caseload meeting the child specific criteria. Another therapist indicated that two parents she invited declined participation due to relative recent initiation of services and/or discomfort with being videotaped. 
Studies by McBride and Peterson (1997) and Brady, Peters, GamelMcCormick, and Venuto (2004) utilized observation, interventionist and family interviews and videotaping of intervention sessions respectively to examine patterns of professional-parent interactions. In particular, McBride and Peterson used a purposive sampling to select family participants by having each interventionist identify two potential families who would be willing to participate. Professional subjects were 15 home interventionists, all White females with a mean age of 40 years, and mean of 8 years work experience with children with disabilities (0-3 years age). Graduate research assistants trained in the use of the Home Visit Observation Form (HVOF) observed interventionists during treatment sessions. The HVOF was described as being developed to document the content covered and processes utilized in home visits. Four categories for data collection were determined during development of and pilot testing of the instrument. These categories were: (a) individuals present by title; (b) interaction partners; (c) content addressed during the interaction; and (d) role of the home interventionist during the interaction (e.g., modeling, direct teaching, listening). The latter two categories could be considered parallel to the observation/action phases of coaching proposed by Hanft et al. (2004). In the study by Brady et al. (2004), the principal investigator and an undergraduate student independently coded each of 15 videotapes utilizing a computerized coding system, Creating A Supportive Environment (CASE) specific to interaction analysis. Seven of 12 total categories reflected either direct or indirect verbal behavior of the professional to parent. 
Verbal behavior, though not specifically categorized as direct or indirect in the 16 videotapes of the present study, was the method of notation for professional/parent interaction sans computerized coding. These last two studies support the mechanism of parent participant recruitment and interaction notation for this study.

\section{Observational Data}

Eisner (1991) indicated that one feature of a qualitative study is that it be "field focused." Observation of the study sample pediatric physical therapists, parents and their children in the environment where PT service was provided at the regularly scheduled session times exemplified this feature. Data gathered via direct observation while filming and observation field notes post filming allowed the researcher to be the primary instrument for collection, another feature/assumption of qualitative research (Cresswell, 1994; Eisner, 1991). Reviewing videotapes added a second opportunity to identify and describe any examples of therapists instructing/coaching the parents in each dyad grouping. The investigator viewed videotapes after all filming was complete solely based on convenience and due to problem solving how to make the TV connections work. This took place in October and early November 2004. Viewing was completed in the researcher's home by linking the digital camera into the home TV system.

Data collection took place where therapy intervention was provided. Analysis of findings transpired during and after the intervention observation video taping. As observation visits proceeded, field note entries included questions or 
reminders of potential links with literature. Videotape reviews were initiated after all sessions were observed primarily due to camera/television linkage difficulties in the investigator's home. These methods were chosen based on previous work by a number of researchers. Hinojosa (1990) interviewed eight parents in an exploratory ethnographic study to describe mothers' perceptions of occupational and physical therapists' influence on family life. Studies by Brady et al. (2004) and McBride and Peterson (1997) utilized videotaping early interventions by various professionals, including a few physical therapists to identify presence of family-centered service delivery. McBride and Peterson used a purposive sampling (interventionists identifying two potential families willing to participate) to select family participants. Brady et al. reviewed a total of 15 videotapes of families of young children with developmental delays and the primary early interventionist.

\section{Quantitative Data}

Quantitative data was limited to gathering informational and demographic information to report subject profiles. Physical therapist demographics collected included age, ethnicity, and years of pediatric practice, including specific number of years working with the $0-5$ population. Additionally, therapists were requested to indicate the extent of their education, either preservice or continuing education, in adult learning and motor learning.

Parental demographic data collection included mother's age, education level, ethnicity, primary language and parenting history (how many children). 
Child demographic data collection included date of birth, birth order, age, disability diagnosis, date of therapy initiation, length of therapy history, and frequency of therapy. This information was used to descriptively report parent and child characteristics that may potentially explain unexpected differences in the subject dyad findings.

An additional quantitative data set, intervention time, was collected during the review of tapes. Total intervention time (therapist direct time with child and parent) was calculated by subtracting start time from finish time noted from a digital clock. Using a stopwatch, with the capacity to mark cumulative running time, the researcher was able to estimate the time therapists directed attention to the parent versus the child. The investigator also reviewed two tapes a second time to serve as a confirmation of therapist/parent interaction observations noted on initial review. This allowed the investigator to know whether she was capturing the instances of therapist/parent interactions accurately.

\section{Data Analysis}

Bilken (1992) stated that descriptive and reflective aspects of field notes were a mainstay of qualitative study. Journaling after each therapy session filmed (or soon after, if two sessions were back to back) was predominantly descriptive in that the notes described the subjects, physical settings, and accounted for the nature of the actions in each session. Reflective accounting of observations was used primarily to generate the investigator's impressions of whether a gestalt level of 
coaching had occurred. Once all taping was completed, review of the same took place.

Using the coaching model outlined by Hanft et al. (2004), strategies observed were categorized according to the researcher's interpretation of the five phases of coaching (initiation, observation, action, reflection, and evaluation). This model was chosen as it is specifically directed to early childhood intervention practitioners. Additionally, the three authors are therapists themselves (occupational, speech, and physical) and thus bring a therapists' perspective to this particular work. Notation forms (Appendix F) divided into four cells that corresponded to the initiation, observation/action, reflection, and evaluation phases established by Hanft et al. were employed in the video review. As per Hanft et al, observation and action phases were grouped together. All videotapes were reviewed in their entirety and the researcher noted examples of therapist to parent interactions in the appropriate cell for each tape. In addition to the descriptive examples of each phase provided by Hanft et al., suggestions by Marcus et al. (2001) and Dinnebeil (1999), noted in the literature review, were used to increase the depth and breadth of identifying specific examples for each of the phases. Their categories were (a) intervention overview for the immediate session, (b) roleplay, (c) model, (d) immediate or delayed feedback, (e) observation, and/or (f) follow-up reinforcement (Marcus et al., 2001).

Further analysis utilized strategies suggested by Dinnebeil (1999) that represented specific feedback. These included: (a) assisting parent in gaining 
awareness of his/her child's new or emerging skills, (b) acknowledging a parent's excitement and recognition of skill achievement by their child, (c) demonstrating or modeling a handling technique, and (d) noting parent performance of skill/technique. Notes taken during videotape reviews specifically in the observation/action phase section provided examples of feedback.

Strategies that supported integration of specific motor learning theory included notation (again in the observation/action cell of data collection forms) of specific PT comments made to a parent that represented knowledge of results and performance (e.g., what the parent did and how well was it done). Feedback comments from therapists, if noted from the video recordings, were either intrinsic (acknowledging the parent's own recognition of accomplishment) or extrinsic/augmented (from another source, PT). Motor learning strategy examples readily illustrated the observation/action phase of coaching. Any instance the PT actively engaged and/or interacted with the parent, representative from the above stated/described criteria, was considered an example of therapist to parent coaching.

The researcher created the following list of questions from a compilation of the items presented above. The questions served as a guide for the researcher to locate each example of therapist to parent interaction in a corresponding phase while she reviewed each videotaped therapy intervention session. Grouping questions according to the phases outlined by Hanft et al. (2004) facilitated what the researcher attended to and thus allowed for reporting of findings in the same 
phase categories. As Hanft et al. (2004) defined coaching as a particular type of adult learning strategy, the phases provided an opportunistic framework for this inquiry.

\section{Researcher Observation Items}

Initiation Phase

- Example of how was parent/professional collaboration promoted

- Example of PT asking parent what would help her in fulfilling her role as mother

- Examples of PT asking parent what she wanted her child to accomplish

- Examples of PT asking parent what she has tried

- Examples of PT asking parent what she thought would indicate that her child had learned

Observation and Action Phases

- How did the pediatric physical therapist include parent education during an intervention? (Direct instruction? Modeling? Demonstration? Role-play? Provide support and referrals to additional resources?)

- How did the therapist observe the parent's performance of requested activities?

- What types of feedback did the therapist utilize when engaged with a parent?

- What evidence is indicative of therapists" attention to parent learning styles in the various contexts of culture, gender and age? 
- How did the PT point out contextual components of activity to parent?

- How did the PT praise parent? Give examples

Reflection Phase

- To what extent did the therapist value the "educator to parent" role? How many times during single session did therapist reflect with parent?

- How did PT guide parent to consider what happened when she practiced a skill?

- How did the PT ask parent what she thought worked well and what didn't? Evaluation Phase

- How did PT ask parent learner what the strengths and weaknesses of the "teaching" session were?

- How did the PT determine if the parent thought the coaching was effective?

- How did the PT and parent determine if the intended outcomes had been achieved?

Two other types of data collection added to what Eisner (1991) referred to as structural corroboration in the process of further triangulation. These were participant interviews and colleague video review. Interviews served as a cogent source of comprehending how the participants grasped their particular situations, teaching and learning roles in the case of this study. The researcher interviewed all therapist and parent participants. Interviews (parent/caregiver and therapist) were used to gain a perspective of the therapists' awareness and responsiveness to concepts of adult learning theory. Questions were also asked to identify the impact, 
if any, diversity aspects of gender and culture had in the coaching of parents and parental learning.

Participant physical therapists and mothers were interviewed, using an unstructured open-ended question format. Therapists' questions (see below) were grouped according to the coaching process as outlined by Hanft et al. (2004) to create a parallel for eventual observation analysis and because these authors define coaching as a particular type of adult learning strategy.

Interview Questions for Pediatric Physical Therapists

Initiation Phase (identify an opportunity for coaching)

- Who sets the session goal, you or the parent? (give examples)

- How do you determine what should be accomplished in each session?

- How do you routinely include parent education during an intervention? (give examples)

Observation or Action Phases

- How do you encourage follow-through of activities?

- What did you request the mother do between intervention sessions?

- How do you reinforce parent performance of requested activities?

Reflection Phase

- What do you think the mother specifically wanted from you in the session?

- How would you describe this parent as a learner? 
- What percentage of your intervention time is directed towards teaching/coaching the parent?

- What are some examples of how you enhanced the mother's actions?

- How were you supportive of the parent?

Evaluation Phase

- How do you know the mother learned from you?

- What was the greatest influence on your service delivery model?

- How did you know if you needed to make changes?

- What indications do you utilize for knowing if there is a need to continue as a parent educator?

- What do you see as the benefits of teaching parents?

- What do you see as barriers to teaching parents?

- Should teaching and learning theories be emphasized in didactic or internship environments?

Gender and Diversity Issues

- What key words would describe your relationship with this parent?

- How do you think this parent views you?

- What is unique about this mother/child family and how does this knowledge impact your interaction?

Interview questions for the parents were structured to determine if parents saw themselves as recipients of PT instruction for their own learning, see below. 
Interview Questions for Mothers

- What do you hope to gain from your child's PT sessions?

- What goal did you establish as an agenda for the therapy session?

- How do you know that the therapists listened to your needs and concerns?

- What did the therapist teach you in the past two sessions?

- Were the therapist's directions clear and specific?

- At session end, do you think that you were a recipient of PT intervention?

- Are the services provided flexible, accessible and responsive to your individual circumstances?

- How was parent and professional collaboration promoted?

- What are the benefits of the PT teaching you something to do with your child?

- What do you see as barriers to your learning?

- How would you describe your relationship to this PT?

- How does the PT respond to your unique situation?

Interview questions were asked in the same order during each interview. Responses were tape recorded in addition to the researcher taking notes during interviews. When necessary, questions were clarified and when a response seemed vague to the researcher, the participant was encouraged to elaborate. One PT asked to see questions in written format during the interview itself and was provided with 
a copy of the questions. One parent requested and received a copy of the questions to look at during the interview to assist her comprehension of what was being asked. Interview responses were read numerous times category by category and/or by individual questions for analysis. Though not transcribed, the tapes were reviewed when necessary to clarify written notes taken during the interview by the researcher.

Additional reflection regarding method and analysis occurred via conversations with colleagues not participating in the study and then following study completion with one of the therapist participants. Some of these conversations were reinforcing, while others were disturbing from the point of questioning whether "coaching" was relevant and valuable. The field notes provided one point of triangulation to provide corroboration of evidence through different sources (Berg, 2001; Cresswell, 1998; Eisner, 1991).

The third mode of triangulation was accomplished by sending two different therapist videos to a physical therapist colleague to establish additional consistency. From a methodological perspective, this mode afforded corroboration of example observations within the coaching phases. The invited colleague has been a physical therapist for more than 30 years, university professor and director in a school of physical therapy in the state of California. She has edited a major physical therapy textbook and her doctoral work was on visual analytical problem solving. She volunteered her time as a collegial reviewer and received no monetary compensation for her participation. Interview responses were read numerous times 
category by category and/or by individual questions. Conversations with one participant and several non-involved therapists took place following observation taping, but during tape reviews. Additional non-participant therapist discussions occurred during the writing of the discussion and conclusion and are included in those sections. Though triangulation serves to corroborate evidence, the researcher being an instrument of information collection typically characterizes qualitative inquiry. Thus, the research investigator must be acknowledged as a measurement instrument.

\section{Position of Investigator}

In any qualitative work, positionality of the investigator must not be ignored as s/he serves as the instrument of information acquisition (Bilken, 1992; Creswell, 1998; Eisner, 1991). As a licensed physical therapist for more than 30 years, predominantly in pediatric practice settings, I was quite familiar with the contextual environments provided by the various locations where observations took place. Teaching in higher education for the past 16 years, a keen interest in the teacher/learner dyad of pediatric physical therapists and parents of children with motor disabilities in early intervention programs where there is a likelihood of family-centered emphasis has evolved. It is my opinion that pediatric physical therapists, like their counterparts in other therapies and general and early childhood special education, are ill-prepared for the parent coaching responsibilities that are inherent with providing best practice early intervention upon graduation from higher education professional personnel preparation programs. This stems from 
current and future practitioners desire to work with children and thus less interested in seeking adult education content. Additionally, entry level graduate programs in physical therapy, as with other professional programs, appear to continue placing a much greater didactic emphasis on the child and the child's functional limitation/impairment/pathology as compared to adult learning theory and skills in educating parents.

For a number of years prior to enrollment in a doctoral program, I practiced clinically one day a week in a local early intervention program, providing in-home interventions to a number of families while teaching at a PT school. Linking the academic teaching, evidence-based practice research regarding family-centered intervention and weekly practice application with occasional observation of colleagues, I began to question the research-to-practice gap that appeared to deter awareness and/or development of the educator role of practitioners. During one home visit, an exceptionally astute parent queried as to how I achieved what I had with her son, noting it was different from the outpatient hospital-based PT her son also experienced. This query led me to the path of inquiry for this research. Her question also caused me to ponder, why I would receive comments from other mothers that I had them do much more than previous therapists, for example modeling handling techniques on them and then having them perform the technique on me before attempting it with the child. In instructing PT students, I had transitioned from my previous clinical style of doing to observing the students practicing the various competency based skills sets, especially considering motor 
learning theory application to their acquisition. Generalization to enhancing motor skill handling to the parents of infants and young with movement dysfunction such as cerebral palsy appeared to be a natural transition. As I peripherally observed clinical colleagues, it was apparent that others were not generalizing, nor did they seem to want to move from a child-centered to a familycentered model when I initiated conversations with them on this topic.

Summary

The purpose of this research was to describe current examples of pediatric physical therapists' educational role strategies, with mothers, while providing a pediatric physical therapy intervention session. Investigation was specifically directed in the area of motor learning and adult learning theoretical application as to whether therapists did or did not coach/instruct parents how to facilitate, guide, and/or support the motor skill development of their young children with movement dysfunction. As such, the research question posed was: if and how pediatric physical therapists, in the context of providing pediatric physical therapy services, instruct mothers of children with physical disabilities to enhance and guide their children's gross motor skill development? The intent of the research inquiry was to describe pediatric physical therapists' strategies, indicative of integrating theories of adult teaching and learning and/or motor learning theories with the parents of young children with physical disabilities, in the context of providing pediatric PT services. It was hypothesized that minimal if any strategy utilization/application would be observed. It was further hypothesized that practicing pediatric physical 
therapists would have a limited knowledge base of adult learning theory. This would be further hypothesized by an expected preponderance of child-centered rather than family-centered intervention emphasis. Observing therapists and parents in the actual sites where therapy was delivered provided the "contextual reality" of outpatient service delivery as practiced by four pediatric physical therapists. Patterns of child-centered emphasis did emerge and were validated through triangulation of several data collection entries: investigator observation, investigator journal notations, video review, participant interviews, and collegial video review. The expected dominance of child-centered service delivery (as identified from observation and video reviews) and the accompanying data from interviews and collegial video review were indicative of diminished application of learning theories and motor learning theories applied to the parent learner of the professional to parent relationship. Validity, established from multiple types of data can be used to foster credibility (Eisner, 1991). Eisner stated "the structural corroboration is a means through which multiple types of data are related to each other to support or contradict the interpretation and evaluation of a state of affairs" (p. 110). A number of potential barriers to therapist coaching emerged from therapist and parent interviews that suggest potential impedance to building coaching skills that would in turn foster adult learning and more successful familycentered interventions. From these differing points of collection sources, analysis of findings and insights was made and presented in chapter 4. 


\section{CHAPTER IV \\ RESULTS AND ANALYSIS}

The purpose of this study was to gain insight and understanding of the applied educational role pediatric physical therapists have with mothers of young children with physical disabilities, specifically motor dysfunction. This role was primarily explored through the theoretical lenses of teaching and learning and motor learning. Hanft et al. (2004), in a recent publication, presented the educational role under the guise of coaching. The coaching phases described by these authors; initiation; observation/action; reflection; and evaluation were utilized as an organizational framework (described in chapter 3 ) for the investigation. As well, these four coaching phases provided a succinct and inclusive structure to discuss the findings. This framework was developed specifically for the early intervention environment and renders a logical and appropriate scaffold to build and generate discussion. Therefore, results are presented in section headings of these coaching phases. Within each phase, video observation findings are reported first followed by interview data of the physical therapists then parent interview data. Additional result analysis derived from researcher journal notes and/or collegial observation comments are presented where appropriate. Therapists are identified by pseudonyms of Alice, Barb, Carol, and Donna. Parents have been numerically identified consecutively as M1, M2 through M8. Thus, procedurally 
Alice served M1 and M2 and proceeding to Donna having served M7 and M8. When present and pertinent, these are followed by reporting of data collected via researcher journal notes and/or collegial review. When applicable and germane to reporting of findings, children were numbered in a similar manner as the mothers, thus M1 was the mother of child one, $\mathrm{C} 1$.

Observations of practice in a limited sample of pediatric private practitioners allowed for an examination of current applications of a "coaching role." As much as possible, research themes of how this role manifested itself in terms of identifying adult learning styles of parents, patterns of motor learning instruction/coaching (types of comments and feedback), recognition of the educator role, and issues of gender and diversity have been melded with the research findings. As appropriate, single or multiple data collection measures have been used to report the findings. The intent for extrapolating from the findings a means to identify potential recommendations for either preservice and/or continuing education programming to improve family-centered service delivery by pediatric physical therapists is presented in chapter 5 .

\section{Demographic Data}

Study participants $(n=12)$ were four pediatric physical therapists and eight parents/caregivers. Parents and therapists read and signed informed consents according to the policies and procedures of the Human Subjects Research Review Committee at Portland State University. Additionally, all participants signed 
release forms for video and audio taping. Parents also gave consent for their children to be video taped.

Demographics for therapists, parent/caregivers, and children are presented in the respective group categories. All adult participants were female. The four physical therapists were private practitioners, three Oregon licensees and one, Washington. Sampling was of convenience and purposeful, recruiting private practitioners in the immediate geographical area who were not employed by either a school system or hospital. This choice was made to circumvent the more likely medical model of service delivery typically seen in hospital-based outpatient clinics and the often more limited treatment frequency of summer vacation schedules in an educational based public school provider environment.

\section{Physical Therapists}

All four therapists were Caucasian, two were 48 years of age and two were 60 years for a mean age of 54 years. Three are mothers themselves. Total number of years as a licensed PT ranged from 15-39 with a mean of 29 years. Number of years specifically in pediatric practice ranged from 14-33 years with a mean of 23.75 years (See Table 2). Three of the PTs had previously worked in the public school system before transitioning to the private practice workplace. Three of the participants (Alice, Carol and Donna) received their Bachelor of Science degree in Physical Therapy and the fourth (Barb) her Master of Science in Physical Therapy. Therapists with a bachelor degree received their education prior to the graduate level PT degree availability. The latter participant was a massage therapist prior to 
entering a graduate PT degree program. Donna completed approximately half the credit hours for an MS degree in Special Education, stating that completion was now less relevant since starting her own private practice. Carol had recently advanced to doctoral candidacy in pursuit of her $\mathrm{PhD}$. Alice has taken a few graduate level courses; however, she is not pursuing an advanced degree at this time. The most recent graduate reported not taking any additional formal graduate coursework to date. Three were members of the American Physical Therapy Association (APTA) Section on Pediatrics, which provides a quarterly journal that from time to time has articles regarding family-centered service provision.

Table 2

Physical Therapist Participant Demographics

\begin{tabular}{|l|l|l|l|l|l|l|}
\hline PT & Age & Practice & $\begin{array}{l}\text { Years in } \\
\text { Pediatrics }\end{array}$ & $\begin{array}{l}\text { PT } \\
\text { Education }\end{array}$ & Other Education & $\begin{array}{l}\text { APTA } \\
\text { Pediatric } \\
\text { Section }\end{array}$ \\
\hline Alice* $^{*}$ & 60 & 37 & 25 & BS & CE & Yes \\
\hline Barb $^{*}$ & 48 & 15 & 13 & MSPT & CE & No \\
\hline Carol $^{*}$ & 48 & 25 & 23 & BS & PhD candidate & Yes \\
\hline Donna* $^{*}$ & 60 & 39 & 33 & BS & BS + & Yes \\
\hline
\end{tabular}

("Pseudonyms)

Three therapists were observed in their respective private clinics. One of these clinics, Donna's, was located in an urban office building, ground floor with wheelchair accessible access. A second (Alice's) was located in a home, recently converted to office space, and a third (Barb's) was an office setting of large open rooms attached to a residence in a rural community. Each of the latter two had outdoor access to a small grassy play area. Individual therapy sessions at the above three sites took place in a large treatment room with wide open floor space, mats on 
the floor or mat tables, low hung mirrors, and cupboards of toys to choose from.

The fourth physical therapist ( $\mathrm{Carol}$ ) traveled to the homes of each family being served. One was a two story residence and the other was a second floor apartment. In-home observed therapy sessions took place in living rooms that were carpeted, had sofas, armchairs and fireplaces. Television and stereo equipment were located in the apartment living room setting and used as a distractor for the youngster. Carol, by virtue of going to the homes, worked in the family's "natural environment" where parents are typically expected to carry out intervention strategies they have supposedly been instructed to do.

All four therapists have participated in professional continuing education, predominantly in the area of child development/therapy interventions, indicating extensive contact hours. Given that family-centered intervention has been described as ways of working with family units (Dunst et al., 1991) and being responsive to parents (Filer \& Mahoney, 1996), it was important to determine what knowledge the therapist participants had in adult learning concepts. During the therapist interviews, two indicated a minimal introduction of less than 2 hours in theories of Adult Learning, while the other two indicated some awareness through approximately 4 hours of continuing education. The most recent graduate therapist reported an introduction to motor learning therapy in her academic preparation. One therapist communicated a moderate 4-6 hours of continuing education regarding motor learning theory. The remaining two indicated a more extensive knowledge base through one or more continuing education programs on this topic 
and reading their professional literature. This information implies a limited formal knowledge base of theories from which application during interventions was to be observed.

\section{Parents}

Interview responses provided the following demographic information regarding the parent participants. Demographic information regarding age, education, and support systems when compared to the same data of the physical therapists was used to make possible linkages that could indicate teaching and learning theory application. As anticipated, the parent participants were not a homogeneous group. Seven birth mothers and one female babysitter/caregiver participated in the study. The women ranged in age from 24 to 62 years with a mean of 36.6 years. All birth mothers were married to the child's birth father except one who was a single parent (M1). The caregiver participant (M3) was also married. One mother (M5) identified herself as Hispanic American, however, she stated that English sas her family's primary language. All other caregivers were Caucasian. Four participants (M4, M5, M6, and M7) do not currently work outside of the home, two (M1 and M2) are employed in hair salons, one (M8) teaches parttime, and the babysitter (M3) provides foster care to other children in addition to the study child participant. Four participant mothers (M1, M2, M4, and M8) indicated that the child receiving PT was their only birth child. One of these parents (M2) has two high school age stepchildren. Two mothers (M5 and M7) have two sons each, one whose eldest son receives therapy and the other's younger 
son receives therapy. The foster mother (M3) reported three birth children, five adopted children, four stepchildren, and foster-parenting 32 children over the years. She currently has seven children living in the home. See Table 3 for parent demographics.

Table 3

Parent Participant Demographics

\begin{tabular}{|l|l|l|l|l|l|l|}
\hline Parent & Age & Education & $\begin{array}{c}\text { Marital } \\
\text { Status }\end{array}$ & \# Children & Ethnicity & Employment \\
\hline M1 & 24 & HS +2 & Single & 1 & Caucasian & Beautician \\
\hline M2 & 39 & HS +2 & Married & $\begin{array}{l}1 \text { birth, } \\
2 \text { step }\end{array}$ & Caucasian & Beautician \\
\hline M3 & 62 & HS +1 & Married & 44 combined & Caucasian & Babysitter \\
\hline M4 & 36 & HS +2 & Married & 2 & $\begin{array}{l}\text { Hispanic } \\
\text { American }\end{array}$ & NA \\
\hline M5 & 40 & HS +1.5 & Married & 1 & Caucasian & NA \\
\hline M6 & 28 & HS & Married & 1 & Caucasian & NA \\
\hline M7 & 33 & BS & Married & 2 & Caucasian & NA \\
\hline M8 & 31 & BS +1.5 & Married & 1 & Caucasian & Teacher \\
\hline
\end{tabular}

Education levels ranged from high school completion to partial completion of a master's degree in education. One (M6) completed high school. One (M2) completed one year of college, one (M3) completed one year of college and one year of beauty school, one (M6) completed one and half years of trade school, and one (M5) completed two years of junior college. Of the remaining three, one (M5) completed two years of college, one (M7) has a BS degree, and the eighth (M8) has partially completed course work for her master's degree (See Table 3 ). This collected demographic information indicates a varied participant pool across age and education, reinforcing the heterogeneity of these adult learners. All the women, except for one single (M1) mother, listed their husbands as primary 
supports in caring for their children with motor deficits. Other extended family member supports identified by the study participants included the mothers' parents or in-laws. In addition, stepchildren, granddaughter, friend, and sister-in-law were mentioned one time each.

\section{Children}

The study children, five boys and three girls, were all receiving physical therapy services for motor impairment (see Table 4). Demographic information, extrapolated from the parent interviews, assured the study parameters of children diagnosed with motor dysfunction (cerebral palsy or suspected CP diagnosis) and less than 5 years of age. One boy (C5) was Hispanic American, one girl (C3) was African American, and the remaining six, Caucasian. Children's ages ranged from 10 months to 46 months with a mean age of 31 months $(x=31)$. Six parents reported an established medical diagnosis of cerebral palsy, though initial diagnosis was developmental delay. Two parents (M1, M3) stated that their child's physician had mentioned a diagnosis of possible cerebral palsy, however, at present the referring diagnosis was developmental delay (DD). Neither of these parents appeared distressed at using the diagnosis of $\mathrm{CP}$, however, they were quite accepting of waiting till their child was chronologically 3 years of age for ultimate diagnosis a commonly accepted practice for service eligibility in the public school setting. The respective physical therapists' clinical/therapy diagnosis would support an ultimate medical diagnosis of cerebral palsy, as the therapists were requested to recruit children with a $\mathrm{CP}$ diagnosis. 
Table 4

Child Participant Demographics

\begin{tabular}{|l|l|l|l|l|}
\hline \multicolumn{1}{|c|}{ Child } & \multicolumn{1}{|c|}{ Age } & \multicolumn{1}{c|}{ Diagnosis } & \multicolumn{1}{c|}{ GMFCS } & \multicolumn{1}{|c|}{ Ethnicity } \\
\hline C1 & 10 mos. & DD & Level I & Caucasian \\
\hline C2 & 39 mos. & CP & Level V & Caucasian \\
\hline C3 & 40 mos. & DD/CP & Level I & $\begin{array}{l}\text { African } \\
\text { American }\end{array}$ \\
\hline C4 & 27 mos. & CP & Level V & $\begin{array}{l}\text { Hispanic } \\
\text { American }\end{array}$ \\
\hline C5 & 34 mos. & CP & Level V & Caucasian \\
\hline C6 & 30 mos. & CP & Level V & Caucasian \\
\hline C7 & 46 mos. & CP & Level V & Caucasian \\
\hline C8 & 24 mos. & CP & Level V & Caucasian \\
\hline
\end{tabular}

Gross Motor Function Classification System (Palisano et al., 1997)

Three children (C4, C5 and C7) presented with athetoid cerebral palsy, three (C2, C6 and C8) with spastic quadriplegia cerebral palsy, and two ( $\mathrm{C} 1$ and C3) with hemiplegia cerebral palsy, according to therapist and parent reporting in either the parent interview or during recruitment of participants. Two children (C1 and C3) presented with Level I severity and the remaining six presented with Level V severity using the Gross Motor Function Classification System (GMFCS) developed by Palisano et al. (1997). Specific to children diagnosed with $\mathrm{CP}$, this system is based on functional abilities and limitations for children who are 12 years of age and younger. Level $\mathrm{V}$ represents children whose self-mobility is severely limited even with the use of assistive technology. Level I includes children who walk or will walk without restrictions, and may display limitations in more advanced gross motor skills. The above demographics are indicative of the investigator's goal to observe therapy with young children presenting with motor dysfunction. 
Seven of the children received physical therapy from the study PT participants once a week. One child (C1) received two PT sessions of 50 minutes per week plus one weekly hippotherapy session in the summer. Child 3 received one weekly session for 30 minutes and the remaining six for between 45 and 60 minutes. Four parents reported physical therapy being initiated prior to their child's first birthday (at 3 months, at 5 months, at 8 months, and at 9 months). The remaining children were referred to the private PT practitioners enrolled in this study at 1 year, 1 year, 14 months and 22 months of age. These data further establish the heterogeneity of pediatric therapy recipients even within one diagnostic category.

For purposes of reporting the findings, results are organized using the phases of coaching already introduced to the reader according to Hanft et al. (2004). Each phase is further delineated by the various collection methods such as observation, journal, and interviews. When appropriate, collegial review information is included.

\section{Results and Analysis}

\section{Initiation Phase of Coaching}

Observation data. The initiation phase of coaching is an opportunity for the therapist to clarify the purpose of and outcomes anticipated during the intervention session and also to identify opportunities for this process to occur. Establishing a plan of action, child-specific goals for individual therapy sessions, appeared to be an assumed entity by the physical therapists in the majority of sessions observed. 
This assumption arises from the consistency of arrival greetings by therapists asking how each child was doing. Acknowledging that therapy sessions had been ongoing for some time, the opportunity to clarify purpose of therapy session may not have been necessary as the relationships were well established. Specific parentlearning outcomes for the immediate session were also not articulated at individual session initiations. Not once was a therapist observed directly asking a parent what she hoped to accomplish during the session. A few mothers requested specific temporal parameters in how often their child should practice an activity, assistance in getting equipment, or when other services would be arranged. Though such examples could indirectly be perceived as parent focused, this researcher interprets these examples as still predominantly child directed because the parent is asking these questions on behalf of the child and not for her own learning of new skills. The majority of implicit goals of individual therapy sessions were child rather than parent specific. This parallels the literature review of pediatric professionals' attention and focus directed to the child, rather than the parent/caregiver (McWilliam et al., 1998; O’Neil \& Palisano, 2000). If the therapist had been asked by a parent to watch her do a certain skill and provide feedback as to the parent's performance, a more parent-directed intervention would have been observed. A generic query of "how's it going?" by several therapists was too broad to elicit a specific tact towards therapists' coaching any of the mothers. In general, establishment of a "coaching contract" between therapist and parent was not observed in the intervention session observations. Therapists not 
being knowledgeable about the coaching process can certainly explain this lack; however, it soundly points out the need to do so, so a more family-centered intervention can be generated.

Physical therapist interview data. The first cluster of interview questions focused on the initiation phase of coaching. Hanft et al., (2004) defined this phase as one directed towards the learner's priorities, desired learner outcomes for their child, conversations to determine what supports are needed, and/or what indications will inform the parent that her child has learned the desired outcome. All four therapists stated that they determine therapy session activities based on standard practice of their initial evaluation, developing a plan of care, writing annual goals, and what the family had prioritized. Individual session activities were determined by parental reporting of what occurred and/or what did or did not work since the previous session were indicators for redirection of session emphasis. This is evident from quotes by Alice: "If the parent reports changes or activities," and Carol: "T ask what worked or didn't work."

When asked who sets the session goal(s), three therapists stated that they did. Barb indicated that this is often "led by what the child wants to do;" Donna stated that "hopefully parents contribute;" and Carol indicated that "though she shared goal setting with parents, the session goals were predominantly set by her." Alice, somewhat circuitously, responded, "The child drives the session," because the session "has to be meaningful for the child," and that she also needs to address a parent's "specific request, especially regarding equipment." These points 
appeared to be interpreted as session goals for that particular appointment and are important, as they are responsive to the many facets of what occurs during a single session. From these therapists' statements, the child-related emphasis appeared to dominate how session goals were established. Alice responded to the query of how do you include the parent education during an intervention by stating, "give suggestions on how to hold child," and "as frequently as possible, have parent be part of session by holding toys or switch and have parent hold child." Interviews of the participating physical therapists were indicative of far greater child-centered goal setting with minimal parental input. The negligible therapists' reporting of what parents stated they wanted, indicated less emphasis on parent learning which makes it difficult to recognize support towards parental competence in handling and making decisions regarding their respective children's development. This is not indicative of family-centered interventions.

Parent interview data. Parent/caregiver participants were asked what they hoped to gain from the child's PT session and what and how they participated in goal setting as a means to determine elements of the initiation phase of coaching. Knowledge of what to do with the child at home was a major hope stated by most of the parents, which can be interpreted as a desire to be learners. Additionally, the parents desired information regarding their child's progress, developmental condition, and an explanation of why the PT was doing what she was doing. When asked what do you hope to gain from your child's PT session?, M7 stated that "long term I want my child to be able to help with transfers." Another (M3) stated, 
"I want her to use her right arm more and not to drag her right leg." When asked what goal did you establish as an agenda for the therapy session, two parents (M6 and M7) each stated that there was no individual session goal set during either of the two taped interventions. The remaining six responded with references to specific child developmental milestone goals such as sitting, crawling, and walking having been established at initial physical therapy evaluation. It was unclear if these milestone goals were cooperatively arrived at or had just become assumed overtime. As to be expected there would be no need to articulate these established goals each and every session, especially for the benefit of the researcher. However, if not done, the clarity of session expectations can potentially lead to lack of accountability on the part of both parties. One mother's (M2) sharing illustrated this when she stated, "I want my child to sit on her own and walk in the future." She also stated, "the PT knows." With this short response it appeared as if she viewed goal setting as the sole responsibility of the physical therapist. It illustrates lack of parent initiation and directing that in an effective coaching model would be encouraged rather than discouraged through inattentiveness to the parent learner in a family-centered delivery program.

Researcher journal and collegial observation data. As described in the methodology, the researcher journaled her observational impressions post filming of each session, unless sessions were consecutive. In this situation, journal notes were completed soon after both sessions were completed. Journal impressions of initiation phase examples indicated higher number of child-specific inquiries and 
concurred with the limited examples of parent-specific inquiries noted during videotape reviews. For example, Carol asked M5 how the wheelchair C5 was seated in was working out for him. Carol asked M6 about C6's range of motion. Notations by Carol, "asked M5 about changes she has observed following the Botox injections" and "how has he been doing the past 2 weeks," showed direct conversations with a parent that were most definitely child-specific.

Like Carol, Alice did ask questions regarding how the particular child had been the previous week. One journal notation regarding initiation phase for Alice with M2, "no real initial conversation to set goals or priorities for session," further demonstrated minimal interactive engagement towards therapist-parent coaching strategy. Though the parent/child multiplicity of therapy interventions are present and the presumption of children improving their motor skills is the ultimate desired outcome, not specifically inquiring about parent performance/practice is indicative of the absence of coaching of the adult learner. By explicitly separating parent from child inquiries, a therapist would be constructing professional/parental reciprocity. Sans parental inquiries, guidance of parental competency development will most likely not be achieved. It was also noted that the "parent essentially watched entire session with her head down a great deal as she stated to therapist she was tired and at last had a "moment to do nothing." This comment appeared (to researcher's interpretation) to set a tone of minimal PT-to-parent interaction for the remainder of the session. During the interview, this therapist commented that sometimes she chose to respect parent's need to disengage, be less attentive, 
because of fatigue. Though not a positive example of interactive coaching, this action does demonstrate respect and understanding of the parental time commitment of supporting a child with disabilities in tandem with work and home responsibilities. Specific journal notes included: "Alice started to say something but held back when she saw M2's head down," and "Alice is very engaged with the child and minimally so with the parent." Initiation by Alice with $\mathrm{M} 1$ and $\mathrm{C} 1$ was unique in that there was the element of child care responsibility transitioning from foster parent to birth parent. Journal notes included: "I was a bit concerned that PT directed many responses to the foster Mom and was only using birth Mom as an entertainer." Following the second session of this particular triad, the first journal notation was "no goal for day established." A thematic pattern that was emerging from the journal comments in conjunction with video review notations of Alice and M1 and M2 was from nil to minimal establishment of parent directed interactions that could be considered as a coaching initiation. Examples, such as noted above, corroborated the video observations made of this particular therapist with each parent during video reviews. Alice was videotaped with M1 and M2 on the same day for the initial taping. She shared that she was not feeling well, which may explain some of the lack of directed parental interactions; however, in subsequent tapes, her parental interactions were not all that much more extensive. Alice's care and empathy to child and mother superseded her skill at establishing a coaching relationship and, though not negative, it did diminish an opportunity to develop coaching skills that would build parental competency. 
A thematic reality of practice that routinely occurred as part of providing therapy intervention that may further exhibit educational coaching was the element of negotiating third party payments and equipment acquisition. Journal notes recorded that $B a r b$ asked M3 and M4 about the respective children's orthotics and acknowledged M4's frustration with an insurance company. As such, these necessary conversations do diminish coaching opportunities for parental handling skill development. These various entities create a competing demand for direction of attention. Acknowledgement must however be given for the potential parental skill development regarding therapists listening and responding to parents' concerns regarding insurance issues and equipment procurement.

At the commencement of this study, it was assumed that all parents would be present during the entirety of each session observed and thereby create a logical opportunity for coaching to occur. In the therapist dyad, Barb and M3, this was not the case, as noted in both journal notes and observation review. Given that M3 did not accompany $\mathrm{C} 3$ into the therapy room, there was no opportunity for $B a r b$ to communicate with M3 as to goal setting or what learning objectives the parent herself might have had for the given session. This particular parent had another very young foster child in her care, which required her to attend to him in the car during C3's therapy session. Once again the competing demands of one or more of the participants bolstered the theme of practice reality being more than a one-onone teaching environment. Donna, similar to the other therapists, began each session with queries regarding the child and how the past week went. Journal notes 
for Donna and M7's first observed session included: "M7 was not present at the very start as she was talking with other parents in the waiting room." Upon review of video observation notations, Donna stated that she allowed M7 and other parents to continue conversations with other parents in the waiting room, recognizing "the importance of parental networking." This exemplifies yet another conflicting demand on the participants' time. Journal notes did not reflect any conversations between Donna and either parent that were identifiable as initiating a coaching opportunity between therapist and parent.

The collegial reviewer, as stated in the methodology section, served as a mechanism for structural corroboration in triangulation directed towards analysis interpretation. She viewed one session tape of Carol working with M5 and C5 and one of Donna working with M8 and C8. She noted that Carol asked M5 "what's new this week?" and "what do you want to do today?" in the initiation phase of the coaching paradigm. She further noted "PT engages Mom throughout session in collaborative environment," and "lots of positive interactions between Mom, child, and PT." Though the reviewer noted that Donna did state "tell me about your son" at session commencement, she commented on how Donna's intervention contrasted with Carol's. Collegial reviewer notes stated "PT began intervention without asking mom anything or what was happening at home," and "PT did not ask Mom much." In summary, there was no outstanding identification of therapists establishing or seizing opportunities to initiate specific parent coaching. Though in some therapy sessions the therapists made inquiries, Carol asking M5 "what do 
want to do today?" was the exception. The parental responses to child-specific questions were reciprocated as child-specific rather than for example wanting to improve their handling or interactions. Indeed, they wanted to know what to do for their child; however, they did not state learning objectives in terms of "I will learn such and such." Collegial reviewer notations confirm investigator journal notations of no initiation examples identified. The reviewer's generic note upon returning the tapes and notation forms was "what a difference in the coaching/teaching styles of the two PTs."

The researcher observations, researcher journal notes, and reviewer observations all appeared to substantiate a conclusion that initiating a parental coaching opportunity was not a major objective. Therapists' own reporting further confirmed this as they articulated goals in terms of what they hoped to accomplish with and for the child. Not once did a parent state that any goals for self-learning were ever considered. Mother 1 had no idea how much her comment "the therapist knows" suggests that goals are some unknown entity to the parent. This one comment in particular appears to be suggestive of Belenky et al. (1986) and Goldberger et al. (1996): women's position of knowing labeled as "silence." It was as if $\mathrm{M} 2$ was in the position of having no voice and was subject to external opinions of authority. The same authors' perspective of received knowledge (receiving and reproducing knowledge but not creating their own) was evident by the parental reporting of child-specific developmental motor milestone goals. The expertise that physical therapists bring to service provision to infants and young 
children with motor dysfunction is a strong knowledge of motor development and motor pathologies. Therapist-parent communication requires constant attention. Given that there was a paucity of parental coaching opportunities established in this sample, it is of no surprise that progression to subjective, procedural, and constructed knowledge, according to Belenky et al. (1986) and Goldberger et al. (1996), cannot be recognized in terms of improving parental handling skills. Perhaps the above reported lack of initiation phase examples and the repeated thematic presence of competing demands suggest a need to introduce a better understanding of teaching and learning theories in this "non-formal" education environment. If best practice is truly led by research and conversely practice guides research, then a demand for continuing education and curricular attention to adult teaching and learning teamed with motor learning theory is crucial. Terming practice strategies as coaching rather than teaching may be impetus-generating force in this direction. Acknowledging the various inhibitors that tug such efforts in various tangents such as competing parental responsibilities, insurance policies, and equipment procurement, must also occur.

\section{Observation and Action Phases of Coaching}

Hanft et al., (2004) provided their readers with key examples of what would connote observation and action in their presentation of the coaching process. As per these authors, observation phase examples potentially include observing activity practice of the parent, parent observing the PT, parent observing herself, and either PT or parent observing aspects of the environment. Examples of the 
action phase include: physical therapist modeling a skill for the parent; parent practicing present or new skill; parent having a discussion with the PT based on a behavior or situation; and/or the parent identifies a behavior, situation, or issue upon which she seeks advice. As in the previous section, initiation coaching phase, findings for the observation/action coaching phase are reported according to the different data collection modes: observation-video review, parent interview, therapist interview, and researcher journal and collegial review. This reporting is then concluded with some quantitative information combined with further analysis from the immediately preceding collection modes.

Observational data. Numerous child-specific exchanges of pointing out what the child was doing and some directives to observe the child handling techniques/strategies being utilized and potentially serving as a model by the PT exemplified the majority of the observation/action phase of coaching. The former exchanges included comments such as "you might need to take the shoe liners out," "did you bring the braces in?," "how is child responding to change in medication?," and therapists listening to parents describe how children were using specific equipment at home. Carol, for example, discussed with M5 the consideration of having her son's bed mattress directly on the floor rather than on the frame, which could eventually allow him independent access. Such examples underscore the importance of family context towards understanding the parent as a coaching recipient and thus the need to develop appropriate and effective coaching strategies tendered by physical therapists. 
Descriptively, without exception, parents "handing" their child to the therapist followed social greetings. Therapists began direct treatment interventions and communication with the children. In some instances, this overlapped those infrequent initiation phase inquiries responding to parental queries dealing with equipment usage and what was new this week mentioned in the previous section. As each therapist continued her direct interventions, she would comment to the parent what she was experiencing and/or observing with the child. Examples included "see the nice response of his foot," "she is taking a stronger step on the right," "she pushed up onto all fours," "nice legs," "he is doing a beautiful job," and "very nice talking today." Such comments could be interpreted as indirect coaching by the therapists to enhance parental observation skills. However, if the point of such comments was to serve as informal instructions for parents to strive for when replicating therapist's action in home follow-up, the researcher can only presume this to be the situation. Direct linkage to such comments to how or what the parent was to strive for at home was not apparent to the investigator. If not apparent to the researcher, the parental linkage is also questionable.

Elements of teaching and learning could be assumed as the therapists pointed out specific examples of child behaviors/motor skills because they did require some parental attention even if not hands on. Motor learning theories emphasize that the practice needs to be performed by the learner for learner skill development (Gentile, 2000; Gordon, 2000; Horak, 1991). Rarely did requesting parent demonstration follow these types of comments. Nor were such comments 
very informative as to how the parent could go about achieving the same results in a home environment, which would exemplify strategies of knowledge of results and knowledge of performance from motor learning literature (Gentile, 2000; Schmidt \& Lee, 1999). Observations of learner performance were rare, with the one exception of Carol, who provided PT services in the family home and who incorporated the most parent-handling time within her intervention session as will be presented later. The significance of these two findings, therapists' describing children's motor skill performance and the sparseness of parent demonstration and/or practice opportunity, create an interesting juxtaposition.

As stated, limited examples of coaching did occur in the observation/action phase in some of the observed therapy sessions. Alice instructed M1 to play with her son's toes while Alice modeled the skill for M1 to watch. Barb demonstrated, by positioning both her hands in front, as if to hold a ball, how the child's body would be more symmetrical if this were to be encouraged at home. With Mom and child 4 , this same therapist demonstrated and verbalized how to flex the child's lower extremity for ease in donning and doffing foot orthotics. The parent observed only, she was not asked to reciprocate demonstration of this skill. The researcher interpreted this as a missed teaching and learning opportunity within the observation/action phase of coaching. Hanft et al. (2004) emphasized the value of coaches observing parents rather than parents observing therapists for the majority of therapy intervention sessions. Carol physically guided C 5's upper extremity to be in front of his body while he was seated in his mother's lap. It appeared as 
though she was waiting for M5 to do the same; however, the PT did not offer any verbal reinforcement to do so. This could have been a rich opportunity to utilize extrinsic augmented feedback from the PT that would be indicative of both knowledge of results and knowledge of performance according to Gentile (2000) and Gordon (2000). If the parent had performed the similar activity, Carol could have encouraged M5 intrinsically to assess the results of her performance.

Research by Dunn et al. (1994) suggested a framework for the ecology of human performance that considers the contextual complexities to enhance the learner's performance. Relationships between the physical environment and person that included temporal, social, and cultural elements are emphasized in this framework. Specific examples of this, exhibited by individual therapists, included: establishing a person's skills and abilities and creating circumstances that promote more adaptable or complex performance in context. This creates a rich opportunity for developing the action phase of coaching. Donna articulated to M8 how she, the PT, had positioned the child on an incline. Pointing out to M8 how her son was able to achieve a right upper extremity weight-bearing prop was a clear demonstration of what this parent should strive for at home trials of the same. Though this parent was not requested to model the activity during the therapy session, the final 4 minutes of the session were devoted to how she could create an incline at home using a phone book and similar chair.

At the subsequent therapy session, M8 shared how she had replicated the inclined sitting environment to practice at home. The therapist had not asked for 
this; rather, the parent initiated the reporting independently, which suggests a possible transition to constructed knowledge (Belenky et al., 1986; Goldberger et al., 1996). This was an opportune moment for the therapist to reinforce parent cognitive development. It is uncertain whether the therapist's comment of "good" would be encouragement enough for this parent to continue such participation, or whether the therapist would recognize the parent learning element of this particular exchange. This also potentially posits Perry's (1981) transition to relativism where problem-solving depends upon the situation, in this case the natural context of what was available in the family home to create a similar practice environment. This particular parent demonstrated accepting the responsibility of figuring out how to accomplish the motor task opportunity for her child. Interestingly, perhaps M8's reported occupation, elementary school teacher, guided her learning rather than PT encouragement. Teasing out the differentiation of therapist recognition and identification from individual parent initiations was not the focus of this study, however it does create a curious future explorative inquiry. The point of situational based problem-solving per Perry (1981) does support the value of therapists specifically inquiring about home context successes in the initiation phase to direct the subsequent intervention sessions to assure responsive teaching and learning by both parties. It also links with the contextual complexities suggested by Dunn et al. (1994) that concomitantly recognize the value of environments, as does Horak (1991) when she discussed the task-oriented approach within "real-world" contexts. 
Of the four therapists participating in this study, only Carol and, to a much less extent, Alice, utilized observation of the mothers' performance in the observation and action phase of their parent/therapist exchanges. Thirty-six and 18 minutes of maternal child handling during the subsequent sessions highlighted Carol's interaction with M5. In both of these sessions, Carol praised the mother with how well she handled her son, "good job Mom," and she suggested that M5 place the toy on a different toe. This therapist also commented on the pelvic alignment that Mom was able to achieve with her child resulting in increased vocalizations. With M6, Carol guided maternal handling for 30 of the 45 minutes therapy visit. Carol praised M6 stating "perfect *Susan, that's right," ("pseudonymn) and "have him take a little step," and suggesting that Mom move the walker rather than the child to accomplish weight-shifting. This task specific, informative feedback exemplifies positive application of teaching and learning within a motor learning theoretical frame of knowledge of results and performance (Gentile, 2000; Schmidt \& Lee, 1999). Of interest is that this appears to have occurred because the parent had the opportunity to handle her child in the presence of the therapist. The likelihood of these comments being made while the therapist handled the child is negligible, because there would not have been a parental reference point. This reflection is very important in stressing the value of parent handling/demonstrating. This particular finding was repeated in one other therapist-parent exchange. 
Alice, like Carol, did include some opportunities for the mothers to handle their children during the treatment session, though much more limited in length of time. Alice requested M1 to demonstrate once each session. The maternal demonstrations were approximately one minute in length and focused on how the mother could facilitate abdominal muscle strength. Alice also encouraged parental involvement by having M1 hold toys for her child in various positions that would entice the child to reach out beyond his base of support, encourage him to move in a certain direction or to motivate him to pull to stand. Alice also observed maternal performance with Mom 2 for 15 seconds, when she asked the parent to assist her daughter in walking. Of note was that when challenged with wanting to enhance this mom's performance, Alice chose to have the parent watch again, rather than providing clear feedback while Mom performed the skill that could have better assisted maternal motor learning. The drive for quality child-specific performance appeared to supersede the family-centered competency development. By choosing a strategy of once again showing the parent, Alice was impeding M2's opportunity to transition her self-learning from dualism to relativism (Perry, 1981). It also suggests an unknowing obstacle of sustaining the parent in the "silent" position in which Belenky et al. (1986) state women are subject to the opinions and demands of some external authority. Mom 2 was inhibited from making decisions regarding her own skill performance when Alice jumped in to have the child walk better. This only served to implicitly reinforce the expert, all-knowing perception of therapist to parent relationship, though this certainly was not intentional. 
Barb did not utilize the strategy of observing maternal performance,

although, as presented later, she extrapolated from the interview questions that this might be something she could do in the future. Donna and the parents she worked with verbalized that parent performance demonstration was a strategy that was used in previous sessions; however, not in the four sessions taped. Therefore, based on the limited observations, it can be concluded that neither Barb nor Donna readily utilized this strategy in the observation/action phase of their therapy sessions.

Researcher observations of the therapy sessions noted in the observation and action phase that, in general, parents were either asked to hold toys/books or given verbal descriptions of specific tasks being accomplished. Parents observing the PT working with the child dominated 14 of the 16 sessions observed. This is explored and discussed further in a later section. It appeared that therapists assumed parents' observations would translate directly to parents' knowing this is what they should do at home. Parents were not asked, for example: "what do you do at home where you could use this handling strategy on a daily basis?" Therapists' observing parents was quite limited, if non-existent, for all but one therapist, who provided service in the home environment. At session end, this therapist provided specific feedback to the parent regarding her handling skills with her child.

Minimal to no observation of parental skills, a prime opportunity for therapists to apply motor learning theory, implies negligible application of this teaching mode directed towards this study's parent participants in the 
observation/action phase of coaching. This is an important finding based on current literature that states the value of actual practice (Gentile, 2000; Gordon, 2000; Horak, 1991; Schmidt \& Lee, 1999). The scarcity of application is worrisome from the stance of research to practice efforts and accentuates the need for facilitating this transition. It further accents the preponderance of childcentered as compared to family-centered approach in service delivery.

Parent interview data. Parents were asked what the therapist taught them in the two study sessions, to critique therapist's instructions, and to provide examples of therapist's recognition of their needs and concerns. Parental responses to what they were taught were very specific. These included back strengthening strategies, positioning, exercises for ankle strengthening, how to adjust equipment, weight shifting, stretching in previous session, and new ways to move toward goal attainment such as sitting independently. According to parent reporting, these examples may illustrate therapists' responsiveness in the contexts of behaviorist and cognitivist adult learning paradigms described by Merriam and Caffarella (1999). From a behaviorist theoretical standpoint, a specific observable behavior such as a child not completing full active ankle dorsiflexion (toes and foot moving in an upward direction) is the focal point from which a PT instructed a parent in a specific exercise to elicit this movement. The therapist thus becomes the external environmental impetus for initiating this learning event that can be repeated as much as necessary. 
In contrast, a cognitive orientation to learning was exemplified by M6 reporting she was taught how to adjust equipment as a direct result of her requesting assistance with this task. The "locus of control" was internal on the part of the parent as reflected by her self-initiated request and resultant therapist directed instruction. This example demonstrates "action" that is parent-centered rather than child-centered. A question that arises is how can therapists facilitate parents' recognition that they are indeed active learners who can generate initiatives that can benefit from therapist coaching? The corresponding video observation captured M6 stating she had attempted some equipment adjustment, hadn't been completely successful, and then requested additional information and assistance. Acquisition of new information and massaging new information to fit new circumstances, suggest integration of the cognitive orientation of adult learning paradigm. All study parents stated that they thought they were recipients of the PT intervention because they had been included to some extent during the child's therapy session. They also responded very positively to how much support they received from their child's respective PT, clearly exemplifying a sense of "belonging and love" listed by Merriam and Caffarella (1999) as distinct example of a humanist orientation. This would appear important in a helping, service delivery for parents of children with disabilities as they accommodate and continually reaccept at each milestone the capacity of their children's abilities. Such positive and affective communication exemplifies skillful coaching because 
the parent feels like she has been heard and sets the stage for development and application of a constructivism paradigm of learning.

A constructivism paradigm of adult learning, as described in the literature review, submits that learning occurs through the building of relationships between a learner and more skilled individual (Merriam \& Caffarella, 1999). This paradigm is also strongly identified with Dewey's and Piaget's value placement towards the importance of environmental context and problem discovery and Vygotsky's scaffolding support to the learner in a myriad of "natural" environments (Phillips \& Soltis, 1998). This includes parent-professional negotiations leading to relationship reciprocity that generates learning that is relevant and meaningful. All parents categorically agreed that the sessions provided were flexible, accessible and responsive to their individual circumstances. This was most evident with comments such as, "she schedules my child's session around my work schedule," and "she was even willing to come to our home." Mother 7 noted "excellent communication between the various professionals," and "a willingness to bring in additional consultants," These are just a few comments that punctuate the critical influence of adult teacher-learner relationships. Throughout each intervention session, but especially during the observation/action phase, therapists are challenged to be responsive to both child and parent. Finding an appropriate parent/child balance tests the skill duality of any service provider.

Several parents expressed knowing therapists had listened to their needs/concerns evidenced by time taken to explain and respond to parent generated 
child-specific questions. Additional indications of therapists being responsive included comments such as the therapist shares information regarding current interventions in the professional literature, medications that the parent could discuss with the child's physician and information the PT learned at a continuing education program. Mother 6 stated, "she advocates well and writes letters to the doctor before I go for my child's annual visit." The nature of pediatric physical therapy provision involves a multitasking process during the observation and action phase of coaching. Therapists provide direct handling with the child, while simultaneously conversing with parents for purposes of describing the intervention and child's response, supporting parent's struggles, and/or responding to specific questions. Pairing this with the earlier stated comments regarding medical and insurance queries/issues and/or equipment solutions mentioned in the initiation phase results, reemphasizes the multiple task demands of pediatric physical therapy delivery.

All parents except one responded in the affirmative when asked if therapists' directions were clear and specific. This particular parent was quite frank in stating that the therapist's directions were sometimes unclear. Her point was that the therapist often used too much technical and professional jargon. As an observer, this comment was confirmed in the journal notes made after this particular session. Professional jargon usage was seen with all the therapy sessions; however, there was no means of knowing to what extent "jargon busting" had occurred during the numerous preceding sessions for any of the partnership 
dyads. Though only one parent shared this comment, the universality of this issue could warrant further investigation and could be an inhibitor to parental learning as they are not licensed owners of the professional lexicon. Several mothers, during the interviews, used terminology obviously picked up from the therapists and/or other service providers. The extent of parents' terminology comprehension was not a focus of this study; therefore, it is an unknown. Use of professional jargon could be interpreted as an example of Perry's (1981) absoluteness, where an authority is the keeper of all knowledge. Professionals' use of technical jargon could indicate a means of sustaining a professional distancing between client and self as well as mindfulness of who the "expert" is. It could also inhibit relationship building, which has been shown to be important for mothers (Case-Smith \& Nastro, 1993; Washington \& Schwartz, 1996). Language may suggest ownership of meaning and therefore jargon usage during parent interviews may suggest that, rather than being characteristic of dualism (Perry, 1981), there is a definitive position shift to multiplicity where they are now a holder of meaning, if in fact they know what the technical terms mean. If not, this is likely problematic from the position of therapists or other professionals assuming parents understand what they are sharing based solely on vocabulary. Thus parents' jargon usage may be an attempt for them to take ownership of what they really might not understand, but are striving to grasp as if word usage alone will provide meaning.

Continuing to extrapolate illustrative examples of coaching in the observation and action phase, parents were asked how parent/professional 
collaboration was promoted during the interview data collection. Several

mothers were not sure what collaboration meant. Describing collaboration as how the parent and PT work together appeared to be better understood by the mothers. Once alternative wording was provided, they responded with descriptions of the therapist being "open," "honest," "straightforward," "makes me comfortable," and "caring toward the child." One parent shared that the therapist encouraged her by "having parent on the floor with her, often helping rather than sitting off to one side." This same parent added that collaboration was also promoted when the therapist "explained treatment as she went along rather than only at the end of the session." Interestingly, the one caregiver not sitting in on the PT sessions did not even mention this as a desired element. She appeared quite content with waiting in the car or waiting room, as this seemed to be a long established pattern. Perhaps the frequency of her having to often bring along other children under her care was the impetus for this pattern. Other parents shared that the therapist "makes it comfortable for me to ask questions" and "she is open to parent suggestions."

Parents were asked how they would describe their relationship to this therapist. The parent/caregivers used adjective descriptors to a much greater extent than nouns in their responses. Two predominant patterns appear to emerge from the list, friendship and professionalism as a teacher as can be seen in the following list that suggests a rich balance between professionalism and friendship that could exemplify good coaching. 
Nurturing and supportive

Friend, good, personable

Trusting, respectful, adores her, considers herself a friend

Open and honest, someone who is firm, starting a friendship

Great, very much a teacher, understanding

Appreciative, capable, knows PT loves her child

Advocate, teacher, respectful, professional

Respectful and open, shares goal of taking child to his highest potential

These descriptor offerings from the parents hint a strong reciprocity interpretation of the parent/therapist relationship. As such they can be further characterized as examples of a constructivist model of learning (Merriam \& Caffarella, 1999) that identifies making sense of numerous experiences and thrives through the building of relationships. Use of descriptors such as honest, trusting, respectful and understanding are not typically expressed for brief encounters, but from extended exchanges that are responsive to the uniqueness of each family. Therapist interviews provided another avenue into reporting and analysis of teaching and learning and motor learning theories that occurred during the observation/action phase of coaching. This list also lends itself to exploration of gender impacting teaching and learning which will be discussed later since all participants were female.

Physical therapist interview data. Except for the one caregiver not present during the therapy session, all other mothers were in close proximity, observing the 
therapy session. What and how much each parent extrapolated from her observations was not determined directly. However, inference of parental learning could be drawn from the preceding parent interviews and this section's reporting of therapists' interview data.

Therapists varied in their verbal descriptions of what they did when requested to give examples of how they taught/instructed parents during an intervention. Barb indicated her focus was on "giving information regarding what she sees as voids in the child's motor development skills." Two articulated that they explain a handling technique with parent observing followed by the parent demonstrating the technique. One of these women, Donna, shared that early on she may "perform the technique on the parent prior to the parent replicating the activity with the child." She indicated that this "lessens as she observes the parent using presented techniques spontaneously." Though reported, this strategy was not observed in any of the four scheduled sessions with this particular PT. The other, $B a r b$, reported that she asked for feedback from the parent regarding how the demonstrated technique "worked or did not work." Video observations showed a preponderance of verbal responses between parents and Barb. However, opportunities for parents to demonstrate their successes or challenges were not utilized or capitalized upon. In fact, during the follow up interview, Barb seemingly created an "aha" scaffold from the various interview questions, by commenting that perhaps she could have "parents demonstrate what they are doing at home." Two features that surfaced from these examples suggest a lack of 
therapists' adaptation to parental responses and possible unconscious persistence to not stray from their predetermined plan.

Alice highlighted how she strives to include parents in the individual sessions as much as possible via "having parent hold toys with an emphasis of where to position the toy." Though this example can be interpreted as a strong demonstration model, it sustains the adult learning at a behaviorist level, as the PT is merely requesting a behavioral response from the parent rather than facilitating the parent to evaluate importance of toy position, which was not evident. Alice added that she will sometimes progress to switching these roles and she becomes the toy holder, while the parent handles the child. "Providing written instructions, handouts on normal development, and carbon copies of reports" were other examples this particular therapist listed as how she included parent education in a therapy session. Though the role switching was observed, it was brief. The other strategies, by happenstance, were not observed during the recorded sessions. These examples are more illustrative of the predominant child-directed therapy session emphasis confirmed by the journal data.

Though not specifically sought for identification purposes, the bulk of therapists' input being child-specific suggests that a humanist orientation, summarized by Merriam and Caffarella (1999), to the parents' learning was not evident. These authors refer to the works of Maslow and Rogers that emphasized adult learning theory focused on needs of learner for explanation of this adult learning theory. This orientation assimilates learner self-initiation and learner 
evaluation, neither of which were reported in interviews nor observed. Learner evaluation might be more appropriately identified in reflection and evaluation phases of the coaching framework. Mothers and therapists reported child-specific session goals rather than any parent-specific goals further supporting paucity of humanist orientation. An example of a humanist orientation was captured from video reviews when $\mathrm{M} 7$ discussed her initial introduction to and joining of a parent support group, Parents of Outstanding Persons (POOP). Mom 6 commented on having difficulty with a piece of equipment that both parent and PT worked on during the latter part of one session. Interestingly, despite being observed on the video and interpreted as such by the researcher, neither mothers nor therapists articulated these as what occurs in therapy during the interviews.

During the observation/action phase of the coaching framework all but one parent were present throughout session entireties. Learning through observing, defining what Merriam and Caffarella (1999) identify as a social learning orientation, was evident via parents watching the therapists work with their children. Interestingly, therapists did not identify generation of or establishment of formal parent learning goals. One would think that this would be an important element to ensure attention to and strategies for parental learning. Merriam and Caffarella, referencing Bandura's work, articulated the importance of environmental context and the learner's interaction with the environment. Though the observational model mentioned earlier was predominantly of parent towards therapist and child and not other parents, many mothers stated this was how they 
learned. Therapists were asked how they knew the parent followed through with handling at home. They stated they could tell from "how the child was" on the subsequent session. Given that a myriad of factors could influence the child's motor behavior from week to week, this criterion of measurement of parental skills is curious to say the least. A more logical measurement could be direct therapist observation of parent handling, with concomitant assessment of the same. Though assessment of parent handling was not an objective of this study, a quantitative observation of the time allocation of therapist task focused to parent as compared to therapist task focused to child provided additional supportive information regarding presence or absence of adult teaching and learning. This information can be generalized to the model of coaching that specifically emphasizes interactions between professional and parent.

Therapist to parent/child time distribution. The observation/action phase of each therapy session appeared to be where therapists expended the majority of their efforts in terms of temporal findings. Sessions ranged in total length from 26 to 60 minutes. Approximate, to the nearest whole minute, times for PT to parent exchanges ranged from 3 to 26 minute (see Table 5). Parent exchanges included time when PTs actively responded to parent questions, when they explained what they were doing with the child, and when they had the parent handle the child. Therapists providing parents feedback to specific task-oriented motor skills (Horak, 1991) for handling their child at home was also included in this time determination. 
Table 5

Therapy and Parent Directed Time

\begin{tabular}{|c|c|c|c|c|c|}
\hline Therapist & Parent & Session & $\begin{array}{l}\text { Total PT Time } \\
\text { (Minutes) }\end{array}$ & Parent Time & $\begin{array}{c}\text { Percentage } \\
(\%)\end{array}$ \\
\hline \multirow[t]{4}{*}{ Alice } & \multirow{2}{*}{ Mom 1} & 1 & 47 & $15^{\prime} 37^{\prime \prime}$ & 31 \\
\hline & & 2 & $58^{\circ}$ & $5^{\prime} 26^{\prime \prime}$ & 8 \\
\hline & \multirow[t]{2}{*}{ Mom 2} & 1 & $51^{\prime}$ & 2'29"' & 4 \\
\hline & & 2 & $60^{\circ}$ & 6' $51^{\prime \prime}$ & 12 \\
\hline \multirow[t]{4}{*}{ Barb } & \multirow[t]{2}{*}{ Mom 3} & 1 & $46^{\circ}$ & 6,7 & 13 \\
\hline & & 2 & 53 & 4'44" & 9 \\
\hline & \multirow[t]{2}{*}{ Mom 4} & 1 & $26^{\circ}$ & $12^{\prime} 48^{\prime \prime}$ & 50 \\
\hline & & 2 & $26^{\prime}$ & 7'14' & 27 \\
\hline \multirow[t]{4}{*}{ Carol } & \multirow[t]{2}{*}{ Mom 5} & 1 & $51^{\prime}$ & $\begin{array}{c}21^{\prime} 13^{\prime \prime} \\
\text { (36' with Mom } \\
\text { handling child) }\end{array}$ & 41 \\
\hline & & 2 & $54^{\prime}$ & $\begin{array}{c}9^{\prime} 31^{\prime \prime} \\
\text { (18' with Mom } \\
\text { handling child) }\end{array}$ & 19 \\
\hline & \multirow[t]{2}{*}{ Mom 6} & 1 & $49^{\prime}$ & 9'16" & 19 \\
\hline & & 2 & $45^{\prime}$ & $16^{\prime} 18^{\prime \prime}$ & 36 \\
\hline \multirow[t]{4}{*}{ Donna } & \multirow[t]{2}{*}{ Mom 7} & 1 & $46^{\circ}$ & 6'19" & 13 \\
\hline & & 2 & $45^{\circ}$ & $8^{\prime} 27^{\prime \prime}$ & 18 \\
\hline & \multirow[t]{2}{*}{ Mom 8} & 1 & 55 & $16^{\prime}$ & 29 \\
\hline & & 2 & $56^{\prime}$ & 9'26" & 16 \\
\hline
\end{tabular}

During the interviews, each therapist was asked to estimate what percentage of therapy sessions they thought were directed toward parental education. Alice indicated that she directed approximately $25 \%$ of a typical session to parents. Of the two parents participating with Alice in the study, Alice indicated $75 \%$ for Mom 1 and $25 \%$ at best for Mom 2. Alice explained that for Mom 2, she has shifted her emphasis to more maternal emotional support because of the mom's emerging realization of her child's limitations and increasing concern regarding cognitive rather the motor abilities. Barb responded $50 \%$ to the query of what percentage of 
therapy time was directed to parent if parent is observing. If not, approximately 5 minutes at beginning of session and another 10 minutes at end of session (between 20-25\%). Carol indicated 50\% of her intervention was spent teaching parent and the other $50 \%$ is parental observation and direct child treatment combined. Donna reported $80 \%$ when asked the same question with the caveat that one has to gauge the parent's desires, her/his willingness to get down on the floor, and how long the PT has known the family. Though the investigator knows of no literature established regarding best practice amount of time, logic suggests that increasing actual coaching time directed to parents would enhance parental learning.

Therapists' generated percentages did not match the cumulative explicit (verbal exchanges) PT-to-parent time measurements obtained by the researcher from video reviews using the stopwatch. Rounding the Parent-Directed Time up or down to the nearest whole minute and dividing it by total minutes of taped sessions provided an estimated time of explicit exchanges between PT and parent. An average per therapist of parent directed time percentage was computed and compared to PT reported per interview question. Alice reported $25 \%$ of her therapy sessions were directed toward parent education while computations suggest a $14 \%$ average. Barb reported 50\% when parent observed sessions and $20-25 \%$ if parent did not observe. This compared to $38 \%$ and $11 \%$ respectively from actual findings. Carol's reported $50 \%$ was higher than the $29 \%$ finding as was Donna's reported 
$80 \%$ parent education compared to $19 \%$ average computed from findings.

Computations are based on only 4 sessions (see Table 6 for summary).

Table 6

Therapist Reported/Calculated Average of Direct Parent Education

\begin{tabular}{|l|l|l|c|}
\hline Therapist & Parent & $\begin{array}{l}\text { Self-reported } \\
\text { Percentage Time }\end{array}$ & $\begin{array}{l}\text { Calculated } \\
\text { Percentage } \\
\text { Average }\end{array}$ \\
\hline Alice & Mom 1 & 75 & 18 \\
\cline { 2 - 4 } & Mom 2 & 25 & 8 \\
\cline { 2 - 4 } & Mom 1 \& 2 & 50 & 14 \\
\hline \multirow{2}{*}{ Barb } & Mom 3 & 50 & $38(16 \%)$ \\
\cline { 2 - 4 } & Mom 4 & $20-25$ & 11 \\
\hline Carol & Mom 5 \& 6 & 50 & 19 \\
\hline Donna & Mom 7 \& 8 & 80 & \\
\hline
\end{tabular}

and must therefore be viewed with a cautious eye. However, the discrepancies warrant potential investigation of self-assessment as to what is deemed parent education. For example, Barb's first session with Mom 4 was only 26 minutes in length. While treating child 4, Barb conversed with Mom 4 for half the time regarding insurance policy hassles as well as the child's equipment and orthotic needs. All this was noted as PT-parent interaction; however, it was not representative of parent learning handling skills and thus appears to skew the percentage for this single professional-therapist interaction. If this one session was removed from the computations, Barb's average becomes $16 \%$ for remainder of interactions noted. The possibility of therapists utilizing parent observations as an indirect coaching strategy cannot go unnoted; however, a chronological measurement was impossible to achieve. The multiple layers of interactions 
(therapist to child, therapist to parent, and parent to child) that occur deem great difficulty in teasing out what a parent is observing and how these observations are interpreted and acted upon.

Summary of observation/action phase of coaching. In summary, the observation/action phase of the coaching framework offered by Hanft et al. (2004) was the predominant portion of the study sample findings. Despite participant mothers stating they wanted to learn, therapist emphasis during intervention sessions was primarily child-centered. It appeared as though therapists thought parents were learning by means of being informed of the child accornplishments. The multiple simultaneous demands on therapists' time seemingly created challenges to coaching/instructing parents on specific handling skills. Lack of therapists' adaptation to parental responses and what appeared to be an unconscious unwillingness to veer from an established agenda were additional examples of declination of family-centered focus. Repeated use of technical jargon could be problematic, while relationship development between therapist and parent was critical in establishing professional-parental reciprocity. Though the study sample was essentially outpatient clinic based, the one therapist who treated in the family homes was noted to use more family-centered like intervention that is strongly suggestive of natural environment context accentuating application of adult teaching and learning and motor learning theory to practice. 
Reflection Phase of Coaching

Hanft et al. (2004) specified the following components in the reflection phase of their coaching process.

1. The coach asking the learner questions to causing him or her to think about his or her current and/or desired knowledge, experience, or practice

2. Feedback by the coach on the learner's use of a targeted skill or practice

3. New information to the learner

4. Acknowledgement and affirmation of what the learner is doing, learning, or already knows. ( p. 44)

The authors stated the overall outcome of the coaching reflection phase should be to enhance a learner's capabilities of self-assessment, self-correction, and generalization to other circumstances. They suggested asking the parent-learners reflective questions that are objective, comparative, or interpretive. Such questions should guide the learner to constructing their own knowledge as defined by adult development and adult learning theorists.

Observation data. The observation data noted from videotape reviews is replete with examples of the physical therapists articulating what did and did not work while they treated the children. For example, Alice states that child 1 is "getting stuck going to the right," and Carol commented on child 5's midline upper extremity alignment. Barb shares with M3 that child 3 "has changed from two weeks ago in that she is now squatting with her arms in front." Mom 8 comments that "child 8 is cruising to the left better" and receives agreement from Donna. Encouragement or promotion of eliciting such comments from the parents was less apparent, though not absent. Rather, therapists seemed to respond to the occasional comment initiated by mothers regarding a skill the child had done at home. This 
was identified in sessions of M5 and M6 with Carol, and M8, an educator, with Donna. Perhaps promotion of mother initiation had already been established and thus the actual strategy of promotion was not captured in these particular sessions. Reflections regarding the children's performance were and are valuable. However, the vagueness of physical therapists guiding parents to consider what happened when they practiced various skills was apparent in several of the sessions. Despite parents reporting what the children had done the previous week, they were not asked to contemplate why a particular skill occurred, thus missing a rich opportunity for building on their comprehension and self-assessment of their own skills or their child's skills. Affirmation of specific parent learning was not direct. It might be presumed in an indirect manner through therapists' descriptive statements of individual child skill accomplishments during the treatment sessions, but this is not known for certain. In summary, the observation data regarding the reflection phase of the coaching framework suggest a lack of inquiry and initiation by the therapists and leads to a consequential lack of the reflective process. Though we are unable to know for certain, such lack may be detrimental to the potential of supporting the child's development.

Physical therapist and parent interview data. Learners' preferences for acquiring new knowledge can be classified according to three multisensory options (Hanft et al., 2004). In an effort to determine therapist attention to parental learning, therapists were asked to label each parent's learning style as visual, auditory, or kinesthetic followed by how they were supportive of parents. If 
therapists' labels closely matched the parents' self-labeling of their learning style, this could suggest therapists were facilitating parental learning. The multisensory option question was positioned within the reflection framework of the coaching model because it could serve as a means of confirming learner understanding, especially when matches occurred. No definitions or descriptions of these labels were provided to the therapists when interviewed. If therapists are to embrace the tenets of family-centered intervention, parents as learners must be understood and approached in appropriate and effective manners.

Parents were asked to indicate how they learned best, by watching (visual), by listening (auditory) or through hands on practice (kinesthetic). No additional descriptions were supplied to either group, so in both instances, therapist and parent comprehension of the terms and thus the request for learning style labeling is poised for some level of inaccuracies. Comparing the learning style identification between learner and therapist/coach showed mixed agreement that may suggest some informal/implicit though inconsistent application of adult learning principles despite therapists' limited self-reported knowledge base of adult learning theories (see Table 7). 
Table 7

Learning Style of Learners

\begin{tabular}{|l|l|l|}
\hline Therapist & Reported Mom As & Mom Self Report \\
\hline Alice & $\begin{array}{l}\text { Mom 1 as a kinesthetic learner } \\
\text { Mom 2 as an auditory learner }\end{array}$ & $\begin{array}{l}\text { Hands on learner } \\
\text { Visual learner }\end{array}$ \\
\hline Barb & $\begin{array}{l}\text { Mom 3 as an auditory learner } \\
\text { Mom 4 as a visual learner with auditory }\end{array}$ & $\begin{array}{l}\text { Listener } \\
\text { Do and then watch }\end{array}$ \\
\hline Carol & Mom 5 as kinesthetic and visual learner \\
& Mom 6 as visual and auditory learner & $\begin{array}{l}\text { Hands on } \\
\text { Hands on and visual }\end{array}$ \\
\hline Donna & Mom 7 as a visual learner & $\begin{array}{l}\text { Hands on } \\
\text { Watch and then do }\end{array}$ \\
\hline
\end{tabular}

The therapists' labels appeared to reflect more the reality of how they each worked with the respective women. For example, Barb described Mom 3 as an auditory learner. Mom 3 stated that she learned best by listening and in actuality therapist to parent communication occurred through a short verbal communication immediately following the unobserved therapy session. Logically, if a session is not observed, it does follow that the learner cannot be identified as a visual learner. Alice described Mom 2 as someone who asks numerous questions, which could lead to her describing Mom 2 as an auditory learner. Of interest was that Mom 2 stated her preferential style of learning as visual because a previous PT, upon requesting parental demonstration, was remembered as being quite critical. This has led to her discomfort in trying any skills in the clinic; however, if it were possible for the therapist to come to her home, she indicated this discomfort would 
decrease. Donna considered Mom 7 as a visual learner. Given that a baby brother demanded peripheral yet constant attention, this perhaps only allowed the mother to observe and discuss tangential topics of support and resources. Mom 2 and Mom 3 did not identify "hands on" as part of their learning repertoire. The other six mothers did, yet other than Mom 5 and Mom 6, no opportunities were given for the women to demonstrate their skills in this sample. This could suggest that the mothers were describing their performances at home, extending the teaching/learning moment beyond the therapy setting. Analysis suggests inaccurate PT assessment of parent learning styles and posits the question of whether therapists really use different styles of "instruction" according to the various reported learning style identifications of parents. Therapists were not asked what their learning styles were. If they had been, perhaps some potential association could have been determined as to whether therapists" "instruction" was more likely in accordance with their own learning style rather than with the parents.

If therapists were to purposefully identify learning styles in concert with improved initiation strategies of identifying what individual parents want to learn, reflection of the intervention session is bound to improve. As Hinojosa (1990) stated "therapists who work with disabled children must be more concerned with their influence on families" (p. 157). He further elaborates on the necessity for therapists to concentrate on the capabilities and potential of the parent in contrast to specific therapist determined activities. This reinforces the supposition of natural environment context importance. Despite querying the therapists' identification of 
parental learning styles, there were negligible examples of active reflection occurring between therapists and parents. Hanft et al. (2004) suggested questions that could promote reflection including facilitating the parent to indicate what happened when she was handling or interacting with her child, what was her desired accomplishment, and how could she do something differently. Not having such discussions with parents could be indicative of therapists not facilitating a reflective component of their coaching role in providing family-centered intervention. This, with, as previously stated, minimal purposeful parent-learner goal determination during the initiation phase shows a poor development of reflection. Physical therapists' inattention to parent learning style, facilitation of parents' self assessment of what their children did, as well as self-assessing their own skills may likely result in a diminished potential of elements that are indicative of the reflection phase of coaching. What therapists and parents identified as benefits of and barriers to therapists coaching parents could further impede reflection.

Though specific parental support examples varied from therapist to therapist, a common theme was that it was a valued entity especially towards parent emotional stability. All four therapists noted the need for supportive recognition that families have full lives and that physical therapy for the child is only one aspect. Carol asking Moms 5 and 6 if they were getting enough sleep and alone time indicated concern for the mother's well being. The challenge of supporting mothers' emotional strife, as the realization of motor and cognitive limitations 
became more apparent over time was yet another example of therapists' supports. Donna shared that changing therapy delivery venue to the home periodically was a strategy used to foster parental support, though this was not observed in the study observations.

Observations and interview responses did not collectively show even a minimal usage of reflection during the selected therapy intervention sessions. This suggests a need to develop reflection skills if physical therapists and other professionals engaged in servicing children with disabilities and their families in a family-centered manner. Researcher and collegial notations further corroborate the above findings that there was a substantial lack of therapist and parent reflection occurrence in intervention sessions.

Researcher journal data. Journal notations reinforced the limited observation of reflection phase examples of parent directed coaching for all but Carol. Journal notes for every session included examples of therapists commenting on the child's accomplishment of a task or skill. Concomitantly, journal notes repeatedly included comments such as "teaching elements appeared limited" when referencing comments directed to parent. For example, "Donna had child 8 do activities, she modeled potential parent participation though no specific instructions were given to parent," and "parent 'motor learning' does not appear to be a priority in any obvious manner." The lack of parent handling negated any opportunity for the therapist to ask the parent how she could have handled her child differently or why she thought she achieved the response she did. Such communication would 
have most definitely been indicative of the reflection phase of coaching as described by Hanft et al. (2004). Though Donna communicated numerous times with each mother, her comments were primarily directed to articulating what and how the child had done in response to her direct hands on intervention, not how the parent may or may not have been successful with achieving a similar result. This would have been difficult since neither parent was given an opportunity to demonstrate handling skills during the selected study sessions. "No task specific instructions were given to parent at end of session" by Alice provided another example of journal notation that was indicative of the lack of parent specific reflection examples. Another post observation taping journal notation, this of Barb, was 'parent 'motor learning' does not appear to be a priority at least in any obvious manner in my observation." By comparison, journal notes for Carol included 'PT responded numerous times to mom's comments, often repeating them as if to get confirmation." Another example was "Mom 6 moved in and started helping child 6 with standing and Carol backed off' while PT gave specific feedback of what to do with walker and child 6's legs. The question again arises, is this purely a reflection of this particular PTs style, education, and/or the element of environment where a parent may be more likely to generate impetus for greater coaching opportunities.

Collegial observational data. Corroboration by a collegial reviewer provided validation to the investigator's observation notations as well as her journal notations while serving as a method of triangulation in a qualitative inquiry for this 
particular coaching phase analysis. Colleague observation data corroborated that both Carol (in a session with Mom 5) and Donna (in a session with Mom 8) did reflect how the child was responding to treatment, which was also noted in the researcher's observational data entries. However, as determined by the investigator, Carol's comments were made over a session that included parent handling her son for 18 of 54 minutes, in comparison to less than a minute for Mom 8 handling her son. Investigator notations included that Mom 5 shared much more information regarding what she does and observes and more readily asked Carol to watch how she works and interacts with her son. It appears as though parental reflection was more readily accomplished in those instances when the parent was handling the child. Collegial accountings of Carol were that she "identified activities that were working and reinforced parent's role." Of Donna, she noted, "PT did ask parent what child was doing but did not coach Mom in any new activities. Mom seemed to inform the PT but I'm not sure how much she (PT) listened." These collegial accountings parallel the researcher's more numerous examples of reflection noted in Carol's session as compared to Donna's session.

Summary of reflection phase. To recapitulate, reflection allows participants (PT and parent) to summarize what has occurred throughout the informal or formal coaching process. It may provide feedback on the observation/action phase, may allow for sharing of information, validate learner understanding, and review what has been accomplished. Examples of reflection were present in each of the dyad therapy sessions included in this study. Of interest was that these examples had a 
child-centered concentration with a very sparse scattering of parent-centered reflection. As this study was designed to explore current practice of educating/coaching parents, the paucity of reflections that would demonstrate the parent learner discovering what she/he already knows or needs to know, would indicate a lack of attention to the adult learner as a recipient in pediatric therapy. Hanft et al. (2004) stated that the goals of coaching should not be prescribed by the coach, but rather desired by the learner. This requires therapists' transition from the long established paradigm of professional remediation of child deficits to guiding a developing competence of parents to identify, clarify, and act upon their abilities related to their child. These authors suggested, and stated support from various leaders in the field of early childhood education, that a good therapist would proceed through each of the coaching phases as part of evidence-based best practice. Success in accomplishing the above can take place in the evaluation phase of the coaching process.

Evaluation Phase of Coaching

Hanft et al. (2004) described the evaluation phase of coaching as an opportunity to review the effectiveness of the interactive process. Rather than evaluating the learner, a coach (in this case the therapist) could examine what changes she needed to make to assist the learner in achieving her/his determined goals.

Observation data. Given that there were no clearly stated parent learner goals at initiation (see initiation phase analysis) in any of the 16 observed therapy 
sessions, evaluation of a nonentity was not possible. In no instance did a therapist ask any of the mothers to comment on the effectiveness of PT instruction/coaching (strengths and weaknesses) directed to the parent. Evaluation was not noted in the observation data collection forms by the researcher, or in the post videotaping journal notes. Lack of any assessment process or procedure that would have been indicative of an evaluation phase of coaching is of concern as it further establishes a poverty of family-centered practice. The coaching model that includes a component of evaluating the coach-learner relationship and effectiveness provides a template towards developing a more effective reciprocal relationship between professionals and parents that would highlight parental competence through constructive and humanistic types of learning.

Therapist interview data. Asking therapists to share how they made changes in their therapy delivery and what indications they used to prompt the changes indirectly addressed possible self-evaluation of the parent/professional interactions. All four therapists indicated they knew mothers had learned by attending to what the parent shared with them. Specific examples included when a mother shared a functional skill the child performed at home or what the parent had done with the child the previous week. Another example given was observing parental handling, though the PT who provided this example did not utilize this strategy during her four sessions of the study data. When asked what was the greatest influence on their service delivery model, the responses were quite varied. One indicated her love and empathy for children, another stated experience and the 
rewards of pediatric practice, a third reported that environment and age of child had the greatest influence, and the fourth was insurance coverage. Interestingly, none considered parents as an influencing factor, correlating to the predominant child-centered approach to service delivery rather than family-centered and therefore lack of concomitant coaching of parent. This finding is yet another key indication that despite articulations of parent instruction/education being valued and accomplished by the participating physical therapists, parents were really not the focus of the intervention delivery.

When each therapist was asked how she determined when changes in her intervention delivery needed to be made, the immediate responses were again childfocused. Included as determinants for change were these child-focused comments: sensory/behavioral feedback from child, if child became fussy, child's behavioral response, and after child reaches four years of age, changes are dictated more by child's growth. Barb and Carol respectively added that one needs to be sensitive to the parent's emotional state and/or the maternal/child behavioral interactions. No parent interview questions were formulated to address this phase of coaching and therefore no reporting of such is included. The coaching model provides a framework to guide pediatric therapists towards improving their interactions with parents. Application of this model could very likely enhance development of more responsiveness to parental learning.

Collegial observation data. Collegial notations stated that evaluation was never done in the videotape observation of Donna with Mom 8 and this validated 
the researcher's zero comments on the parallel corresponding data sheet for Donna and Mom 8. Investigator notations for Carol and Mom 5 showed some limited efforts suggestive of therapist-parent interaction evaluation. This was validated through the mechanism of collegial review of the same dyad pairing. Collegial comments on evaluation phase for Carol with Mom 5 attempted to infer that evaluation occurred with her comment of "although the PT never asked the Mom directly what were the strengths and weaknesses of the session, both knew them and talked about the child's learning." This shows that child rather than parent outcomes were more of an emphasis. She also noted that "again, neither the PT or the Mom stated in the beginning the treatment outcomes nor objectively measured anything at the end."

Summary of evaluation phase. Examples of active evaluation were not readily identified by any means of analysis. This appears to be an untapped entity in coaching parents that correlates with such a strong absence of family-centered emphasis in the majority of observed sessions. Specific attention to future development in this area of family-centered intervention will be warranted. It would also require therapists to evaluate their parent coaching skills, which appear to be undeveloped.

Summary of phase analysis. The coaching process described by Hanft et al. (2004) provided an organizational structure to present findings describing how a small cohort of pediatric physical therapists inform and instruct parents in physical handling of their respective children. In general, therapists had a narrow 
knowledge base of adult learning and motor learning theories, which limited their application of the same in their treatment sessions. Examination of their interventions with young children with motor disabilities and their families displayed a predominance of child-centered strategies within the context of a coaching framework as was expected. Though therapists reported 'teaching parents," observation findings suggested the contrary. Child-specific generated session goals in an initiation phase; limited action/observation, where parents infrequently handled their children during sessions; minimal reflection; and absence of evaluation examples characterized therapist intervention strategies and practice. The exception to these fairly consistent findings was that of Carol, the PT who provided home-based/natural environment service and who also reported the higher knowledge base of adult and motor learning theories. During her interview, Carol stated that the natural context of in-home service provision had altered her intervention approach from previous outpatient clinic based provision. How much natural environmental contexts can assist in implementation of the coaching model described by Hanft et al., (2004) is an unknown that would warrant inquiry. Introducing and reinforcing adult and motor learning theories within the framework of a coaching model in efforts to achieve responsiveness to family-centered service is recommended.

Identified Benefits and Barriers to Coaching Therapists and parents were asked what they viewed as the benefits and barriers to parent learning. Three themes emerged from the interview-generated 
therapists' examples of benefits gained from teaching parents. Parents becoming better consumers of service (medical and educational) for their children by developing advocacy skills, and thus decreasing professional dependency was a repeated theme from all four PTs. A second theme was that parents would gain skills in reinforcing therapy activities, follow through with home programs, and learn physical management skills for their child's lifetime. The third theme appeared to be a focus on valuing the parent as an individual and as a parent whereby the parent-child bond was enhanced. Despite these identified themes, the limited observations did not suggest practice delivery that would build on these potential benefits, as the interventions were child rather than parent-centered. As a group, these four pediatric physical therapists obviously recognized parents as learners, but they did not truly provide parental education as evidenced by limited opportunity for parent handling and reflection.

Two themes, identified by the therapists, surfaced as to the barriers of teaching parents. The most common was the element of time limitation due to reality of busy full life styles, especially when both parents work. The second barrier theme identified was parents' inability to follow-through, not listening, and sensing some parents' fear of "not doing it right." Interestingly, therapist's lack of skills to enhance parental learning was never brought up as if parents solely shoulder the onus of learning. Perhaps therapists did not believe that parents would follow through on the prescriptive home programs. Hinojosa (1990) advocated diligence towards assisting mothers with a means to adapt their lives in a manner 
that minimally disturbed the family function while meeting the needs of their children with disabilities. His implication is an emphasis toward what he labels "mother-directed" intervention rather than therapist-directed. The juxtaposition of therapists' thematic benefit and barrier examples is troubling, especially if they do not view their role or rather lack of coaching/teaching skills as a major factor.

The parent/caregiver responses to what they viewed as the benefits of the PT teaching them something were varied yet consistent with attention to the child receiving therapy. The following list exemplifies this point and seemingly reinforces a more prescriptive nature of therapist-directed rather than motherdirected intervention:

The PT made me feel educated about my child's challenges

Home programs help move my daughter toward achieving her goals

I now know how to hold him

It has allowed me to interact with my child

Gave me ideas of how to play with toys differently

I understand better what my child is working on developmentally

Saves me time because I can do home programs on my own schedule

Child's progress would be much slower if I didn't do things with her None of the above statements showed any strong indication of adaptation for supporting family function or activities.

Three mothers stated no barriers existed that would impede their learning. Two adamantly stated that time constraints were a major factor to their learning. 
"Being overwhelmed," "other siblings," "lack of equipment," and "limited number of insurance reimbursed sessions" completed what the respondents felt were barriers. Perhaps these parent-identified barriers are most informative in light of mother-directed need identification. These and similar statements should indicate an alternative therapist response and approach that would be supportive of the parent, rather than continuing to have the parent "observe" weekly therapy sessions. Decreased frequency or episodic visits with a very specific focus towards parent-directed needs and goals could diminish some of these identified barriers. It could also improve therapists' understanding of what Hinojosa (1990) conveyed as the consequences of their interventions.

Other components of therapist/parent interaction considered were the issues of gender, ethnicity, and age. As described in the literature review, teaching and learning does not exist in a vacuum. Elements of the aforementioned issues were considered to determine if they had any impact on the therapist-parent teaching/learning strategies and application within the context of physical therapy intervention as well as therapist understanding and attention to the same.

Gender, Ethnicity, and Age

\section{Gender-Related Findings}

Issues of gender, specific to how women process information and make meaning of the teaching and learning experiences, in the reciprocal relationships explored in this study appeared to match the findings of the reviewed literature. Parent interview responses describing their relationship with their respective 
physical therapist were discussed earlier. Three mothers used the word "friend" to describe their relationship with the respective therapist. Others used descriptors such as personable, understanding, appreciative, open and respectful, all of which suggest a positive social relationship. These findings are supported by Washington and Schwartz (1996), Case-Smith and Nastro (1993), and Hinojosa (1990), physical and occupational therapist researchers who reported parents' valuation of the social relationship support developed with their child's therapist. Perhaps this parental valuation can also be interpreted as parents viewing therapists as mentors. Beyond learning paradigms with the earlier discussion, relationship descriptors can also serve as indicators for gender-related positions of knowing according to Belenky et al. (1986).

Belenky et al. (1986) presented a gender lens perspective of women's learning. This perspective is identified by key positions of women knowing that transition from silence, through received knowledge, subjective knowledge, procedural knowledge, and finally to constructed knowledge. All eight parents were definitively beyond the "silent" voice, described by these authors, as evidenced in their comfort level of discussing the parent/therapist relationship with the researcher. Also contributing to this interpretation is the ease of sharing their opinions throughout the interview session. Their comments by no means suggest subjection to the opinions or demands of an external authority.

Received knowledge positions the learner such that she expects to learn from powerful and knowing others (Goldberger et al., 1996). Where the parent 
views the PT as a teacher, nurturing, and someone who is firm, was readily apparent in several responses. Voices of subjective (knowing is personal and intuitive) and procedural knowledge (knowledge acquisition is developed and honored) could be confirmed with the descriptors of the PT being open, honest, understanding, and respectful (Goldberger et al., 1996). The latter voices are also recognized by earlier examples provided - when the therapist took time to respond to parent generated child-specific questions. The relationship will ultimately reflect the personal styles and characteristics, as well as roles that each person plays.

The mother of the oldest participant child described the PT as an advocate for her son. Given his age and the severity of his motor impairments, the need to construct knowledge for his long-term prognosis and care has been facilitated via a reciprocal relationship. The advocacy aspect of this particular response illustrates the position of constructed knowledge where the knower is part of what is known (Goldberger et al., 1996). The PT was most supportive of this parent's introductory involvement with a local parent support group. Her encouragement of both the mother and father attending can be viewed as supporting this parent creating her own knowledge construction, that of parenting a child with significant impairments and needing support from other parents of children with disabilities. This was but one single example by parent report. Constructed knowledge, initiated by parents especially in terms of their need for assistance in what influences family life was otherwise unidentified, nor was it solicited or facilitated by therapists. Parents appeared to be quite established in a routine of bringing their children to a physical 
therapist to receive therapy. Thus they were doing what they should be doing, transporting the child to the therapy appointment, but with resultant little to nil parent skill development or need generation.

When asked how therapy sessions would differ if a male caregiver accompanied the child, therapists stated that their approach would be different. For one family, the therapist indicated that her conversation with one father would be structured more as an intellectual discussion than with the mother. Collectively, the other therapists indicated their sessions with fathers would typically include more "rough-housing," more physicality, specific games, and be much more directive given the limited contacts they had with the fathers. This finding is indicative of the study's therapist participants "intuitive shift" to alter their strategies when working with a father. The more directive nature of their potential therapist to father encounters may be directly related to the limited contact time and thus an impetus to provide a very specific task/skill to do when interacting with the son or daughter. The absence of fathers as study participants was anticipated. However, despite the brevity of responses to the potential differences, the study therapist comments imply a need to be more curious regarding "how" professionals "know" to be different in their interactions with fathers as compared to mothers. Ethnicity-Related Findings

Given the predominately Caucasian ethnicity of parents and therapists, no interpretation as to how ethnic diversity played out in the sessions observed was feasible. Even though one family was of Hispanic ethnicity, English was the first 
language and the mother didn't comment on her ethnic background as coming into play with her relationship with the PT. This particular PT didn't even comment on this specific family when asked how her intervention would change if a family were of different ethnicity than her own. Anecdotally, commenting that she has found Asian families to be more reserved, she shared that she typically scales down her exuberant enthusiasm. This statement does imply that the therapist has a sensitivity awareness that cultural influences need to be considered when delivering services as indicated in the literature (Hanson \& Lynch, 1990; Harry \& Kalyanpur, 1994; Masin, 1995). Another therapist indicated that diversity of ethnicity would not alter her approach, which puts into question her awareness of the value of attending to ethnic diversity. Rather than country of origin ethnicity, another therapist expressed the importance of knowing the family culture within the home. She further indicated that a home visit would be most beneficial in determining potential cultural mores, as did McCollum et al. (2000) and Danseco, (1997). A specific example shared was how individual families choose to establish sleeping routines, such as sharing the parental bed well into early childhood.

Though as stated, minimal inference can be made from this study due to the limited ethnic diversity of the participants, interview comments suggest a need for attention to this aspect of diversity. The inclusion of diversity influences in physical therapy education at entry level and post graduation is imperative. Rather than a glazing over recognition of the topic or giving lip service to diversity awareness, the implications advance the need for future studies that specifically 
highlight this intersection of ethnic diversity of parent and professional.

Studies specific to service provision by non-White professionals are non-existent and are sorely needed to advance a more comprehensive understanding of the role of ethnic diversity in service provision. Integrating attention to ethnic diversity would foster coaching that is even more inclusively effective in developing familycentered intervention. Additionally, good coaching should also include diversity aspects of age.

Age-Related Findings

When asked what differences a parent's age would have on therapy provision, one PT stated she was not sure about this. Another stated that with younger mothers, she typically would have much more social conversations to gain initial rapport. She also indicated that older moms were "more intense" and younger, "more laid back." "The younger moms seemed to be 'more adaptive' due to their lower social-economic-status (SES) as the family hadn't had as much longevity in the work force." A third stated she would change her approach, but did not provide any specifics as to what the changes might be. The implications for service access, especially in regards to age related SES were not a priority of this study. However, future investigations should consider this factor in light of the one comment from above, if in fact SES does impact a parent's ability to actively participate in therapy sessions.

As expected, the therapists appeared to have a sense that they needed to address issues of diversity when appropriate; however, they did not have the 
theoretical contexts to position or label specific strategies in their interventions. Perhaps if there had been a greater diversity (ethnic or gender) within the dyads, therapists could have articulated strategy alterations more clearly, despite not being able to label them. Given that the mean age of the mothers was 36 years, age differences in this small selected sample did not appear to have any appreciable influence on any different intervention approaches. The 24-year-old single mother was dealing with regaining guardianship of her child and the 62-year-old had a significant parenting experience in years alone. However, neither of these participants was mentioned as examples by the respective therapists in regards to age related learning abilities. Rather, it was more of being sensitive to the guardianship procedures for the single mom and the physical inability of the older woman to get down on the floor. It appeared that chronological age of a parent was not taken into consideration for teaching and learning efforts at least by this select group of therapists. It establishes a need for further investigation. Another therapist mentioned physical ability needing to be considered for one mother who was quite overweight, also making it difficult for her to get down on the floor. The physical capacities of individual parents appeared to be of greater attention than age and subsequent linkage to cognitive development in the decision-making process for parent education. This is certainly understandable given the physical nature of reproducing handling of young children with physical disabilities. However, to do so, is yet another indication of therapists striving for a very prescriptive replication of their handling skills rather than creating a learning encounter that is responsive 
to parents based on an understanding of teaching and learning and motor learning theories within a coaching model approach. Summary of Gender, Ethnicity, and Age-Related Findings

The purpose of this study was to gain insight and understanding of the applied educational role pediatric physical therapists have with mothers of young children with physical disabilities. The findings, as reported in this qualitative exploration of a small selective participant pool, have provided an initial understanding of current practice in private practice pediatric physical therapy. What stands out is the strong prominence of child-centered therapy intervention as compared to family-centered therapy as evidenced by so few examples of parental coaching recorded and/or noted in the three means of data collection. As per Effgen and Chiarello (2000), Cochran et al. (1990), Mahoney et al. (1999), and Hanft and Pilkington (2000), professional preparation places an emphasis on working with the child. Kelly and Barnard (1999), as well as Effgen and Chiarello (2000), reported the poverty of family-related or adult-learning content in professional education programs. The four physical therapist participants certainly fit this pattern. The other quite apparent observation was how comfortable the therapists were in "talking the talk" of valuing parent education as part of their service; however, application or "walking the walk" was not in strong evidence by the same methods of measure. O'Neil and Palisano (2000), in describing attitudes of pediatric physical therapists toward family-centered care, reported that $76 \%$ of the therapists identified child characteristics as the most important in their clinical 
intervention. Only $20 \%$ indicated family considerations as most important. Despite knowledge of family-centered paradigms, application of the same continues to be limited.

Interpretation of the findings noted in the individual sections of the preceding analysis and suggestions for continued research could play an important role in planning and developing future preservice, internship, and/or continuing education opportunities for pediatric physical therapists. Implications of the findings are discussed in chapter 5. Limitations of the study, future research suggestions, and conclusion complete the following chapter. 


\section{CHAPTER V \\ DISCUSSION AND CONCLUSION}

The findings of this study support the hypothesis that pediatric physical therapists would display a minimal family-focused intervention, evidenced within the context of a coaching framework, while concurrently investigating related issues of gender, ethnicity, and age. Sparse professional to parent teaching interactions during scheduled therapy sessions with minimal application of adult learning and motor learning theory dominated the observations. An acute absence of parent/learner goals was especially evident. The impetus for session goals appeared to have been professional initiated based on the therapists referencing their initial child evaluations as a source of goal construction and embraced by the parents as exemplified by their reporting of developmental milestone acquisition rather than home environment functional needs. Goals of interventions were childcentered as evidenced by the impairment and developmental level focus as compared to being functionally driven. In no instance did professionals or parents state any example of parental learning goal when asked to identify intervention goals.

Brady et al. (2004) stated that despite early intervention literature's strong emphasis towards the value of family-centered service approach, assessment data as to the outcome and impact of such an approach is minimal. These researchers 
further stated that the paucity of research, examining the formative process of professional-parent collaboration in addition to the disparate definition, implementation, and evaluation of family-centered approach, challenge the determination of collaboration efficacy. More specifically, Brady et al. expounded that scarce scrutiny of the "moment-to-moment" professional to family interactions warrants attention. The explorative inquiry of this present study was an attempt to initiate contemplation of the same in the specific context of pediatric physical therapy for young children with physical disabilities and their families. Summarizing some specifics of the current study that highlight the lack of professional to parent adult learning application is followed by how the coaching model could be adapted and implemented, the potential barriers to application, limitations, suggestions for future inquiries, and conclusion.

\section{Summary}

The findings of the current study computed on average less than $20 \%$ of intervention time directed toward parent learning and much of that characterized by descriptively sharing the child's performance. These findings are supported by Mahoney, Robinson, and Perales (2004) who found that despite interventionists reporting "working with parents," what they did and how much they interacted was erratic. The current study findings are specifically supported by Mahoney et al. (2004) observations that showed more direct work with children as compared to collaborative work with parents. Mahoney et al. suggested a need for new treatment paradigms in the delivery of early motor interventions. As part of their 
comparison of two motor intervention approaches, these researchers found that children's general development was promoted when parents learned effective parent-child interactive strategies.

Analysis of the observed sessions reflected a preponderance of childcentered service delivery as hypothesized. Estimated temporal measures of professional to parent interactions were much less than actually recorded. Though most of the interactions were in conjunction with the parent being present for all but one study participant, the interaction content characteristically comprised child development, progress, and care information and/or discussion. By far, the participating therapists were acting as the "agents of change" as compared to guiding or coaching the mothers' skill development to be this agent.

Overall, physical therapists and mothers were very complimentary of one another in this study. Mothers communicated feeling supported and respected by their child's physical therapist. Furthermore, the mothers stated that the therapists did 'teach" them and that they were recipients of the therapists' intervention. However, investigator observation notations, journal notations, and collegial notations did not corroborate therapists specifically coaching parents' skill development for interacting with their children. This was substantiated by the majority of therapists' communications being child-focused, such as reporting what and how the child did during each session. Therapists self-assessed the presence of professional-parent engagement to a lesser degree than their professional-child interactions, which though affirmed by the investigator, was to a much lesser 
degree than therapist reported. Though infrequent, specific suggestions for home program follow through was more prescriptive than responsive to what is naturally occurring in daily child management. The predominant exception to this finding was with Carol, who provided intervention in the family home.

These findings were not dissimilar to those of $\mathrm{McBride}$ and Peterson (1997). The study purpose of McBride and Peterson was to initiate a description of content addressed and the processes employed by early childhood special educators (interventionists) during home visits. Though younger, less experienced, and educators rather than therapists, findings by $\mathrm{McBride}$ and Peterson reported greater child-focused interactions (89\%) similar to the current study. McBride and Peterson reported that half the interventionists' time was observed to be direct teaching with the child, $25 \%$ spent providing information to parents or others, and listening (7\%), observing ( $7 \%$ ), or modeling for parents $(0.47 \%)$ much less frequently. Percentage computations were not established as part of the methodological mechanics of this study. Extrapolations from the estimated time physical therapists directly spent with the child suggest a similar infrequency of parent-focused intervention.

Also similar to the present study, Brady et al. (2004) videotaped 15 families of young children with developmental delays and the primary early interventionists who had invited the parent participants from their caseload. Like the previously discussed study by McBride and Peterson (1997), Brady et al. (2004) showed that $95 \%$ of professional statements were about the child. Both studies add validation 
evidence to present study findings. The coaching model advocated by Hanft et al. (2004) provides a significant framework from which to generate a practice paradigm shift. This study added a perspective lens that would suggest model adaptation to include parallel personnel preparation in terms of adult teaching and learning and motor learning theories specifically applied to parental learning that would bridge the linkage void seemingly preventing transition to more familycentered interventions.

\section{Model Adaptation and Implementation}

Exploring a family-centered focus within the pediatric physical therapy profession rather than merely extrapolating from studies of early child special educator interventions for young children with disabilities is imperative to establishing physical therapy professional preparation education implications. Practice based on research (evidence-based practice) is shifting the traditional paradigm of professionally centered model (so-called experts) that has long emphasized remediation of a child's deficits to a family-centered paradigm that enhances parental competency. As such, recommendations for including adult learning theory, illustrating the oft unidentified parental learner of pediatric intervention by linking current research not routinely found in PT literature, and reinforcing practice application of motor learning theory strategies to parents as well as children with motor dysfunction may facilitate transition.

Notations made from 16 videotapes of the four participating pediatric physical therapists suggest that these convenience-selected professionals continue 
to work directly with the child not having made the transition. Furthermore it may be indicative of professionals not knowing, not interested, or not yet having developed strong, effective coaching, in other words not adult learning centered. As such, there is ample room for professionals, specifically pediatric physical therapists to improve in the realm of adult teaching-learning centered strategies. If therapists and other early intervention professionals had a working comprehension in particular of the constructivist theory of teaching and learning, parental learning would be enhanced because interventions would be learner directed according to the constructed meaning initiated by parents. Supporting parents in what will make a difference to them creates a stronger "buy in" that will ultimately eliminate professional dependency and enhance family empowerment.

Therapists more consistently including parents in the identification of functional goals for their child in the home environment would be an example of improvement. Darrah, Law, and Pollock (2001) are proponents of this familycentered approach following a pilot study that stipulated parents be included in the decision-making of functional goals for their children. This was not evident in the current study by means of limited interview questions because this was not the study focus, nor by the observed interactions. Additional improvement could be realized by therapists continuing to inform their practice via evidence-based research that is countering such intervention techniques such as neurodevelopmental treatment that emphasize child-directed intervention sans task and environment considerations. Darrah et al. concluded that when they present the 
family-centered functional approach, clinicians often misinterpret the framework to mean no treatment. It appears as though therapists have difficulty in viewing their value as a parental coach, especially given that it was hardly observed in this study.

Another improvement that should be pursued is the collaborative nature of adult teaching and learning. This can be viewed in the context of Freire's (2000) problem-posing versus banking approach to the teacher-learner relationship. In the banking approach the teacher determines goals; the teacher talks and students listen; and the teacher is knowledgeable, imparting knowledge while students are ignorant and receive knowledge. Contrasting this is the problem-posing approach whereby learners determine goals; learners apply the knowledge and skills relatively early in the process; coach and learner discuss issues; direction of future sessions are jointly decided upon; and the process generates new avenues. Meade (1998) described an interview process that encourages parent-directed approach. This process encourages therapists to discontinue their assessment mode of practice that focuses on identification of deficits and replace it with active listening as to what the parent/family wants to see happen in the context of their home and life. Such an approach would also generate improvement towards a more adult learner paradigm similar to the problem-posing approach generated by Freire. The pursuit of collaborative nature is also reflective of the constructive structure expounded by Dewey, Piaget, and Vygotsky (Phillips \& Soltis, 1998). Generating learning goals and objectives from an interview process at the initiation of a therapeutic 
partnership and periodically thereafter, a constructive structure that is responsive to the needs and desires of the parent and family learners is fostered. It encourages and empowers parents to explore their family context environments rather than the artificial environment of a therapy clinic office or school setting. These other environments should not be ignored, but rather receive less priority from a therapist perspective, especially at commencement of therapy services. Constructivism further supports guiding learners towards reaching their full potential, in this case parents gaining competence through skilled therapist coaching. Pairing such informative knowledge within the coaching model, specifically the initiation and reflection phases could give more credence to value of coaching parents in the context providing early intervention.

\section{Potential Barriers}

Given this was an initial exploration of current practice, none of the therapist participants had been provided information or resources regarding familycentered models of intervention or coaching concepts from the investigator prior to study initiation. The investigator was not surprised when one therapist participant seemed baffled when asked what extent of continuing education regarding adult learning theory she had. The bulk of literature revolving around family-centered models is typically under the rubric of education, early intervention, and special education. It is unknown how common a source of reference this is especially for non-education environment service providers. 
Interestingly, therapists' interview responses suggest their valuation of parents performing home programs and physical management follow-through. However, therapists' actions appeared to be negligibly supportive of making such activities successful in terms of applying motor learning theory to instructing parents in physical handling techniques. Unknown is what effect differences on children's motor development would be if motor learning theories were applied to parent's motor learning of handling skills. Even though therapists could potentially presume that having parents present and therefore subsuming attentive observation of therapist handling, there was minimal concurrent discussion/instruction of what they were doing while modeling/demonstrating from a motor learning context. Thus, queries of where, how, how much, frequency, in what context, and so forth leaves the onus on parents to ask specific questions. If parents were not intrinsically assertive, nor guided to be so, they could easily become stagnated in Perry's (1981) suggested first adult cognitive position of dualism where the therapist "authority" is the keeper of all knowledge. Applying a constructivist philosophy, building on what has meaning for individual families, should result in a transition from dualism to relativism where parents are empowered to make their own meaning as they gain competence and confidence. Perry's later stage of commitment within relativism will be recognized as parents make their own decisions and choices as how to proceed regarding their children's and families development and activity as a family unit rather than a medical, impairment entity. Therapists' reluctance, ignorance, discomfort, or child-focus preference may be 
reasons for not transitioning to a more family-centered model. Since the private practice environment is dependent upon third party reimbursement, the element of billing codes that are interpreted as likely to decline parent education as a billable service may be an additional deterrent. However, to not transition runs a high risk of supporting/sustaining parents' stagnation in the dualism position with potential negatively affecting children.

Parents in this position are likely to initially seek a child-related focus, after all, it is the child who presents with deficits that need remediating, especially in a more traditional medical model of service delivery. McWilliam, Tocci, and Harbin (1995) have acknowledged that families report being quite pleased with childfocused interventions. We have become a society where one takes what is "broken" to the "repair person" and then everything will be good again. Even the professional title pediatric physical therapist connotes professional attention toward the child. In an Australian study by Litchfield and MacDougall (2002), 10 physiotherapists serving children with disabilities were interviewed to gain insight regarding family-centered philosophy the reported findings included therapists feeling an exclusive family-centered model could invalidate their professional knowledge and skills. Additionally, these therapists felt that many parents desire and expect professionals to direct parental decision-making on behalf of the child. Hinojosa (1990) and a discussion with an occupational therapist colleague point out that care must be taken not to have parents think that they are to assume a therapist role. 
Another explanation for the apparent child-focused emphasis may stem from the physical therapy higher education curriculum preparation that is scant in adult learning theory, family-centered models, and parent-professional collaborative skills. Viewing the parent as the predominant client/recipient of a pediatric physical therapy intervention seems counterintuitive at face value. However, despite research promoting family-centered service and common sense acknowledgement that parents are with children more than any group of professionals, transition to a parent-coaching model appears to be slow and resistant.

Other potential barriers to a parent-centered intervention model via coaching in tandem with adult and motor learning were certainly identified by the study participants. These included inhibitors such as parents being tired, parent not present, logistic and financial competing factors, and need for parent to parent networking. In light of these noted inhibitory barriers, it is difficult to determine if a coaching model demands too much of the learning partners. Another may be that therapists can only go so far without parental involvement thus necessitating therapists to recognize, clarify, and encourage the parental role of a collaborative learner early on. Another potential barrier is resistance by physical therapists to view their role as a parent coach given that many professionals enter pediatric practice environments because they want to work with children.

Following completion of data collection, a conversation with a former private practice pediatric therapist colleague not involved with this study reflected 
this resistance. When presented with the premise that pediatric therapists should consider and develop their coaching/teaching of parent skills, this colleague countered with "perhaps in school district service delivery, but not in private practice." She offered the analogy of, if a parent desired her child learn to play the piano, one would not give the parent the piano lessons. In other words, she was imparting that therapists' well-honed handling skills should be imparted directly to the child. Viewpoints such as this can be problematic within the profession if, as suspected, they are widely shared. Litchfield and MacDougall (2002) reported expressions of career dilemma concerns such as losing "hands-on" physiotherapy skills as a result of lessened daily practice as a result of family-centered practice. This view could be countered with the analogy of the child being the piano and parents the recipients of the piano lesson regardless of practice settings. Parents will learn "to play" as they are appropriately and supportively coached to physical manage their child "the piano" on a daily basis in environments of family choice. This further recognizes the natural environments of where, how, and when families live their daily lives. Perhaps the very nature of private practice and billing third party payers, disallows or at best discourages and/or diminishes the value of parental coaching. However, continuing to be a direct provider regardless of practice setting negates a constructivist model and evidenced-based literature to the contrary. Despite examples of resistance and numerous potential barriers that would inhibit transition to more responsive family-centered service delivery, hints of interested positive support are affirming. 
Additional External Corroboration

A subsequent conversation with therapist participant Carol suggested that findings from this research could be potential impetus for current practitioners to "buy into" a coaching emphasis shift from a dominant child-centered intervention emphasis. This particular participant had the most post PT degree education, especially in motor learning theory and was also providing PT service in the home environment. Her willingness to discuss the possibility of altering her style of approach could stem from her more extensive formal knowledge base beyond child and pathology content. Carol shared an example of her interactions with a family not involved in this study where the father has been the primary parent present during PT sessions. Evidently this father watches Carol in an activity, then selfinitiates his own trial by stating, "let me try it." This discussion gives pause as to whether this is a result of gender-related, learning theory, or merely an isolated individual difference. Given that this was an isolated recollection and not part of the data collection, it becomes germane for future inquiries that specifically select parental gender comparisons as a study purpose.

As Carol listened to my formative study analysis comments regarding the dearth of direct parent coaching/instruction observations, she contemplated how this particular father had been more directive than other parents with whom she worked. Her inquisitive facial expression reflected her recognition of his selfevaluation when he began a particular session by informing her what had worked for him and his child during the previous week. Carol proceeded to think aloud as 
to how she might encourage such involvement with other parents she with whom she works. This was not dissimilar to Barb, who noted during the follow-up interview from the series of questions, that she could consider having the parents demonstrate their handling for her to observe and evaluate. As she spoke of the potential benefits of using more parent coaching, Carol did broach the complexity that each family unit "brings to the table." The multiple layers of parents' learning styles, their emotional, intellectual, and social affordance, their comprehension of their child's disability, the extent of the child's disability, the child's personality, the generic environmental forces, and the therapist's own knowledge, skill, and emotional contexts create a most challenging learning and teaching opportunity. Such complexities suggest a definitive need for recommending provision for professional preparation opportunities that designate coaching elements in tandem with adult and motor learning theories in collaboration with a professional-parent focus that will meld with child-focused efforts. Potential venues for the above would range from preservice and inservice continuing education. Anticipating therapist resistance as speculated from the aforementioned barriers, enticing therapist attention would be challenging to say the least. Shifting the paradigm from child to family-centered will be arduous given the slow path already traveled according to the literature review presented. A preservice presentation of this paradigm, model, and theories, prior to therapists establishing a pattern of childcentered, may be the logical approach. However it comes with its own barriers 
mentioned previously, competing educational competencies and practice demands that position pediatric PT as a small entity in the practice recruitment arena.

An additional conversation regarding the findings of this study was made with Vickie Meade, MPH, PT at a recently attended professional continuing education program. Her presentation emphasized professional/parent collaboration with a strong focus of following parental leads, improving interpersonal communication and relationships, and attending to infant and parental behaviors. She shared a number of videotapes of her interventions of young children with disabilities and their families. The prominent parent was the mother. What was quite informative was the total absence of footage that showed her, the PT, handling the child. The physical therapist audience participants commented numerous times regarding their recognition of not seeing PT handling. The participants' comments and queries reinforced this study's premise that parent teaching, or more appropriately labeled coaching, is not an established intervention strategy. Additionally, the audience was quite intrigued by the once a month frequency that Meade routinely schedules as compared to their more typical weekly visits. Meade shared that she has found parents taking on more ownership of the goals when they have to problem-solve over the extended time frame, sometimes two or three months due to geographical constraints. This fortuitous continuing education program provided an informal support to this investigator's research and further established the need for similar continuing education programs and 
mentorship support of developing family-centered strategies that incorporate adult and motor learning theories.

\section{A Holistic Model}

This initial explorative inquiry demonstrated the paucity of parent coaching in the delivery of pediatric physical therapy to young children with cerebral palsy and their mothers in a limited cohort of private practice providers. Despite using a select and small group of therapists, the overall findings were comparable to studies by McBride and Peterson (1997), Brady et al. (2004), and McWilliam, Tocci, and Harbin (1995). Similarity of participants in these studies supports generalization for the current study.

The process of coaching appears to be relatively new amongst pediatric physical therapist practitioners as evidenced by limited research, use of this terminology, and absence of practical application as found in this study. Publication of Hanft et al. (2004) is recent enough that this intervention model is not likely to have percolated to most practitioners. Given that physical therapist Meade continues to be invited to present nationally on the topic of family-centered is encouraging. What she acknowledges and what is missing in the Hanft et al. coaching model is the formal linkage to adult learning theory and practical application of motor learning directed to the parent learning rather than the "patient" who has been the commonly accepted recipient of service intervention. A more holistic model that emerges from the findings of this study is the need to recognize and value the parent learner within the context of early intervention. 
This recognition can permeate to other learners as well, that would include the teachers (general and special education), educational assistants, other early intervention professionals, and other care providers a child may have. Application of a more holistic model can also be beneficial to other patient populations where caregiver support and participation exists. Improved understanding of the adult learner styles, capacity, and need of the parents who physical therapists are equally responsible to in providing therapy intervention can only enhance efficacy. In turn, addressing parental learning should ultimately impact the development of the children who are the initial impetus for collaborative, constructive learning experience.

\section{Limitations}

The scope of this work was limited to the private practice environment. Given that children with motor disabilities and their families are served in other service settings demands a need for further and more inclusive investigation. As a qualitative study, this inquiry had some success in examining the "what, how, when, and where" of early intervention in a limited convenience sample of four private practitioners (Berg, 2001). The nature of qualitative inquiry accepts the limited sampling, as compared to quantitative work, by emphasizing the natural contextual richness that would be otherwise lost (Cresswell, 1998; Mellion \& Tovin, 2002). This limitation, though of some concern, is common as previous works used similarly small study populations (Brady et al, 2004; Case-Smith \& Nastro, 1993; McBride \& Peterson, 1997; Washington \& Schwartz, 1996). 
This study is limited in its capacity to generalize to families of color, to fathers, and to children with motor dysfunction other than cerebral palsy. Ethnic and racial diversity, as well as gender, should not be overlooked and would offer yet another dimension to future investigations. Measurement of maternal learning of physical handling skills was nebulous as interview questions merely required self-reporting of occurrence but not descriptive or demonstration of the same. Despite the study's focus on observing and qualitatively measuring professionalparent interactions, it was challenging to ignore professional-child interactions that are equally demanding. Though the investigator's personal paradigm transition from a child-centered to a family-centered was the impetus for embarkation of doctoral study, quality professional-child interactions are also important from the standpoint of child learning. In some instances the application of motor learning and problem-posing learning possibilities from the child's perspective appeared to be ignored. Given that the seasoned therapist study participants completed their PT education long before family-centered information and motor learning theory were introduced in PT curricula, this is recognized as a significant study limitation.

The focus of this study was on the professional-to-parent learning relationship. Potentially, greater familiarity with family-centered and motor and adult learning theory literature paired with college teaching experience positioned the investigator in a different frame than the study participants. More recently graduated physical therapists providing pediatric physical therapy may provide a completely different picture if in fact motor learning and adult learning theories as 
well as family-centered concepts are being imbedded in current physical therapy preparation educational programs. As an observer, with the aforementioned information base, objective observations were not able to discriminate if therapist participants were applying adult and motor learning theories to the parent participants. The investigator is mindful of the multilayered complexities of providing physical therapy intervention in terms of child, task, and environment, as well as broader cultural contexts that include family and health care.

This study, as an explorative pilot, did not extensively delve into the therapist participants' theoretical knowledge base of adult and motor learning, or comprehension of family-centered intervention. Nor did it examine in any significant detail the parent participants' interactions with their respective children outside of the immediate therapy sessions. These points further the limitations of generalization of the study findings, but do suggest future directions.

Future Studies

Future studies are indicated that could explore parent-coaching existence in school delivered early intervention where there is a greater likelihood commensurate with the more consultative model in this practice setting. In school delivery settings, coaching of non-parent learners such as educators, special education educators, and educational assistants is yet another thread of exploring this untapped PT role. As the therapist participants in this study were a chronologically older and more "seasoned" group, exploring the practice of more 
recently graduated therapists could address and reflect differences as a result of current professional preparation.

Surveys of pediatric therapists, both physical and occupational, regarding awareness and comprehension of family-centered intervention appear to be needed. Such inquiries could include questions regarding sources of information and what research is read and attended to. Surveys of both clinical and didactic instructors' knowledge of and their inclusion of adult development and learning, teaching/coaching skills, and family-centered practice to physical therapy students could provide greater insight as to the extent of paradigm transition. Clinical instructors have a unique opportunity to demonstrate and model coaching to student interns. Since this may be an opportune entrance for developing family-centered practice, a qualitative study that explores (a) clinical instructors' coaching practice with parents and (b) teaching parent coaching with PT students would be most informative. Findings could guide and/or facilitate improved clinical preparation of the entry-level PT student. Research whereby therapists are observed pre and post a "coaching model" continuing education program could further inform direction of personnel preparation.

\section{Recommendations}

Recommendations beyond encouraging future research as stated earlier could include academic centers or professional organizations offering local, state, and national continuing education programs regarding formal coaching. Various appropriate agencies could be identified to consult with practitioners who may not 
yet be aware of research evidence. A new practice niche could emerge for an aspiring entrepreneur to mentor and consult practitioners in developing familycentered practice. Institutes of higher education may be cajoled into incorporating adult learning theory across the PT curriculum and also be a source of information to community practitioners. Uitimately, changes through a successful paradigm shift from child-centered to family-centered could benefit children with disabilities, assist families in being less dependent upon professionals, assist parents in self assessing their skills, and facilitate parents' ability to identify what is relevant for their individual family.

This study, intended as an initial exploration of parent coaching under the auspices of family-centered intervention in pediatric physical therapy practice, only begins to crack the door of current practice. Knocking at the transition door whereby service focuses on enhancing an adult's competence, rather than childcentered/professional directed, is not yet loud or extensive enough to have been heard. Ongoing research, developing educational modules on parent coaching skill development, and implementing the same lies ahead. To not ask the question, as individual therapists or as a profession, "is pediatric physical therapy intervention of infants and young children with motor dysfunction and their families truly enhancing a parent or colleague's competence?" is potentially ignoring our greatest tool to impact change.

The complex nature of servicing young children with disabilities and their families regardless of environment demands attention to appropriately preparing 
future professionals as well as building skills of current practitioners. The complexities of serving two clients (parent and child) simultaneously while attending to their respective learning abilities and the social, emotional, and environmental contexts are considerable and thus challenging for imbedding into entry-level graduate programs. Though physical therapy preparatory education has moved to a professional doctorate level, pediatric content continues to be considered a specialization that is not afforded adequate attention at the entry-level. Mechanisms must be put to action to ameliorate this inadequacy that might include soliciting demands from practitioners to increase pediatric content.

Major competing forces are the abundant employment opportunities and demand for therapists in outpatient orthopedic (higher salaries) and skilled nursing/home health agencies (aging population growth) that will and do draw more interest and job potential than a pediatric work environment. As difficult as it is to accept, another competing force that restricts practice change may be that pediatric practice, especially in school settings and thus early intervention, is more attractive to women as a supporting salary to augment their own young family scheduling with continuing education less of a priority. Many pediatric therapists state that they do not belong to professional organizations or attend professional continuing education offerings due to cost. Until such time that continuing education is required for licensure, the likelihood of research-to-practice transition will be limited. Addressing these specific barriers to changing practice therefore has to be even more creative and attractive to entice practitioners. In a recent 
conversation with the current president of the Oregon Physical Therapy Association, continued education requirement for licensure is likely to pass with the present state legislative session. Making the continuing education courses for members at a significantly reduced cost may encourage therapists to join their state and national associations, which in turn could increase the number of participants at educational offerings regarding family-centered service with a holistic approach. Membership, in particular additional Section on Pediatric membership through the American Physical Therapy Association (APTA) would accord the member the Pediatric Physical Therapy journal with applicable research reporting.

Simply accepting that specialization in pediatrics be acquired post entrylevel matriculation is frustrating; however, it seems to be a reality. Continuing education unit credits are available on a limited basis and as mentioned above are not yet mandated. As study participant Donna stated, "school preparation should almost include a social work component in order to successfully coach and empower parents as to what is important in the lifelong management of their children." Unfortunately, academic programs' ability to do so fiscally or programmatically appears to be the exception. Brown et al. (1997) challenged educators to explore how they can embed new content into existing content in already full curricula. Though the role of physical therapists across practice arenas and patient populations requires more "teaching/instructing" by the therapists, it is doubtful that academic programs will create opportunities for this content given the already burgeoning competency content requirements, especially as it specifically 
applies to pediatric practice. Approaching this challenge in the clinical internship component of entry-level preparation would offer a potential though partial solution.

How much such content can be or is currently imbedded within clinical internships is not known. Investigative inquiries of pediatric physical therapy clinical instructors that specifically address parent coaching do not exist. The expectation of pediatric PT employers is that the practitioner will be well skilled in all areas of service delivery, however, family-centered practice paradigms may not be well established in sites of supervised internships. Though skills, such as parent coaching presumably could be acquired over time and with experience, the findings of this study suggest that experience alone does not assure such expertise. Consequently, these findings indicate a need to create continuing education opportunities that specifically focus on coaching in tandem with adult and motor learning theories with a strong component of application and the role delineation coach and learner/therapist and parent in a collaborative and reciprocal manner. Continuing education offerings from professional association as well as schools of physical therapy are two examples of information could be distributed.

Moving from the strongly established traditional service approach that is professional-centered will be slow (Litchfield \& MacDougall, 2002). Applying research evidence to practice is arduous and often disruptive to established practice comfort zones. Hanft et al. (2004) stated that the process for moving from a traditional service model to a coaching model includes that the early childhood 
practitioners identify their role as a coach and that parents and family members be identified as the primary learners. Attitudinal changes of the practitioners who typically embark on pediatric practice because they want to work with children will most likely be gradual. Perhaps initiating introductory comments in higher education preparatory programs can begin to implement this important paradigm shift for entry-level graduates of physical therapy. Reinforcement can be generated at internship opportunities and through ongoing continuing education for clinical educators, and especially in post entry-level graduate programs that specialize in pediatrics. Study findings suggest a paucity of adult learning theory application. Providing inservice opportunities to the clinical internship instructors, especially in pediatric practices, that emphasized adult learning as it applies to parent participation and learning could be beneficial. Unfortunately, practitioners appear to more likely seek continuing education topics that build upon their child-centered practice as evidenced by only 10 physical therapists and one PT student attending the Meade workshop on working with families. The propensity of child-centered topic responses to "what future programs would you desire professional organizations to sponsor" is yet another indication of lack of awareness and/or interest. The fact that one current PT student and two recent graduates attended the course may suggest a shift, though it was the only pediatric topic on the program.

A recent flyer announced a new training program in pediatric physical therapy clinical skills. Of the six topics offered in this specialized training program, all were focused on the child. Most focused on the pathology and 
subsequent impairments that ensue. The absence of family-centered and adult learning subjects demonstrates a necessity to communicate to appropriate partners the negative impact of this negligence. As therapist participant Donna stated in her interview, pediatric practice preparation needs to include an element of social work. A final therapist directed interview question asked if teaching and learning theories should be emphasized in either the didactic or internship environments of PT entry level preparation. All four therapists affirmed the importance of teaching and learning theories in the classroom. Consensus was present for reinforcement of these concepts in student internship experiences as well. One PT indicated the value of these concepts across the age spectrum of PT patient populations, while another stated that modeling concepts in a clinical setting would be invaluable. More in depth research, specifically relevant to pediatric physical therapy practice, is yet another means to acquire and disseminate these concepts to practitioners so they may provide quality service.

\section{Conclusion}

In conclusion, findings indicated minimal paradigm shift from childcentered to parent-centered intervention on the part of selected private practice pediatric physical therapists. Physical therapists' adult learning theory knowledge was negligible. Concepts of motor learning theory were somewhat limited and except for one PT were not applied to maternal handling skill acquisition. The bulk of interventions was directed in the observation/action phase of coaching as described by Hanft et al. (2004). However, as noted and reported, most of the 
examples were tangentially directed to the participant mothers as therapists described what and how the children were or were not doing. Initiation, reflection, and evaluation phases of coaching were less apparent, especially evaluation of the coaching process. The limited initiation and reflection opportunities really emphasized the lack of constructivist paradigm for potential parental learning. This would be expected since parental coaching was not the emphasis of the majority of sessions observed. Absence of ethnicity and gender diversity between therapists and mothers negated attention to this framework of inquiry. Consequently these frameworks should be considered in future studies with attempts to seek such subject dyads. These findings urge other directions of inquiry as well.

Despite being an initial descriptive exploration, this study suggests that pediatric physical therapists are not yet directing their skills to the parents of young children with motor dysfunction. It further suggests that lack of theoretical knowledge and a preference for child-centered focus may be stifling development of an adult-centered approach while providing interventions. A wide chasm appears to exist between practice and research. Construction of a much-needed educational bridge may be hampered by lack of support and interest at higher education preparation programs, practitioner interest, advanced practice educational opportunities, and/or enthusiastic informed mentors. Until competence of a parent or colleague is viewed as the actual agent of change in early intervention and the concomitant personnel preparation responds to this curricular content need, therapists are likely to continue with the status quo of directly serving infants and 
young children with motor dysfunction. Simultaneously, such a status quo stance creates a parental dependency need on the therapist rather than instilling family generated problem solving that enhances family functioning in natural environments of their choosing. Though it will continue to face a very steep uphill campaign, perseverance of developing and disseminating a coaching model integrated with adult teaching and motor learning theories is necessary for practitioners to become competent adult learner change agents as evidenced by research. Accomplishing such a transition will facilitate parents of children with movement dysfunction gaining confidence and competency as the agents of change for their children's development. This strongly links parent coaching to child outcomes. 


\section{REFERENCES}

Bailey, D., McWilliam, R., Darkes, L., Hebbeler, K., Simeonsson, R., Spiker,D., \& Wagner, M. (1998). Family outcomes in early intervention: A framework for program evaluation and efficacy research. Exceptional Children, 64, 313-328.

Belenky, M., Clinchy, B., Goldberger, N., \& Tarule, J. (1986). Women's ways of knowing. New York: Basic Books.

Berg, G. (2001). Qualitative research methods for the social sciences. Boston: Allyn and Bacon.

Bilken, B. (1992). Qualitative research for education: An introduction to theory and methods. Boston: Allyn and Bacon.

Brady, S., Peters, D., Gamel-McCormick, M., \& Venuto, N. (2004). Types and patterns of professional-family talk in home-based early intervention. Journal of Early Intervention, 26 (2), 146-159.

Bronfenbrenner, U. (1995). Developmental ecology through space and time: A future perspective. In P. Moen, G. Elder, \& K. Luscher (Eds.), Examining lives in context: Perspective on the ecology of human development (pp. 619-647). Washington, DC: American Psychological Association.

Brown, S., Humphry, R., \& Taylor, E. (1997). A model of the nature of familytherapist relationships: Implications for education. American Journal of Occupational Therapy, 5I (7), 597-603.

Case-Smith, J., \& Nastro, M. (1993). The effect of occupational therapy intervention on mothers of children with cerebral palsy. American Journal of Occupational Therapy, 7(9), 811-817.

Chiarello, L., Effgen, S., \& Levinson, M. (1992). Parent-professional partnership in evaluation and development of individualized family service plans. Pediatric Physical Therapy, 4 (2), 64-69.

Cochran, C., Farley, B., \& Wilhelm, I. (1990). Preparation of physical therapists to work with handicapped infants and their families: Current status and training needs. Physical Therapy, 70, 372-380. 
Cresswell, J. (1994). Research design: Qualitative and quantitative approaches. Thousand Oaks: Sage Publications.

Cresswell, J. (1998). Qualitative inquiry and research design. Thousand Oaks: Sage Publications.

Danseco, E. (1997). Parental beliefs on childhood disability: Insight on culture, child development and intervention. International Journal of Disability, Development, and Education, 44 (1), 41-53.

Darrah, J., Law, M., \& Pollock, N. (2001). Family-centered functional therapychoice for children with motor dysfunction. Infants and Young Children, 13(4), 79-87.

Dinnebeil, L. (1999). Defining parent education in early intervention Topics in Early Childhood Special Education, 19 (3), 161-164.

Dunn, W., Brown, C., \& McGuin, A. (1994). The ecology of human performance: A framework for considering the effect of context. The American Journal of Occupational Therapy, 4(7), 595-607.

Dunst, C., Johanson, C., Trivette, C., \& Hamby, D. (1991). Family-oriented early intervention policies and practices: Family-centered or not? Exceptional Children, 58 (2), 115-126.

Education of All Handicapped Children Act, PL 94-142 (1975).

Education of All Handicapped Children Act amendments, PL 99-457 (1986).

Effgen, S., Bjornson, K., \& Chiarello, L. (1991). Competencies in physical therapists in early intervention. Pediatric Physical Therapy, 3 (2), 77-80.

Effgen, S., \& Chiarello, L. (2000). Physical therapist education for service in early intervention. Infants and Young Children, 12 (4), 63-76.

Eicher, P., \& Batshaw, M. (1993). Cerebral palsy. Pediatric Clinics of North America, 40 (3), 537-551.

Eisner, E. (1991). The enlightened eye: Qualitative inquiry and the enhancement of educational practice. New York: Macmillan Publishing Company.

Filer, J., \& Mahoney, G. (1996). Collaboration between families and early intervention service providers. Infants and Young Children, 9 (2), 22-30. 
Freire, P. (2000). Pedagogy of the oppressed. New York: Continuum.

Gentile, A. (2000). Skill acquisition: Action, movement, and neuromotor processes. In J. Carr, \& R. Shepherd (Eds.), Movement science: Foundations for physical therapy in rehabilitation (pp.111-188). Gaithersburg, MD: Aspen Publishers.

Goldberger, N., Tarule, J., Clinchy, B., \& Belenky, M. (1996). Knowledge, difference, and power. New York: Basic Books.

Gordon, J. (2000). Assumptions underlying physical therapy intervention: Theoretical and historical perspectives. In J. Carr \& R. Shepherd (Eds.), Movement science: Foundations for physical therapy in rehabilitation (pp. 1-32). Gaithersburg, MD: Aspen Publishers.

Gordon, S. Benner, P., \& Noddings, N. (Eds.). (1996). Caregiving. Philadelphia: University of Pennsylvania Press.

Hanft, B., \& Pilkington, K. (2000). Therapy in natural environments: The means or end goal for early intervention? Infants and Young Children, 12 (4), 1-13.

Hanft, B., Rush, D., \& Shelden, M. (2004) Coaching families and colleagues in early childhood. Baltimore: Paul H. Brookes.

Hanson, M., \& Lynch, E. (1990). Honoring the cultural diversity of families when gathering data. Topics in Early Childhood Special Education, 10 (1), 112132.

Harry, B., \& Kalyanpur, M. (1994). Cultural underpinnings of special education: Implication for professional interactions with culturally diverse families. Disability and Society, 9 (2), 145-165.

Hinojosa, J. (1990). How mothers of preschool children with cerebral palsy perceive occupational and physical therapists and their influence on family life. The Occupational Therapy Journal of Research, 10 (3), 145-162.

Horak, F. (1991). Assumptions underlying motor control for neurologic rehabilitation. In Lester, M. (Ed.), Contemporary management of motor control problems. (pp. 11-28). Fredericksburg, VA: Bookcrafters.

Individuals with Disabilities Education Act, PL 105-17, (1997) 
Iversen, M., Shimmel, J., Ciacera, S., \& Prabhakar, M. (2003). Creating a family-centered approach to early intervention services: Perceptions of parents and professionals. Pediatric Physical Therapy, 15 (1), 23-31.

Keene, B. (1990, March 15). The Family Circus. Oregonian.

Kelly, J., \& Barnard, K. (1999). Parent education within a relationship-focused model. Topics in Early Childhood Special Education, 19 (3), 151-156.

Ketelaar, M., Vermeer, A., Helders, P., \& Hart, H. (1998). Parental participation in intervention programs for children with cerebral palsy: A review of research. Topics in Early Childhood Special Education, 18 (2), 108-117.

Kolobe, T., Sparling, J., \& Daniels, L. (2000). Family-centered intervention. In S. Campbell, D. Vander Linden, \& R. Palisano. (Eds.), Physical therapy for children (pp. 881-907). Philadelphia: W. B. Saunders.

Kubler-Ross, E. (1969). On death and dying. New York: Macmillan.

Leonard, V. (1996). Mothering as a practice. In S. Gordon, P. Benner, \& N. Noddings (Eds.), Caregiving (pp.124-140). Philadelphia: University of Pennsylvania Press.

Levinson, D. (1980). Toward a conception of adult life. In N. Smelse \& E. Erickson (Eds.), Themes of work and love in adulthood (pp. 265-290) Cambridge, England: Cambridge University Press.

Litchfield, R., \& MacDougall, C. (2002). Professional issues for physiotherapists in family-centered and community-based settings. Australian Journal of Physiotherapy, 48 (2), 105-112.

Mahoney, G., Kaiser, Al, Giorlametto, L., MacDonald, J., Tobinson, C., Safford, P., \& Spiker, D. (1999). Parent education in early intervention: A call for a renewed focus. Topics in Early Childhood Special Education, 19 (3), 131 141.

Mahoney, G., Robinson, C., \& Perales, F. (2004). Early intervention: The need for new treatment paradigms. Infants and Young Children, 17 (4), 291-300.

Mahoney, G., \& Wheeden, C. (1997). Parent-child interaction: A foundation for family-centered early intervention practice. Topics in Early Childhood Special Education, 17 (2), 165-184. 
Marcus, B., Swanson, V., \& Vollmer, T. (2001). Effects of parent training on parent and child behavior using procedures based on functional analyses. Behavioral Interventions, $16(2), 87-104$.

Masin, H. (1995). Perceived maternal knowledge and attitudes toward physical therapy during early intervention in Cuban-American and AfricanAmerican families. Pediatric Physical Therapy, 7 (3), 118-123.

McBride, S. \& Peterson, C., (1997). Home-based early intervention with families of children with disabilities: Who is doing what? Topics in Early Childhood Special Education, 17, 209-233.

McCollum, J. (1999). Parent education: What we mean and what that means. Topics in Early Childhood Special Education, 19 (3), 147-149.

McCollum, J., Gooler, F., Appl, D., \& Yates, T. (2001). PIWI: Enhancing parentchild interaction as a foundation for early intervention. Infants and Young Children, 14 (1), 34-45.

McCollum, J., Ree, Y., \& Chen, Y. (2000). Interpreting parent-infant interactions: Cross-cultural lessons. Infants and Young Children, 12 (4), 22-33.

McEwen, I., \& Shelden, M. (1995). Pediatric therapy in the 1990s: The demise of the educational versus medical dichotomy. Physical and Occupational Therapy in Pediatrics, 15 (2), 33-45.

McWilliam, R., Ferguson, A., Harbin, G., Porter, P., Munn, D., \& Vandiviere, P. (1998). The family-centeredness of individualized family service plans. Topics in Early Childhood Special Education, 18 (2), 69-82.

McWilliam, R. Tocci, L., \& Harbin, G. (1995). Family-centered services: Service providers' discourse and behavior. Topics in Early Childhood Special Education, 18 (4), 206-221.

Meade, V. (1998). Partners in movement: A family-centered approach to pediatric kinesiology. San Antonio, TX: Therapy Skill Builders.

Mellion, L., \& Tovin, M. (2002). Grounded theory: A qualitative research methodology for physical therapy. Physiotherapy Theory and Practice, 18, (3), $109-120$.

Merriam, S., \& Caffarella, R. (1999). Learning in adulthood. San Francisco: Jossey-Bass. 
Noddings, N. (1996). The caring professional. In S. Gordon, P. Benner, \& N. Noddings. (Eds.) Caregiving (pp. 160-172). Philadelphia: University of Pennsylvania Press.

Olney, S., \& Wright, M. (2001). Cerebral palsy. In S. Campbell, D. Vander Linden, \& R. Palisano. (Eds.) Physical therapy for children (pp. 533-570). Philadelphia: W. B. Saunders.

O'Neil, M., \& Palisano, R. (2000). Attitudes toward family-centered care and clinical decision making in early intervention among physical therapists. Pediatric Physical Therapy, 12 (4), 173-182.

Palisano, R. (1994). Pediatric physical therapy: An individual perspective. Pediatric Physical Therapy, 6 (3)140-141.

Palisano, R., Rosenbaum, P., Walter, S., Russell D., Wood, E., \& Galuppi, B. (1997). Development and reliability of a system to classify gross motor function of children with cerebral palsy. Developmental Medicine and Child Neurology, 39, 214-223.

Perry, W. (1981). Cognitive and ethical growth: The making of meaning. In A. Chickering. (Ed.), The modern American college (pp. 76-116). San Francisco: Jossey-Bass.

Phillips, D., \& Soltis, J. (1998). Perspectives on learning. New York: Teachers College Press.

Piggot, J., Hocking, C., \& Paterson, J. (2003). Parental adjustment to having a child with cerebral palsy and participation in home therapy programs. Physical and Occupational Therapy in Pediatrics, 23(4), 5-29.

Robertson, D. (1998). Developmental phases. In Self-directed growth (pp. 57-71). Munci, IN: Accelerated Development.

Rush, D., Shelden, M., \& Hanft, B. (2003). Coaching families and colleagues: A process for collaboration in natural settings. Infants and Young Children, $16(1), 33-47$.

Schmidt, R, \& Lee, T. (1999). Motor control and learning: A behavioral emphasis. Champaign, IL: Human Kinetics

Schreiber, J., Effgen, S., \& Palisano, R. (1995). Effectiveness of parental collaboration on compliance with a home program. Pediatric PhysicalTherapy, 7 (2), 59-64. 
Seideman, R., \& Kleine, P. (1995). A theory of transformed parenting: Parenting a child with developmental delay/mental retardation. Nursing Research, $44(1), 38-44$.

Tennant, M., \& Pogson, P. (1995). Learning and change in the adult years. San Francisco: Jossey-Bass.

Turnbull, A., Blue-Banning, M., Turbiville, V., \& Park, J. (1999). From parent education to partnership education: A call for a transformed focus. Topics in Early Childhood Special Education, 19 (3), 164-172.

Washington, K., \& Schwartz, I. (1996). Maternal perceptions of the effects of physical therapy services on caregiving competency. Physical and Occupational Therapy in Pediatrics, 16 (3), 33-54.

Winton, P., Sloop, S., \& Rodriguez, P. (1999). Parent education: A term whose time is past. Topics in Early Childhood Special Education, 19 (3), 157-161. 
APPENDIX A

PHYSICAL THERAPIST INVITATION LETTER 


\section{APPENDIX A}

August 5, 2004

The Role of Pediatric Physical Therapists in Family-Centered Service Provision

Dear pediatric physical therapist:

My name is Nancy Cicirello, MPH, PT, and I am a graduate student at Portland State University. I am beginning a study on how physical therapists provide therapy to infants and young children with movement dysfunction and their families, and would like to invite you to participate.

You are being asked to take part because you are a licensed physical therapist who provides therapy to young children with physical disabilities such as cerebral palsy. I am hoping the information I collect from this study will improve the preparation of new graduates from schools of physical therapy for practice in family-centered delivery of physical therapy. If you decide to participate, you are asked to recruit two families you are currently working with who would agree to allow me to videotape two of their child's PT treatment sessions. Following the video taping, I will individually interview you and the parent (mother) at a convenient time. The video taping of the treatment session will take place during a regularly scheduled appointment. The interview is anticipated to last approximately one hour and will be arranged at your convenience.

As a result of this study, you may be inconvenienced by the potential interruption of my presence during the treatment time and the additional hour interview. You may not receive any direct benefit from participating in this study, however the study may increase knowledge that may help others in the future.

Any information and recordings that are obtained in connection with this study and that may be linked to you or identify you will be kept confidential. Subject identities will be kept confidential by using pseudonyms for any reporting of information and tapes (visual and audio) will be stored in a locked file cabinet at the investigator's locked office.

Participation is entirely voluntary. Your decision to participate or not will not affect your relationship with the researcher or with Portland State University in any way. If you decide to take part in the study, you may choose to withdraw at any time without penalty. Please keep a copy of this letter for your records.

If you have concerns or problems about your participation in this study or your rights as a research subject, please contact the Human Subjects Research Review Committee, Office of research and Sponsored Projects, 111 Cramer Hall, Portland State University, (503) 725-4288. If you have questions about the study itself, contact Nancy A. Cicirello, MPH, PT at School of Physical Therapy, Pacific University, Forest Grove, Oregon (503) 352-2741, (home: 503-848-7102).

Sincerely,

Nancy A. Cicirello, MPH, PT

Associate Professor

Pacific University

School of Physical Therapy 
APPENDIX B

PARENT INVITATION LETTER 


\section{Parent Invitation Letter}

August 5, 2004

The Role of Pediatric Physical Therapists in Family-Centered Service Provision

Dear parent:

My name is Nancy Cicirello, MPH, PT, and I am a graduate student at Portland State University. I am beginning a study on how physical therapists provide therapy to infants and young children with movement dysfunction and their families, and would like to invite you to participate.

You are being asked to take part because you are a parent whose child is receiving physical therapy from a therapist who thought you might be interested in participating in this study. I am hoping the information I collect from this study will improve the preparation of new graduates from schools of physical therapy for practice in family-centered delivery of physical therapy. If you decide to participate, you will be asked to give permission for me to videotape two of your child's PT treatment sessions. Following the video taping, I will individually interview you at a convenient time. The video taping of the treatment session will take place during a regularly scheduled appointment. The interview is anticipated to last approximately one hour.

As a result of this study, you may be inconvenienced by the potential interruption of my presence during the treatment time and the additional hour interview. You may not receive any direct benefit from participating in this study, however the study may increase knowledge that may help in the education of physical therapy students interested in working in pediatrics.

Any information and recordings that are obtained in connection with this study and that may be linked to you or identify you will be kept confidential. Your identity and your child's will be kept confidential by using pseudonyms for any reporting of information. Tapes (visual and audio) will be stored in a locked file cabinet at the investigator's locked office.

Participation is entirely voluntary. Your decision to participate or not will not affect your relationship with the researcher or with Portland State University in any way. If you decide to take part in the study, you may choose to withdraw at any time without penalty. Please keep a copy of this letter for your records.

If you have concerns or problems about your participation in this study or your rights as a research subject, please contact the Human Subjects Research Review Committee, Office of research and Sponsored Projects, 111 Cramer Hall, Portland State University, (503) 725-4288. If you have questions about the study itself, contact Nancy A. Cicirello, MPH, PT at School of Physical Therapy, Pacific University, Forest Grove, Oregon (503) 352-2741.

Sincerely,

Nancy A. Cicirello, MPH, PT

Associate Professor

Pacific University 
APPENDIX C

PHYSICAL THERAPIST NFORMED CONSENT FORM 


\section{Portland State University School of Education \\ Physical Therapist Informed Consent Form}

\section{The Role of Pediatric Physical Therapists in Family-centered Service Provision}

You are invited to participate in a research study conducted by Nancy A. Cicirello, PT, MPH, student at Portland State University, Graduate School of Education. The researcher hopes to identify specific strategies that pediatric physical therapists employ when they provide family. centered physical therapy to young children with motor disabilities. This study is being conducted in partial fulfillment of the requirements for a doctoral degree and is under the supervision of Christine Cress, Ph.D. You were selected as a possible participant in this study because you are a practicing pediatric physical therapist.

If you decide to participate, the researcher will videotape two consecutive physical therapy sessions that you provide to a child and his/her family. Every effort will be made to videotape the session during the regularly scheduled time and in the established location of therapy provision. The researcher will request one additional hour of your time to complete an interview. While participating in this study, it is possible that you may experience the inconvenience of the intrusion of being videotaped and the additional time necessary for the interview. Every effort will be made to respect your time constraints and work schedule. You may not receive any direct benefit from taking part in this study, but the study may help to increase knowledge that can improve the professional preparation of future pediatric physical therapists.

Any information that is obtained in connection with this study that can be linked to you or identify you will be kept confidential. This information will be kept confidential by using pseudonyms for you, the parent, and child in any report of findings. Videotapes and coding documentation will be stored in a locked file cabinet in the researcher's office for three years following completion of the study. The researcher will view the videotapes and possible random viewing by another experienced PT for establishing reliability of category coding only.

Your participation is voluntary. You do not have to take part in this study, and it will not affect your relationship with Portland State University. You may also withdraw from this study at any time without affecting your relationship with Portland State University.

If you have concerns or problems about your participation in this study or your rights as a research subject, please contact the Human Subjects Research Review Committee, Office of Research and Sponsored Projects, 111 Cramer Hall, Portland State University, (503) 725-8182. If you have questions about the study itself, contact Nancy Cicirello at Pacific University, (503) 3522741.

Your signature indicates that you have read and understand the above information and agree to take part in this study. Please understand that you may withdraw your consent at any time without penalty, and that, by signing, you are not waiving any legal claims, rights or remedies. The researcher should provide you with a copy of this form for your own records.

Date 
APPENDIX D

PARENT INFORMED CONSENT FORM 


\author{
Portland State University \\ School of Education \\ Parent Informed Consent Form
}

\title{
The Role of Pediatric Physical Therapists in Family-centered Service Provision
}

You are invited to participate in a research study conducted by Nancy A. Cicirello, PT, MPH, student at Portland State University, Graduate School of Education. The researcher hopes to identify specific strategies that pediatric physical therapists employ when they provide familycentered physical therapy to young children with motor disabilities. This study is being conducted in partial fulfillment of the requirements for a doctoral degree and is under the supervision of Christine Cress, Ph.D. You were selected as a possible participant in this study because you are a parent of a child who is receiving physical therapy.

If you decide to participate, the researcher will videotape two consecutive physical therapy sessions that your child receives in your presence. The relationship and interaction between the physical therapist and your child should not be affected. Every effort will be made to videotape the session during the regularly scheduled time and in the established location of therapy provision. The researcher will request one additional hour of your time to complete an interview. While participating in this study, it is possible that you may experience the inconvenience of the intrusion of being videotaped and the additional time necessary for the interview. Every effort will be made to respect your time constraints and work schedule. You may not receive any direct benefit from taking part in this study, but the study may help to increase knowledge that can improve the professional preparation of future pediatric physical therapists.

Any information that is obtained in connection with this study that can be linked to you or identify you will be kept confidential. This information will be kept confidential by using pseudonyms for you, the parent, and child in any report of findings. Only the researcher will view the tapes, except for a possible random viewing by an outside experienced physical therapist educator to establish reliability of descriptions. Videotapes and coding documentation will be stored in a locked file cabinet in the researcher's office for three years following completion of the study.

Your participation is voluntary. You do not have to take part in this study, and it will not affect your relationship with Portland State University. You may also withdraw from this study at any time without affecting your relationship with Portland State University.

If you have concerns or problems about your participation in this study or your rights as a research subject, please contact the Human Subjects Research Review Committee, Office of Research and Sponsored Projects, 111 Cramer Hall, Portland State University, (503) 725-8182. If you have questions about the study itself, contact Nancy Cicirello at Pacific University, (503) 3522741.

Your signature indicates that you have read and understand the above information and agree to take part in this study. Please understand that you may withdraw your consent at any time without penalty, and that, by signing, you are not waiving any legal claims, rights or remedies. The researcher should provide you with a copy of this form for your own records.

\section{Date}


APPENDIX E

VIDEO/AUDIO/PHOTO RELEASE FORM 
Portland State University

School of Education

\section{Demonstration/Photo/Video/Audio Tape Consent Form}

Video and audio-tapes are useful tools for collecting data to be used in research studies. Your cooperation in this project is greatly appreciated.

\section{Consent:}

I, give permission for Portland State

University student, Nancy Cicirello, MPH, PT, to photograph, videotape, or audio tape me and/or my family member during participation in this research study. It is my understanding that tapes will be used for data collection and educational purposed only. These educational purposes may include classroom presentations, presentations at professional meetings, professional education conferences, and/or publications.

\section{Witness}

Date
Participant or Guardian

Date 
APPENDIX F

OBSERVATION NOTATION FORM 
Observation Notation Form

\begin{tabular}{|l|l|}
\hline \multicolumn{1}{|c|}{ Initiation } \\
Phase \\
How was \\
collaboration \\
promoted? \\
PT ask Mom what she \\
needs \\
PT asks Mom what \\
she wants child to \\
accomplish \\
PT asks Mom what \\
has worked \\
PT asks Mom what \\
are indicators that \\
child has learned \\
\\
\\
\\
\\
\hline Observation and & \\
Action Phase & \\
Direct Instruction & \\
Modeling & \\
Demonstration & \\
Role-playing & \\
Observation of Mom \\
performance \\
Types of Feedback \\
Evidence of learning \\
concepts \\
PT pointing out \\
contextual \\
components of activity \\
to parent \\
Parental praise \\
\end{tabular}




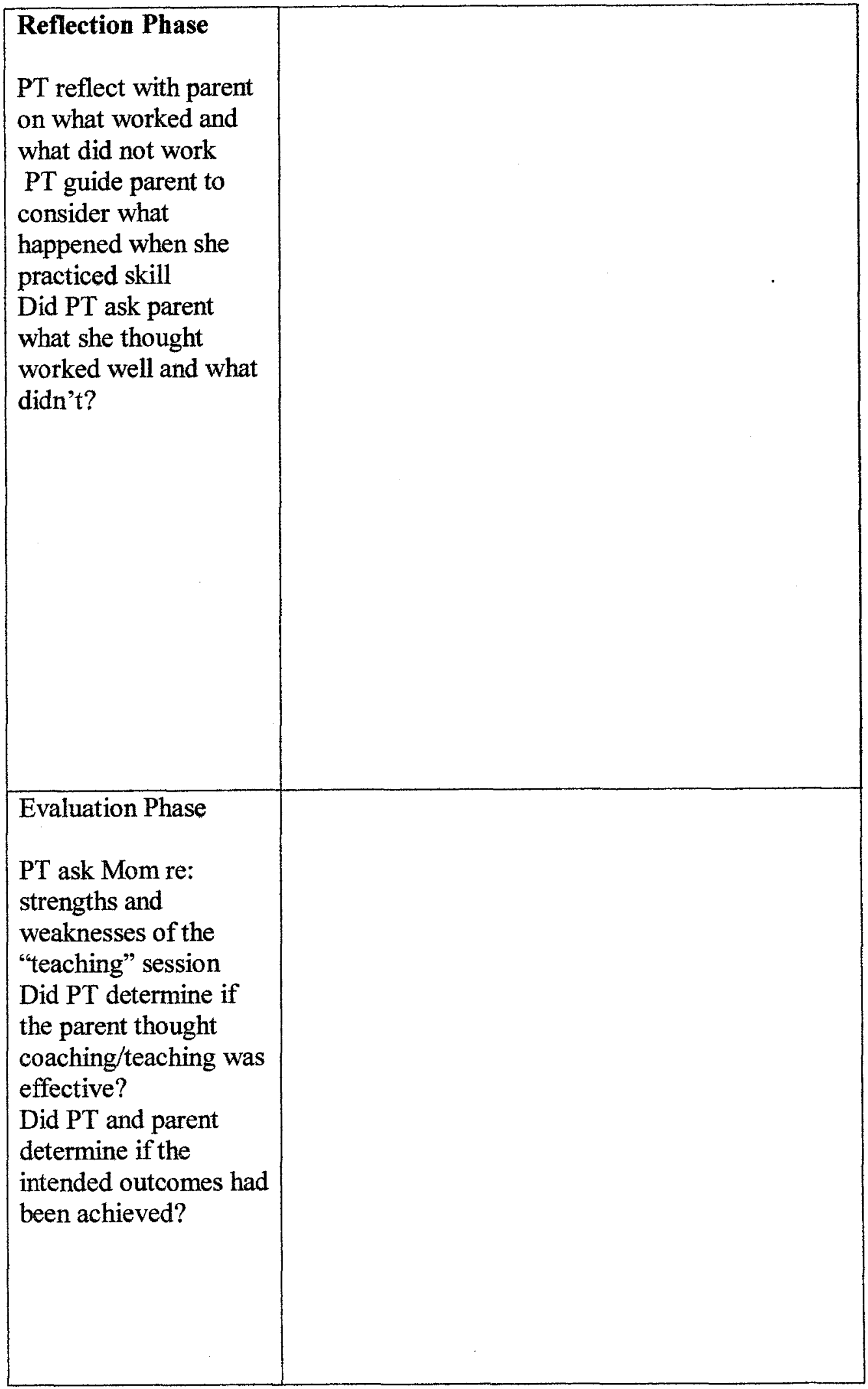

